$1 / 28 y \quad J-1733 \quad$ (1) $\quad D R=2116-0$

YISANDIA REPORT SAND82-0053 • Unlimited Release • UC-13

Printed January 1982

24107115

\title{
A Thermal Analysis of a Linear Infrared Lamp
}

$$
\begin{gathered}
\text { NOTICE } \\
\text { THIS REPORT IS ILLEGIBLE TO A DEGREE } \\
\text { THAT PRECLUDES SATISFACTORY REPRODUCTION }
\end{gathered}
$$

James T. Nakos

\section{Prepared by}

Sandia National Laboratories

Albuquerque, New Mexico 87185 and Livermore, California 94550

for the United States Department of Energy

under Contract DE-AC04-76DP00789

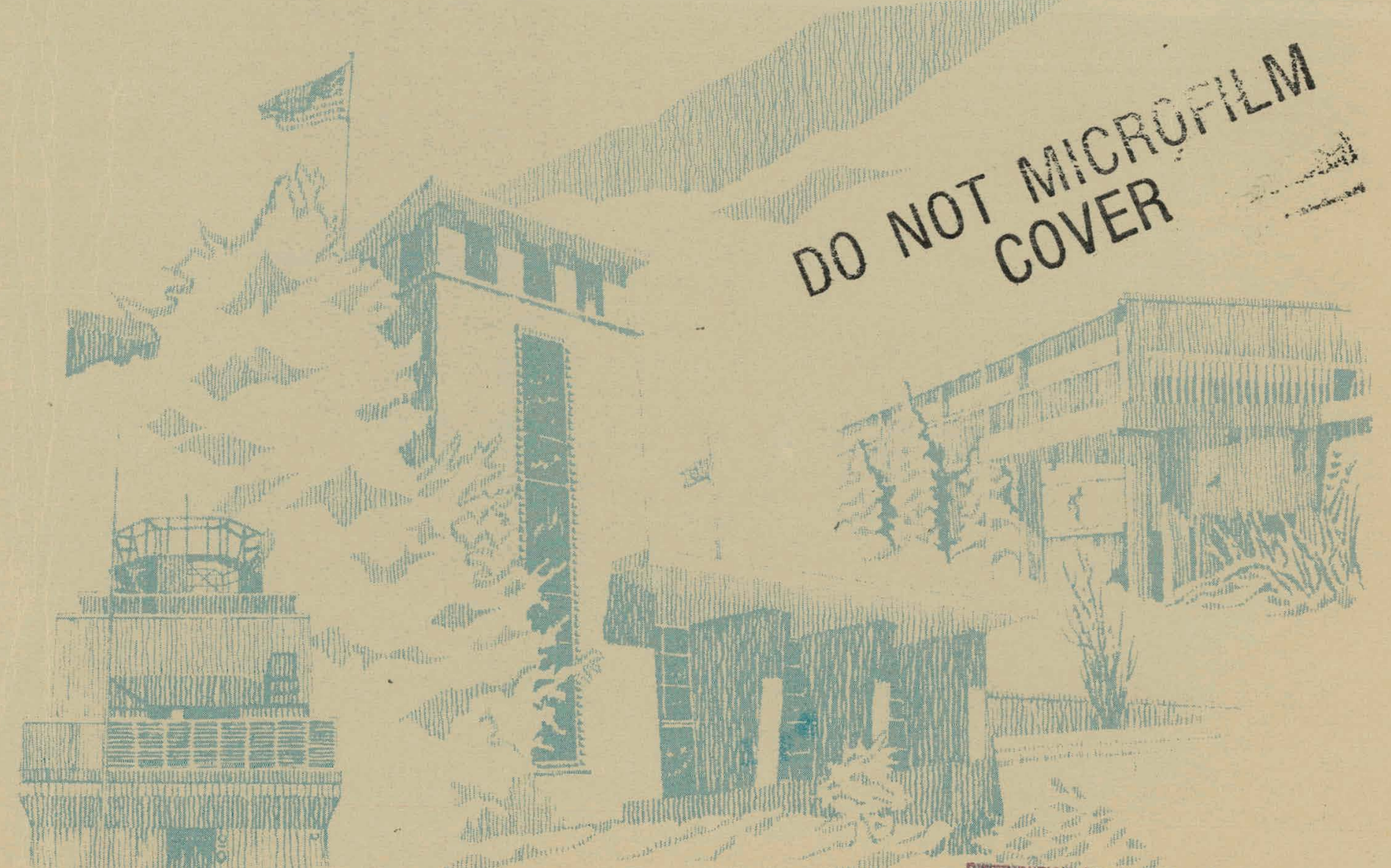




\section{DISCLAIMER}

This report was prepared as an account of work sponsored by an agency of the United States Government. Neither the United States Government nor any agency Thereof, nor any of their employees, makes any warranty, express or implied, or assumes any legal liability or responsibility for the accuracy, completeness, or usefulness of any information, apparatus, product, or process disclosed, or represents that its use would not infringe privately owned rights. Reference herein to any specific commercial product, process, or service by trade name, trademark, manufacturer, or otherwise does not necessarily constitute or imply its endorsement, recommendation, or favoring by the United States Government or any agency thereof. The views and opinions of authors expressed herein do not necessarily state or reflect those of the United States Government or any agency thereof. 


\section{DISCLAIMER}

Portions of this document may be illegible in electronic image products. Images are produced from the best available original document. 
Issued by Sandia National Laboratories, operated for the United States Department of Energy by Sandia Corporation.

NOTICE: This report was prepared as an account of work sponsored by an agency of the United States Government. Neither the United States Government nor any agency thereof, nor any of their employees, nor any of their contractors, subcontractors, or their employees, makes any warranty, express or implied, or assumes any legal liability or responsibility for the accuracy, completeness, or usefulness of any information, apparatus, product, or process disclosed, or represents that its use would not infringe privately owned rights. Reference herein to any specific commercial product, process, or service by trade name, trademark, manufacturer, or otherwise, does not necessarily constitute or imply its endorsement, recommendation, or favoring by the United States Government, any agency thereof or any of their contractors or subcontractors. The views and opinions expressed herein do not necessarily state or reflect those of the United States Government, any agency thereof or any of their contractors or subcontractors.

Printed in the United States of America Available from

Tech

National Technical Information Service

U.S. Department of Commerce

5285 Port Royal Road

Springfield, VA 22161

NTIS price codes

Printed copy: A05

Microfiche copy: A01

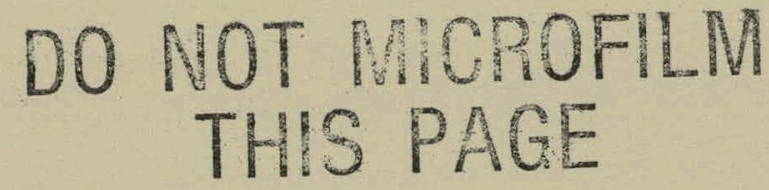


This book was prepared as an account of work sponsored by an agencey of the United States Government. Neither the United States Government nor any agency inereof. nor any of their employees, makes any warranty, express or implied. Or assumes any legal liability or responsibility for the accuracy, complereness, or usefulness of ony intormation, apparatus. product, or process disclosed, or represents that its use would not intringe privately owned rights. Reterence herein to baty specille

\section{A THERMAL ANALYSIS OF A LINEAR INFRARED LAMP}

James T. Nakos

Radiant Heat Division 1531

Sandia National Laboratories

Albuquerque, New Mexico 87185

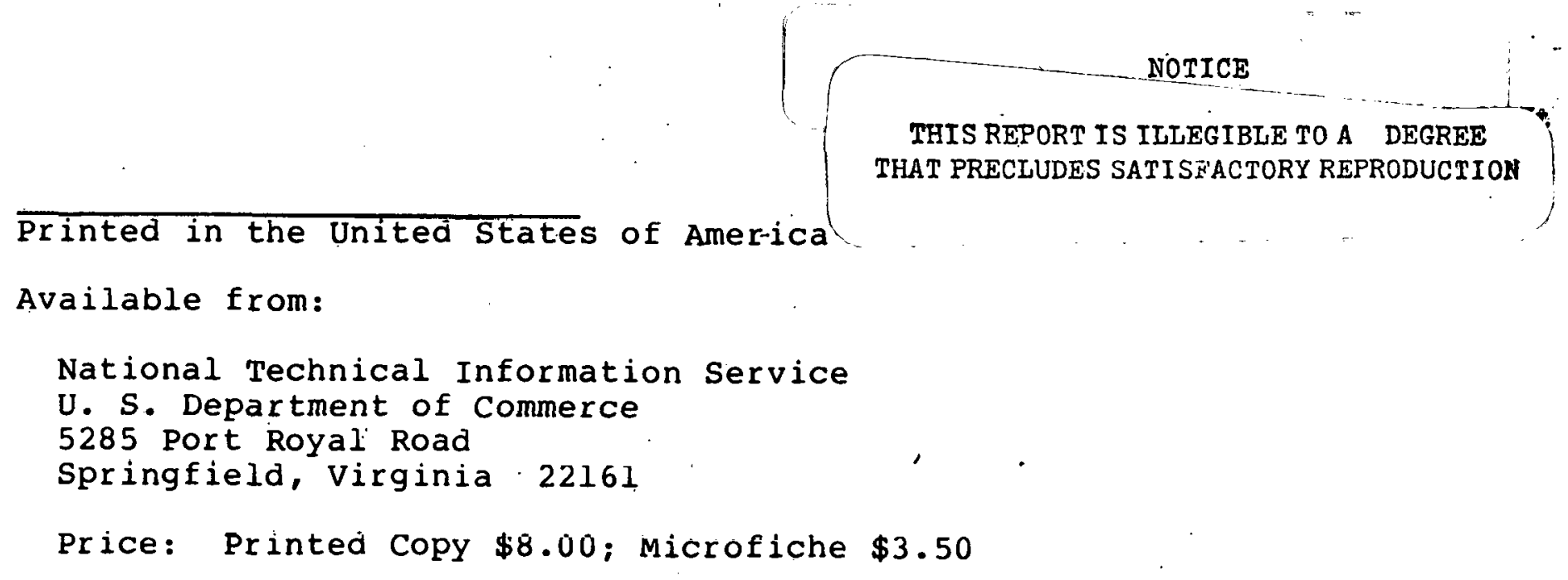


SAND 82-0053

\title{
A THERMAL ANALYSIS OF A IINEAR INFRARED LAMP
}

\author{
James T. Nakos \\ Radiant Heat Division 1531 \\ Sandia National Laboratories \\ Albuquerque, New Mexico 87185
}

January 1982

\begin{abstract}
A theoretical and experimental analysis of an infrared lamp is presented based on radiant heat transfer theory. The analysis is performed on a specific type of linear lamp which has a coiled tungsten filament surrounded by a fused quartz onvelope. The purpose of the study was to model the lamp thermally, not electrically, to arrive at a better understanding of the operation of the lamp.
\end{abstract}


CONTENTS

PAGE

LIST OF SYMBOLS

iv

I. INTRODUCTION • • • • • • • • • • • • • • • • • • • • • 1

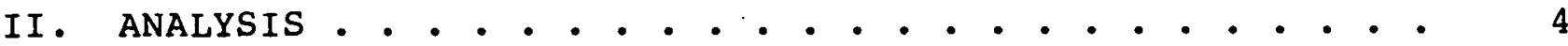

A. Theoretical Model . . . . . . . . . . . . . . 4

1. Assumptions . . . . . . . . . . . . . . . 4

2. Model Description . . . . . . . . . . . 5

B. Computer program. . . . . . . . . . . . . . 14

1. What it Does................... 14

2. Main Program.................. . 17

3. Subroutines . . . . . . . . . . . . . 18

a. Subroutine SHAPE............... . 18

b. Subroutine FRACTN . . . . . . . . . . . 19

c. Subroutine QTEMP . . . . . . . . . . . . 22

d. Subroutine TUNGST . . . . . . . . . . . . 22

e. Subroutine EMISS . • • • • • . • • • • • . 24

f. Subroutine QUARTZ . . . . . . . . . . . 28

C. i. Theoretical Results . . . . . . . . . . 32

2. Experimental Setup and Results......... . 32

3. Error Analysis... . . . . . . . . . . 36

4. Discussion of Results . . . . . . . . . . 48

III. CONCLUSIONS • • • • • • • • • • • • • • • • • • • • • • 49

FIGURES 1-12 • . • . . . . . . . . . . . . . . . . . . 51-62

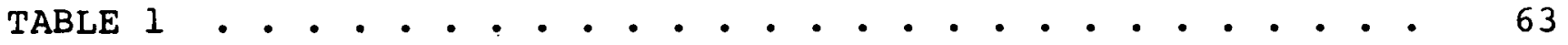

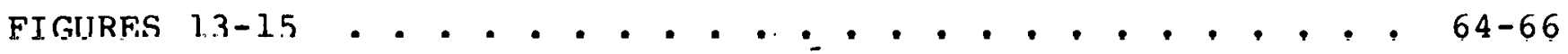

TABLE 2 .

REFERENCES . . . . . . . . . . . . . . . . . . . . 68-69

ACKNOWLEDGEMENTS . • • • • • • • • • • • • • • • • • • • • • 70

APPENDIX • • . . . . . . . . . . . . . . . . . . . . 72 
List of symbols
A
$\mathrm{C}_{1}, \mathrm{C}_{2}$
$\mathrm{Co}_{0}$
e
$\mathrm{F}_{\lambda_{\mathrm{n}-1}}-\lambda_{\mathrm{n}}$
i)
n
K
$\sigma$
$\mathrm{T}$
$\lambda$
$\omega$
$\varepsilon$
$\tau$
$\alpha$
$S$
Q
q
$\triangle$
$\mathrm{Fdl}-\ddot{2}$
r
i
$k W$
Surface Area
Constants in Planck's spectral energy distribution equation
speed of electromagnetic radiation in a vacuum
Emissive power
Fraction of total biackioody emissive power in the spectral region $\lambda_{n-1} \leq \lambda \leq \lambda_{n}$
Planck's constant, p. 20 only
Distance between center of cylincer and aifferential area (a $\perp 1$ other pages)
boltzinann constant
Stefan-Boltzmann constant
Absolute temperature
Wavelength in vacuan
Solid angle
Emittance
Transmittance
Absorptance
Distance between emitting and absorbing elements
Energy per unit time, energy rate
Energy per unit area per unit time, energy flux
Change in quantity
Contiguration factor between a difierential area $\mathrm{A}_{1}$ and a finite area $\mathrm{A}_{2}$
Radius of cylinder
Intensity
Kilowatt 
List of Symbols (Continued)

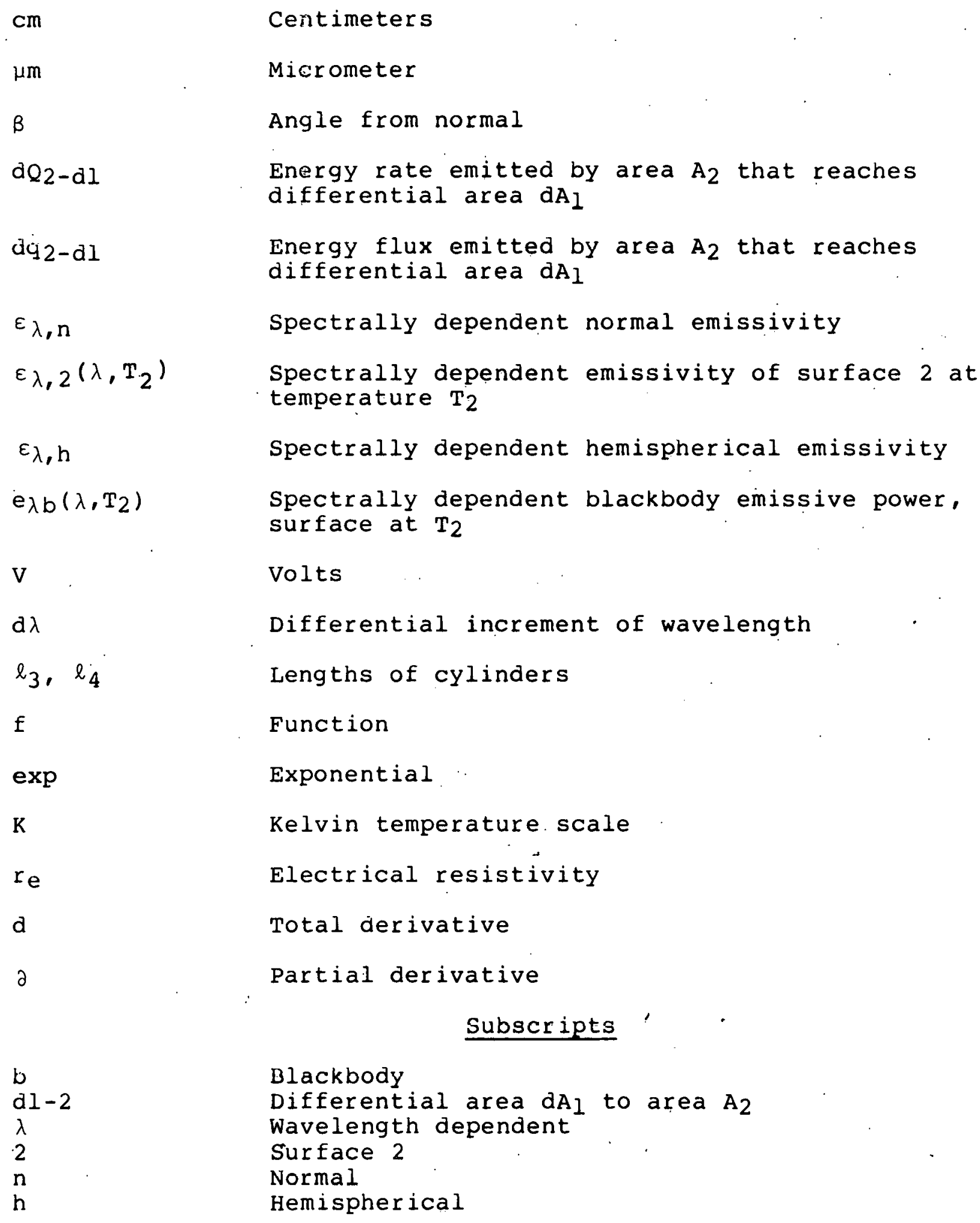

Subscripts

Blackbody

Differential area $d_{1}$ to area $A_{2}$ Wavelength dependent

Surface 2

Normal

Hemispherical 
List of Symbols (Continued)

Superscripts

- 2

Quantity depends on two differential quantities

vi 


\section{A THERMAL ANALY̌SIS OF A LINEAR INFRARED LAMP}

\section{INTRODUCTION}

The type of lamp analyzed in this study is used almost exclusively in the Radiant Heat Facility as a heat source in high temperature, high heat flux testing. The mode of heating normally used with these lamps is thermal radiation heat transfer. A more thorough understanding of the operation of the lamp would enable us to not only perform more effective experiments, but also enable us to interpret and understand the results of those experiments. The initial interest in this study stemmed from the Five-Tube Test in. which a (five tube) section of a boiler (close to the one to be used on the Barstow Splar pilot plant) was irradiated using arrays of these infrared lamps. The maximum heat flúx required during the testing dictated the use of high power lamps, but the quartz envelopes on these lamps would not survive the power levels needed without some mechanism for cooling. The final design incorporated 
large volume, low-pressure fans with supply ducts which covered the lamps with a blanket of ambient air. However, it was experimentally found that the flux gage output would increase substantially (25 percent) when the fans were turned off at low voltage levels (heat flux gages were used to measure incident flux on the tubes). This increase in output was not caused by an increase in the temperature of the filament because.the electrical power was kept constant. The lack of convective loss from the flux gage itself had a small effect, but the majority of the increase seemed to be coming from the lamp itself. The increase in the temperature of the quartz envelope of the lamp apparently contributed to a large increase in the total flux emitted by the lamp. This implies that the tungsten filament and the quartz envelope both contribute to the heat flux emitted by the lamp and that a large fraction of that emitted flux comes from the quartz envelope. This could have had significant effects on the flux absorbed by the boiler tubes. The radiation spectrum emitted by the quartz is different than that emitted by the tungsten and the absorptivity of the coating on the tubes was wavelength dependent. This study was born to attempt to qualitatively and, if possible, quantitatively understand the characteristics of the heat flux emitted by these lamps. The voltage levels in this study bracketed the lower end of the voltage levels in the Five-Tube test, up to $113 \mathrm{~V}$, where on the test we went up to almost $480 \mathrm{~V}$ on the lamps.

To attempt such a study, a model of the lamp was needed. This model was developed using the equations of radiant heat transfer and various simplifying assumptions. A model may be formed in two ways; one using an "electrical" analysis and the pther. using a "thermal" analysis.

The electrical analysis may be done by estimating the flux emitted from the lamp knowing the electrical energy input to the device and, assuming it to be a line source, one can calculate the flux output. This approach was taken by pfahl [1] and the model 
worked well. The theoretical results obtained from Pfahl's work will be compared to the experimental results from my work.

This thermal analysis calculates the flux emanating from the lamp as a sum of the flux from the filament and from the quartz envelope. The temperature, shape factors, emissivities, and blackbody fractions necessary to calculate the flux from the familiar Stefan-Boltzmann Law were determined either experimentally, from brochures provided by the manufacturer. (General Electric), or published information from other sources. Completion of this analysis required much research since the data needed is hard to find and, in the case of the emmissivity of quartz, very rare.

The only type of lamp analyzed may be viewed in Figure 1. Although available in various lengths and power ratings, the only real restrictions are that the lamp be linear and have a transparent (not translucent) fused quartz envelope. The experimental data were gathered using General. Electric lamps, but the lamps manufactured by Sylvania would probably give similar results both experimentally and theoretically. The lamp has a coiled tungsten filament enclosed by a fused quartz envelope. The lamps come in several lengths--the most common being $30.3,45.6$, and $73.2 \mathrm{~cm}$ in overall length. The highest power lamp, $6 \mathrm{~kW}$ each and $30.3 \mathrm{~cm}$ long, has a halogen gas in the lamp to recycle the tungsten after it is vaporized and deposited on the quartz. In this manner the tungsten does not collect on the quartz envelope. All of the lamps have sealed ends and are gas filled to prevent oxidation of the filaments. The end seals can withstand temperatures up to about $340^{\circ} \mathrm{C}$ and have nickel leads about $14 \mathrm{~cm}$ long. Figure 2 shows a photograph of a typical lamp showing close-up details of the filament and tilament supports. 


\section{Analysis}

\section{A. Theoretical Model}

1. Assumptions:

The assumptions used in arriving at a suitable model are important in that they dictate how complicated the model will be. The assumptions made in this analysis were kept to a minimum so that the most knowledge, both qualitatively and quantitatively, could be gained.

The basic assumptions used in this analysis are listed below:

1. Both the tungsten and quartz are considered difuse radiators.

2. Both the tungsten filament and the quartz envelope are considered isothermal.

3. The coiled tungsten filament is considered as a solid cylinder ot outside diameter equal to the outside diameter of the coil. This simplifies the shape factor equations considerably.

4. The emission of radiant energy from the quartz can be characterized by an apparent or effective emissivity which takes into account the thickness of the envelope. Note that the emission of radiant energy from transparent materials is not a surface phennmennn hut occurs from the whole volume of the radiator.

Assumptions 1 and 2 are made for ease of calculation and to be able to have enough information to do the analysis at all. Angular-dependent properties of tungsten and fused quartz are most likely nonexistent for all temperatures and wavelengths considered. It is known that neither the tungsten filament [2] nor the quartz envelope is isothermal; however, a suitable "average" temperature was assumed because detailed temperature 
profiles were unknown and the increase in complexity of the model would be large.

Assumption 3 was made because of a lack of information. The shape factor from a coil to a differential area outside the coil is not readily available, if at all. The effective emissivity of a tungsten coil, as compared to a solid tungsten cylinder, is unknown, and it is unknown even if they are different. It is felt that the most improvement in the model could come from gaining more insight into the shape factor and effective emissivity of the filament.

The last assumption was made on the basis of the papers by Gardon [3-4] and the data of Petrov and Stepanov [5]. If an effective emissivity is used from [5], then one can consider the emission of radiant energy from the quartz to occur from the surface only and then use shape factor algebra as if the surface were opaque. From [4] it is stated that part of the radiation originating in the interior of a diathermanous (moderately transparent) material does reach the surface and crosses into the medium surrounding the radiator. Therefore, transparent materials may be called volume emitters. However, in opaque materials none of the radiation originating in the interior of a body reaches its surface and all the radiant energy that does leave the radiator originates at its surface. Opaque materials may then be called surface emitters.

Certain optical effects such as the total reflection angle and its effect on the backside radiation were not taken into account in this model.

2. Model Description:

The model consists of breaking down the lamp into its two basic parts: the filament and the envelope, and then analyzing each component separately. The temperature, spectral emissivity and geometry of each component was either measured or gathered 
from other experimental or theoretical data. Then, from Stefan-Boltzmann's Law, the heat flux was calculated separately for the tungsten filament and the quartz envelope using the assumptions detailed above and the "band-energy approximation" detailed in [6]. Assuming that neither the gas in the lamp nor the air between the lamp and the heat flux gage was an absorbing medium, the flux reaching the gage could be estimated.

The energy source for the lamp was electrical. The tungsten reached its equilibrium temperature due to Joule heating and radiative dissipation. The quartz envelope, however, attained its equilibrium temperature due to the absorption of part of the radiant energy emitted by the filament, radiation of energy by the envelope and from conduction of energy into the glass by the filament supports (see Figure 2). The conduction through the filament supports is probably a small effect. The quartz envelope is spectrally selective in that it absorbs and emits energy in certain wavelengths and transmits energy in other wavelengths. Figure 3 shows a plot of transmittance versus wavelength averaged over a number of data sets. The temperature at which this curve was generated was unknown since it came from General Electric product data on their "Type 214 clear fused quartz circular tubing." The point to remember is that from about 270 nanometers to 3.5 micrometers $(\mu \mathrm{m})$, the quartz is at. least 90 percent transparent, while at wavelengths greater than about $5.0 \mu \mathrm{m}$, the quartz is essentially opaque. Because of this partial opacity, the quartz absorbs some of the energy from the tungsten filament. The temperature rises until the net amount of energy regeived from the filament is balanced by the amounl of energy the quartz radiates to the colder environment away from the lamp. At this point, the filament and quartz temperature stabilize into a steady-state condition. At this condition, a relatively simple model may be assumed and the basic assumptions for this model have already been discussed. 
Because the quartz emission is modeled as if all the energy.. were coming from the surface, surface-geometrical properties were used to calculate the shape factor from the quartz envelope to the heat flux gage used to measure the flux. The shape factor equations used were such that the envelope had to be modeled as two distinct half cylinders. Each radiated a portion of energy to the measuring gage but the "front" half of the cylinder contributed the most. Figure 4 schematically shows how the lamp was modeled. A different shape factor equation was used for each half cylinder and the flux reaching the gage from each half was calculated. Since the quartz emits most of its energy at wavelengths where it transmits very little energy, very little of the energy emitted by the back half of the cylinder passed through the front half of the cylinder. However, this was not the case with the tungsten. Since tungsten is opaque, none of the energy from the "back half" passed through the "front half." Therefore, the energy emitted by the "front half" of the tungsten filament and attenuated by the envelope was the total amount of energy that reached the gage from the filament.

In summary, the model may be described thusly: the lamp is broken down into its two main components--the quartz envelope and the tungsten filament which are assumed to be diffuse, isothermal, solid cylinders. The direct contribution from the tungsten filament to a measuring device outside the cylinder is that which is transmitted through the quartz envelope. That which is transmitted through the envelope is that emitted by the filament minus that which is absorbed by the envelope. The contribution from the quartz may be broken down further into two more sources: the half-cylinder closest to the measuring device and the half-cylinder farthest from the measuring device. The half-cylinder closest to the measuring device will contribute the largest part of the total coming from the quartz envelope. 
The radiant energy transport equations necessary to estimate the total flux emitted by the lamp can be derived from basic theory, as in siegel and Howell[6]. To be consistent, I will use the same notation as in siegel and Howell; all the relevant terms are defined in the List of symbols in the beginning of this report. See Figure 5 for the geometry used.

From Siegel and Howell[6], the total energy per unit time leaving $\mathrm{dA}_{2}$ that is incident upon $d A_{1}$ (both surfaces are blackbodies and isothermal) is:

$$
d^{2} Q_{d 2-d 1}=\frac{i_{b, 2} d A_{2} \cos \beta_{2} d A_{1} \cos \beta_{1}}{s^{2}},
$$

but:

$$
i_{b, 2}=\frac{e_{b, 2}}{\pi}=\frac{\sigma T_{2}^{4}}{\pi}
$$

so:

$$
\mathrm{d}^{2} \mathrm{Q}_{\mathrm{d} 2-\mathrm{d} 1}=\frac{\sigma \mathrm{T}_{2}^{4}}{\pi} \frac{\left(\mathrm{dA}_{2} \cos \beta_{2} \mathrm{dA_{1 }} \cos \beta_{1}\right)}{\mathrm{s}^{2}},
$$

integrating over area $A_{2}$ gives: -

$$
d Q_{2-d 1}=d A_{1} \int_{A_{2}} \frac{\sigma T_{2}^{4} \cos \beta_{1} \cos \beta_{2}{d A_{2}}_{2}}{\pi \varepsilon^{2}}
$$

the total hemispherical energy leaving $A_{2}$ is:

$$
Q_{2}=\int_{A_{2}} \sigma T_{2}^{4} d A_{2}
$$


Now, the configuration factor from area $A_{2}$ to differential area $d A_{l}$ is $d F_{2-d l}$ :

$$
d F_{2-d l}=\frac{d 2_{2}-d l}{Q_{2}}
$$

or :

$$
\mathrm{dF}_{2-\mathrm{dl}}=\frac{\mathrm{dA_{1 }}}{\mathrm{A}_{2}} \int_{\mathrm{A}_{2}} \frac{\cos B_{1} \cos B_{2} \mathrm{dA}_{2}}{\pi \mathrm{S}^{2} .} \text {. }
$$

because body 2 is assumed to be isothermal.

Eqn. (6) may be written as

$$
d Q_{2-d l}=A_{2} d F_{2-d l} \sigma T_{2}^{4}
$$

where:

$$
\begin{aligned}
\mathrm{dQ}_{2-\mathrm{dl}} \quad & \begin{array}{l}
\text { total energy emitted by area } \mathrm{A}_{2} \text { that } \\
\text { reaches differential area } \mathrm{dA}_{1} \cdot
\end{array} \\
\mathrm{A}_{2}= & \text { area of surface } \mathrm{A}_{2} \cdot \\
\mathrm{dF}_{2-\mathrm{dl}}= & \begin{array}{l}
\text { configuration factor between an area } \mathrm{A}_{2} \\
\text { and a differential area } \mathrm{dA}_{1} \cdot
\end{array} \\
\mathrm{T}_{2}= & \begin{array}{l}
\text { temperature of surface } \mathrm{A}_{2}, \text { assumed } \\
\text { isothermal. }
\end{array}
\end{aligned}
$$

However, by reciprocity:

$$
A_{2} d F_{2-d l}=d A_{1} F_{d l-2} \text {. }
$$


So:

$$
d Q_{2-d 1}=d A_{1} F_{d 1-2} \sigma T_{2}^{4}
$$

or:

$$
\begin{aligned}
d q_{2-d l} & =\frac{d Q_{2-d 1}}{d A_{1}} \\
=F_{d 1-2} \sigma T_{2}^{4} & =\begin{array}{l}
\text { total eriergy } \\
A_{2} \text { that remitted by } \\
\\
d A_{1}
\end{array}
\end{aligned}
$$

This would be the incident flux reaching $\mathrm{dA}_{1}$, if $\mathrm{A}_{2}$ were a blackbody surface, $\varepsilon=1$. But in the real case of either the tungsten or quartz, the emissivity is a complicated function of temperature, wavelength, and angle. Reasonable estimates of the wavelength and temperature dependence of emissivity of tungsten and quartz are available but the angular dependence will be ignored.

For my case, then, Eqn. (12) can be modified to work for the non-black case and is called the "band-energy approximation": $[6]$

$$
d q_{2-d 1}=\left(F_{d l-2}\right)(\varepsilon)\left(\sigma T_{2}^{4}\right)=\left(F_{d l-2}\right)(\varepsilon)\left(\dot{e}_{b, 2}\right)
$$

or for the case where the emissivity is a function of wavelength and temperature $\varepsilon=\varepsilon_{\lambda, 2}\left(\dot{\lambda}_{,} T_{2}\right)$ and

$$
e_{b, 2}=e_{\lambda b}\left(\lambda, T_{2}\right)
$$

So: 


$$
d q_{2-d l}=F_{d l-2} \int_{0}^{\infty} \varepsilon_{\lambda, 2}\left(\lambda, T_{2}\right) e_{\lambda b} \cdot\left(\lambda, T_{2}\right) d \lambda,
$$

where $e_{\lambda b}\left(\lambda, T_{2}\right)=$ spectrally dependent blackbody emissive power of surface $A_{2}$.

NOTE: $\mathrm{F}_{\mathrm{dl}-2}$ is a purely geometrical parameter not affected by wavelength or temperature. This shape factor can be found by first breaking area $A_{2}$ into two cylinders of lengths: $\ell_{3}$ and $\ell_{4}$ (see Figure 6 ).

Then by shape factor algebra:

$$
F_{\mathrm{d} 1-2}=F_{\mathrm{d} l-3}+F_{\mathrm{dl}-4}
$$

Siegel and Howell ${ }^{[6]}$ (p. 788) has a formula for the shape factor $\mathrm{F}_{\mathrm{dl}-3}$ or $\mathrm{F}_{\mathrm{dl}-4}$ ' from a cylinder to a differential area located directly under one end of the cylinder.

The formula is:

$$
\begin{gathered}
F_{d 1-3}=\frac{1}{\pi H} \tan ^{-1} \frac{L}{\sqrt{H^{2}-1}} \\
+\frac{L}{\pi}\left[\frac{(X-2 H)}{H \sqrt{X X}} \tan ^{-1} \sqrt{\frac{X(I I-1)}{Y(H+1)}}-\frac{1}{H} \tan ^{-1} \sqrt{\frac{H-1}{H+1}}\right]
\end{gathered}
$$

where: 


$$
\begin{gathered}
H=h / r, \quad L=\ell_{3} / r \\
X=(I+H)^{2}+L^{2}, Y=(I-H)^{2}+L^{2} .
\end{gathered}
$$

See Figures 6 and 7 for the geometry used.

If :

$$
\ell_{3}=\ell_{4}
$$

then

$$
F_{\mathrm{d} 1-3}=F_{\mathrm{dl}-4}
$$

and

$$
F_{\mathrm{d} 1-2}=2 F_{\mathrm{dl}-3}
$$

So in general, Eqn, 14 may be modified to:

$$
d q_{2-d l}=\left(F_{d 1-3}+F_{d 1-4}\right) \int_{0}^{\infty} \varepsilon_{\lambda, 2}\left(\lambda, T_{2}\right) e_{\lambda b}\left(\lambda, T_{2}\right) d \lambda .
$$

Eqn. (18) may be further modifiēd:

$$
d q_{2-d l}=\sigma T_{2}^{4}\left(F_{d l-3}+F_{d l-4}\right) \int_{0}^{\infty} \varepsilon_{\lambda, 2}\left(\lambda, T_{2}\right) \frac{e_{\lambda b}\left(\lambda, T_{2}\right) d \lambda}{\sigma T_{2}^{4}} .
$$

Now, if $\varepsilon_{\lambda, 2}$ is considered a constant in the interval $\lambda_{n-1} \leq \lambda \leq \lambda_{n}$ at temperature $\mathrm{T}_{2}$, then the integral may be changed to this: 


$$
\int_{0}^{\infty} \varepsilon_{\lambda, 2}\left(\lambda, T_{2}\right) \frac{e_{\lambda b}\left(\lambda, T_{2}\right)}{\sigma T_{2}^{4}} d \lambda=\sum_{d \lambda} \int_{\lambda_{n-1}}^{\lambda_{n}} \varepsilon_{\lambda, 2}\left(\lambda_{n-1}-\lambda_{n}, T_{2}\right) x
$$

$$
\frac{e_{\lambda b}\left(\lambda_{n-1}-\lambda_{n}, T_{2}\right) d \lambda}{\sigma T_{2}^{4}}
$$

Since $\varepsilon_{\lambda, 2}\left(\lambda_{n-1}-\lambda_{n}, T_{2}\right)$ is assumed to be a constant in the interval $d \lambda$, it may be taken outside the integral:

$$
\int_{0}^{\infty} \varepsilon_{\lambda, 2}\left(\lambda, T_{2}\right) \frac{e_{\lambda b}\left(\lambda, T_{2}\right)}{\sigma T_{2}^{4}} d \lambda=\sum_{d \lambda} \varepsilon_{\lambda, 2}\left(\lambda_{n-1}-\lambda_{n}, T_{2}\right) x
$$

$$
\int_{\lambda_{n-1}}^{\lambda_{n}} \frac{e_{\lambda b}\left(\lambda_{n-1}-\lambda_{n}, T_{2}\right) d \lambda}{\sigma T_{2}^{4}}
$$

The integral

$$
\int_{\lambda_{n-1}}^{\lambda_{n}} \frac{e_{\lambda b}\left(\lambda_{n-1}-\lambda_{n}, T_{2}\right) d \lambda}{\sigma T_{2}^{4}}=F_{\lambda_{n-1}}-\lambda_{n} \begin{aligned}
& \text { fraction of the } \\
& \text { total energy } \\
& \text { emitted by a } \\
& \text { blackbody in } \mathrm{d} \lambda .
\end{aligned}
$$

To make the notation a little less cumbersome, I will call the emissivity this:

$$
\varepsilon_{\lambda, 2}\left(\lambda_{n-1}-\lambda_{n}, T_{2}\right)=\varepsilon_{d} \lambda_{n, 2}
$$


Therefore:

$$
\begin{aligned}
\partial q_{2-\mathrm{d} l}= & {\left[F_{\mathrm{dl}-3}+F_{\mathrm{dl}-4}\right] \sigma \mathrm{T}_{2}^{4} \times } \\
& {\left[\varepsilon_{\mathrm{d} \lambda_{1,2}} F_{0-\lambda_{1}}+\varepsilon_{\mathrm{d} \lambda_{2,2}} F_{\lambda_{1}-\lambda_{2}}+\ldots+\varepsilon_{\mathrm{d} \lambda_{n, 2}} F_{\lambda_{n-1}-\lambda_{n}}\right] } \\
= & {\left[F_{\mathrm{dl}-3}+\mathrm{F}_{\mathrm{d} l-4}\right] \sigma \mathrm{T}_{2}^{4} \sum_{n=1}^{\infty} \varepsilon_{\mathrm{d} \lambda_{n, 3}} F_{\lambda_{n-1}-\lambda_{n}} }
\end{aligned}
$$

Eqn. (24) is the one used to estimate the flux from each component. For a fixed geometry, $F_{d 1-3}$ and $F_{d l-4}$ are constant. For a fixed power input to the lamp, $T_{2}$, the temperature of the filament or of the envelope will eventually reach a steady-state value. Finally, for known values of $\varepsilon_{d \lambda_{n, 2}}$, the summation in Eqn. (24) can be found. In practice, one need not carry the summation too far in wavelength to get out to about 99.99 percent of the total energy. This will be discussed in detail in the description of the main program and its subroutines.

\section{B. Computer program}

1. What it Does:

As would be expected with añy real problem, the emissivity of either the tungsten or the quartz is not a well behaved function but rather a complicated function of both wavelength and temperature. Because of this complexity simple graybody assumptions are not really sufficient to tharoughly understand the problem. To get an adequate understanding of the operation of the lamp, Eqn. (24) should be used without further simplification. The wavelength intervals chosen to obtain a reasonably accurate solution were small enough to require many calculations which in turn suggested use of a computer program. 
The program calculates the flux incident on a differential area $d_{1}$ a distance ' $h$ ' from the centerline of the lamp and with the plane of $\mathrm{dA}_{1}$ perpendicular to the line joining $\mathrm{dA}_{1}$ and the centerline of the lamp (see Figure 6). It calculates the flux. from the half-cylinder of quartz closest to the area $\mathrm{dA}_{1}$ by using Eqn. (24). The amount of flux emitted by. the tungsten and transmitted through the quartz that reaches the area $\mathrm{dA}_{1}$ is also calculated using Eqn. (24) but is modified by multiplying it by the spectral transmittance of the quartz. The amount emitted by the back half-cylinder of.quartz that is transmitted by the front half-cylinder of quartz is also estimated, even though it is a small part of the total flux from the lamp. This calculation is done by first calculating the amount emitted by the back half-cylinder, subtracting from that amount the amount blocked by the filament and then multiplying that reduced amount by the transmittance of the front half-cylinder. Note that the front half-cylinder and back half-cylinder are assumed to be at the same temperature. Then the program sums each of the three components to find the total calculated flux and the percentage of the total that each component contributes.

The program is broken down into seven subroutines, each one performing a particular function or set of functions. This enables easy understanding of where each parameter comes from and reasonable "debugging." From Eqn. (24) we can get an idea of what the subroutines calculate..

In Eqn. (24) there are four distinct parameters needed: the shape factors $\mathrm{F}_{\mathrm{dl}-3}$ and $\mathrm{F}_{\mathrm{dl}-4}$, the filament or envelope temperature $\mathrm{T}_{2}$, the emissivities of tungsten or quartz $\varepsilon_{\mathrm{d}} \lambda_{\mathrm{n}, 2}$ ' and the blackbody fractions $F_{\lambda_{n-1}}-\lambda_{n}$. The same subroutine can be used to calculate $\mathrm{F}_{\mathrm{dl}-3}$ and $\mathrm{F}_{\mathrm{dl}-4}$ for both the tungsten. and the front half of the quartz since they are both modeled as cylinders. So the shape factor algebra for both the filament and the front half-cylinder is calculated in the subroutine 
called "SHAPE." The exact shape factor equation for the (concave) half-cylinder farthest from the gage is not known but can be reasonably estimated by a concave half-cylinder of infinite length at the same distance ' $h$ ' from the gage and with the same diameter as that of the envelope. The equation used was obtained from [7] (pg.19). Using this formula and comparing the results with the exact shape factor equation from the front half-cylinder, agreement was within 0.5 percent. Since the formula assuming an infinite length of cylinder came so close to the exact value for the front half-cylinder it is felt that similar accuracy can be assumed if the approximate formula is used to estimate the shape factor for the back half-cylinder. As it turned out, the error incurred by using the above approximation was negligible. This is because the average value of energy contributed by the back half-cylinder was only about 3 percent of the total. So an error of 0.5 percent in the 3 percent is on the order of 0.015 percent which is not significant in this analysis.

The tungsten filament temperature is different from the quartz envelope temperature so each are calculated separately. The tungsten filament temperature is estimated in the subroutine called "TUNGST" and the quartz envelope temperature is calculated in the subroutine called "QTEMP." The spectral emissivities of the tungsten and quartz also have to be calculated separately. They are done so in subroutines "EMISS" and "QUARTZ," respectively. The black body fractions are functions of temperature and wavelength, but not of the material so are calculated in one subroutine called "FRACTN."

These, then, are the six subroutines used to calculate the necessary parameters that are used in the main program called "LAMP." A discussion of the mechanics of LAMP along with a flow chart will precede detailed discussions of all six.subroutines. 


\section{Main Program}

The main program, LAMP, does the heat flux calculations in Eqn. (24). The flow chart shown in Figure 8 indicates the sequence of events that are performed in LAMP. A copy of LAMP and all of its subroutines may be seen in the Appendix.

Initially, all necessary constants, geometrical measurements and electrical measurements are specified. Then the spectral transmissivity of quartz is specified. Because there is a minimal variation in the transmissivity of a similar type (G.E. type 106) of quartz with temperature [8], the values of the spectral transmissivity of quartz actually used (G.E. Type 214) were assumed to be independent of temperature. All of these inputs and initializations were grouped in block 1 of Figure 8 . The quartz temperature calculation is performed in block 2 where the subroutine QTEMP is called. The shape factor for the front half of the quartz envelope was calculated in block 3 where SHAPE is called. With the temperature of the quartz known from block 2, the spectral emissivity of the quartz can be calculated in block 4 where QUARTZ is called. Block 5 calculates the summation of emissivity times blackbody fraction $\left(\varepsilon_{d} \lambda_{n-1,2}\right) x$ $\left(F_{\lambda_{n-1}}-\lambda_{n}\right)$ in each wavelength interval. This summation may be seen in Eqn. (24). Block 6 calculates the same summation as in block 5 except that each $\left(\varepsilon_{d \lambda_{n-1,2}}\right)\left(F_{\lambda_{n-1}}-\lambda_{n}\right)$ product is also multiplied by the transmissivity of quartz at the same temperature in that wavelength interval. The summation in block 6 is therefore the actual amount emitted by the back half-cylinder that is transmitted through the front half-cylinder. Block 7 uses the full Equation (24) to calculate the flux from the front half-cylinder to the-differential area $\mathrm{dA}_{1}$ (at the gage). Block 8 is simply an initializing of values necessary to calculate the shape factor for the back half-cylinder which is done in block 9. Block 10 uses the shape factor from block 9 and the summation from block 6 to estimate the flux emitted from the back half-cylinder that passes through the front half-cylinder and reaches the area $d A_{1}$. The values 
from blocks 7 and 10 complete the calculations that estimate the total flux from the quartz envelope that reaches the gage at $\mathrm{dA}_{1} \cdot$

Block 11 re-initializes values again for use with the filament calculations. Block 12 calculates the shape factor (from SHAPE) for the filament and block 13 calculates the tungsten temperature from TUNGST. The order of when the shape factor and material temperature are calculated is not important. The shape factor may be calculated first as with the tungsten or the temperature may be calculated first as with the quartz. Block 14 calculates the tungsten spectral emissivities at the temperature found from TUNGST. Block 15 calculates the summation of Eqn. (24) and multiplies each $\left(\varepsilon_{a} \lambda_{n-1}{ }^{2}\right)\left(F_{\lambda_{n-1}}-\lambda_{n}\right)$ emissivity-blackbody fraction product by the transmissivity of quartz in that wavelength interval. This summation, as with the one in block 6 , allows easy calculation of the actual amount that passes the quartz envelope. Block 16 uses all of Eqn. (24) to calculate the flux emitted by the tungsten filament that is passed through the quartz envelupe which arrives at the gagc at $\mathrm{dA}_{1}$. Block 17 is the output producing segment which calculates the contribution of the quartz and tungsten components in heat flux values $\left(w / \mathrm{cm}^{2}\right)$, the percentage of the total flux that each component contributes and the total flux itself. 'Block 18 simply prints out the desired results in a reasonable format.

\section{Eubroutines}

The six subroutines uced in LAMP will now be discugaed in detail.

\section{a) Subroutine SHAPE}

This first subroutine calçulates the shape factor from a cylinder of finite dimensions to a plane differential area $\mathrm{dA}_{1}$ with the normal of the elemental area passing through the center of one end of the cylinder and perpendicular to the cylinder axis. This shape factor may be found in [6], 
pg. 788, configuration 21 and is shown in Figure 7 . Since the differential area $d A_{1}$ is directly under one end of the cylinder, the calculation must be performed twice for lengths $\ell_{3}$ and $l_{4}$ (if they differ) and the results added to get the total shape factor (shape factor algebra enables me to add the results for each individual part). See Figure 6. This subroutine is used for both the front half-cylinder of quartz and the whole tungsten filament. The filament was modeled as a solid opaque cylinder of diameter equal to the outside diameter of the wound filament. Since the quartz envelope was broken into the front half and back half-cylinders, different shape factors for each half. were needed. The front half was modeled using the shape factor from an opaque cylinder and so is the same as that used for the tungsten filament. The back half-cylinder shape factor was approximated by a concave half-cylinder of infinite length since the exact equation was not found. This approximate equation came from Ref. 7, pg. 19'. This configuration may be seen in Figure 9. Note the simplicity of the final equation for the shape factor assuming an infinite length. Since the final equation was so simple, it was not put in this subroutine but in the main program. It was discussed here only for convenience.

The inputs to SHAPE were geometrical. The radius of the component, the distance the differential area was away from the centerline of the cylinder, and the lengths of the two cylinders were all inputs into SHAPE. The outputs were the two shape factors corresponding to the two cylinders. The shape factors were equal if the two lengths were equal.

\section{b. Subroutine FRACTN}

To determine the fraction of blackbody emissive power in the wave length interval $\lambda_{n-1}-\lambda_{n}$, the basic equations given in [6] were used. Note that these fractional values are already tabulated in most books on radiation heat transfer, 
but to try to insert these tabulated values into a program would be a formidable task. The equations used started with Planck's formula for the spectral distribution of emissive power:

$$
e_{\lambda b}(\lambda)=2 \pi c_{1} / \lambda^{5}\left(\exp \left(C_{2} / \lambda T\right)-1\right)
$$

where $c_{1}=h c_{0}^{2}=.59544 \times 10^{-4}(W)\left(\mu m^{2}\right)$

and $\mathrm{r}_{2}=h \mathrm{hC}_{\mathrm{O}} / \mathrm{K}=14388.0(\mu \mathrm{m})\left({ }^{\circ} \mathrm{K}\right)$

In these two equations ' $C_{0}$ ' is the speed of light in a vacuum, ' $h$ ' is Planck's constant and ' $k$ ' is Boltzmann's constant.

If Eqn. (25) is divided by $T^{5}$ ( $T=$ temperature);

$$
\frac{e_{\lambda E}(\lambda, T)}{T^{5}}=\frac{2 \pi c_{1}}{(\lambda T)^{5}\left(\exp \left(c_{2} / \lambda I^{\prime}\right)-1\right)}
$$

Equation (26) gives the quantity $\varepsilon_{\lambda b} / T^{5}$ as a function of the single variable $\lambda T$.

The fraction of the total emissive power that is emitted in a given wavelength band is needed; calling this $\mathrm{F}_{\lambda_{1}-\lambda_{2}}$ :

$$
F_{\lambda_{1}-\lambda_{2}}=\frac{\int_{\lambda_{1}}^{\lambda_{2}} e_{\lambda b}(\lambda) d \lambda}{\int_{0}^{\infty} e_{\lambda b}(\lambda) d \lambda}=\frac{1}{\sigma T^{4}} \int_{\lambda_{1}}^{\lambda_{2}} e_{\lambda b}(\lambda) d \lambda
$$


or

$$
\begin{aligned}
F_{\lambda_{1}-\lambda_{2}} & =\frac{1}{\sigma T^{4}}\left[\int_{0}^{\lambda_{2}} e_{\lambda b}(\lambda) d \lambda-\int_{0}^{\lambda_{1}} e_{\lambda b}(\lambda) d \lambda\right] \\
& =F_{0-\lambda_{2}}-F_{0-\lambda_{1}}
\end{aligned}
$$

Now changing the variable from $\lambda$ to $\lambda T$ the form of Equation (28) changes to this:

$$
\begin{aligned}
F_{\lambda_{1}-\lambda_{2}}=\lambda_{1} T-\lambda_{2} T & =\frac{1}{\sigma}\left[\int_{0}^{\lambda_{2} T} \frac{e_{\lambda b}(\lambda)}{T^{5}} d(\lambda T)-\int_{0}^{\lambda_{1} T} \frac{e_{\lambda b}(\lambda)}{T^{5}} d(\lambda T)\right] \\
& =F_{0-\lambda_{2} T}-F_{0-\lambda_{1} T}
\end{aligned}
$$

Each of the integrals in Equation (29) can be found with the help of Equation (26) and a program subroutine. This evaluation was accomplished in subroutine FRACTN where the integrals were approximated using the "trapezoidal rule" of numerical integration. Although not the most accurate method for integration it worked quite well for the integrals in Eqn. (29). The maximum error encountered was at the upper values near fraction $=1$ and was no more than 0.04 percent. This error was negligible. in this analysis.

The inputs to FRACTN were the minimum and maximum wavelengths, encountered in the interval under evaluation and the temperature of the component being investigated. The output was simply the fraction of energy emitted by a blackbody in the wavelength interval under question. 


\section{c. Subroutine QTEMP}

This subroutine calculates the quartz envelope temperature from the known voltage as an input. The program. was written by using experimental data to correlate the relationship between the input voltage to the lamp and the quartz envelope temperature. For both the $2 \mathrm{~kW}$ and $6 \mathrm{~kW}$ lamps the relationship between the quartz temperature and the input voltage to the lamp was found to be almost linear. Data points were taken at each value of input voltage and the temperature could be linearly interpolated in between the data taken. This linear interpolation. represents a reasonable estimate of the envelope temperature for voltages in between those obtained experimentally. So the input to QTEMP was the input voltage (in volts) to the lamp and the output was quartz envelope temperature in Kelvin.

\section{d. Subroutine TUNGST}

This subroutine calculates the tungsten filament temperature in Kelvin from inputs of the input voltage and the rated (maximum) voltage. Geneial Electric's product data brochure on infrared heating [9] includes a plot of percent of maximum color temperature versus percent of maximum input voltage. The graph depicts the relationship as linear on a log-log scale-. The same brochure also indicates the maximum color temperature of the 2000 watt, $30.3 \mathrm{~cm}$ lamps to be $2450 \mathrm{~K}$ and that of the 6000 watt, 30.3 cm lamps to be $3150 \mathrm{~K}$. The equation can be estimated to be:

$$
8 \text { color temperature }=10^{2}
$$

where

$$
\mathrm{z}=(0.389166) \log _{10} \cdot \frac{\text { voltage }}{\text { rated voltage }}
$$


The color temperature of an object. is the temperature of a blackbody that has the same "color" as the object under question. For instance, a blackbody at $5000 \mathrm{~K}$ looks white, so if the object--in this case tungsten--looks white, then its color temperature is $5000 \mathrm{~K}$. This color temperature is not the true radiating temperature which is needed. The true temperature is a function of the emissivity of the surface under question. Fortunately, this function has already been determined and a table of values of true temperature versus color temperature for tungsten has been assembled $[10]$. The relation between the two temperatures is almost linear over the range of true temperatures from $1000-3600 \mathrm{~K}$. The range of temperatures. found in the experiments was between about $1300-1800 \mathrm{~K}$. To give a little better accuracy, the whole range was broken up into two smaller ones, the first from 1000-2600 $\mathrm{K}$ and the second from $2600 \mathrm{~K}$ to $3600 \mathrm{~K}$. Tabulated values were available at intervals of $100 \mathrm{~K}$ over the whole range (for true temperature) so the two Iinear equations estimating the true temperature given color temperature could be checked with the tabulated values. This was done and it was determined that the maximum percent error to be 0.53 percent (at $1500 \mathrm{~K}$ true temperature) or $7.91 \mathrm{~K}$ and the maximum absolute temperature error was at $1900 \mathrm{~K}$ and was $9.60 \mathrm{~K}(.51$ percent). As it turns out this error is not significant. This will be shown in the error analysis section of this report. What may be significant is that the accuracy of the graph of color temperature in [9] is not known and may not be very good.

So, in summary, the subroutine comes in with voltage and rated voltage as inputs and gives the true tungsten temperature' (K) as an output: 
e. Subroutine EMISS

Subroutine EMISS calculates, values of the hemispherical spectral emissivity of tungsten at the specified input temperature and at wavelengths every $.05 \mu \mathrm{m}$ from $.25 \mu \mathrm{m}$ out to $20 \mu \mathrm{m}$ in the range of temperatures between 1000 to $3200 \mathrm{~K}$. The procedures to estimate all these values were very similar to the ones used by Branstetter ${ }^{[11]}$ with some modifications.

Numerous experimenters have compiled data on the normal spectral emissivity of tungsten: [11], [12], [13], [14], [15]. Very few have compiled any data out past 4-5 $\mu \mathrm{m}$ or below . $25 \mathrm{\mu m}$. The area below .25 $\mathrm{\mu m}$ is really not of much consequence since even at the highest temperatures seen, $3150 \mathrm{~K}$, the fraction of the blackbody energy up to .25 $\mathrm{\mu m}$ is on the order of .I $\times 10^{-4}$ or .0018 which is negligible. The area from 4-5 um up to larger values of $\lambda$ is of greater consequence since at the lowest temperature considered, 1000 $\mathrm{K}$, the energy fraction above $4 \mu \mathrm{m}$ is about .52 or $52 \%$. Therefore estimates had to be made of the spectral emissivity out to larger values of $\lambda$.

After studying the available data on the spectral emissivity of tungsten it was decided to break up the infinite wavelength spectrum. into 5 sections. These were as follows:

\begin{tabular}{cc} 
Section & Wavelength Interval \\
\hline I & $0 \leq \lambda \leq 0.25$ \\
II & $0.25 \leq \lambda \leq 0.40$ \\
III & $0.40 \leq \lambda \leq 4.00$ \\
IV & $4.00 \leq \lambda \leq 20.00$ \\
V & $20.00 \leq \lambda \leq \infty_{\infty}$
\end{tabular}

These intervals were chosen mainly because of the availability of experimental data. Section I $(0-.25 \mu \mathrm{m})$ had no readily available experimental data over the range of wavelengths and temperatures needed. Even if the data were 
available it is doubtful that it would have been of much use. since so little of the energy is in this interval, as previously shown. The data from section II $(.25-.40 \mu \mathrm{m})$ was taken from [15] and increased slightly to agree with the data from section III which was taken from [12]. Reference 12 had the most complete set of data of the references seen for the normal spectral emissivity of tungsten from .40-4.00 $\mathrm{m}$ and from 1200 to $2600 \mathrm{~K}$. Since [12] was used as the bulk of the experimental data and the authors seemed to have a good understanding of the errors involved in their investigation, the remaining data below .40 $\mu \mathrm{m}$ and above $4.00 \mu \mathrm{m}$ was adjusted to agree with this basic block of. data. The data for temperatures below $1200 \mathrm{~K}$ and above $2600 \mathrm{~K}$ were extrapolated using what limited experimental data were available from the other sources. The wisdom of this approach is, of course, debatable but there seemed little choice considering the other options. Therefore, the data in section II [15], was first adjusted down 2.58 to correct for light scattering as suggested in [16] then extrapolated up to meet the data of [12] at $\lambda=.40 \mu \mathrm{m}$. The values at temperatures below $1600 \mathrm{~K}$ and above $2800 \mathrm{~K}$ were extrapolated using other experimental data available, if any. The values in section II for increments of $\lambda=.05 \mu \mathrm{m}$ were therefore determined.

The data of [12] between ${ }^{-} .40-4.00 \mu \mathrm{m}$ for each .05 $\mathrm{\mu m}$ were not always available so they were estimated by Iinear interpolation. This gave values of the normal spectral emissivity for each .05 $\mu \mathrm{m}$ between .40 and $4.00 \mu \mathrm{m}$ and 1200-2600 K. The values for $1000 \mathrm{~K}$ 'were extrapolated using the existing trends as a guide. The values at temperatures between $2600-3200 \mathrm{~K}(200 \mathrm{~K}$ intervals) were extrapolated using the trends in the data of [13] which went out to a temperature of $3200 \mathrm{~K}$ and [14] which went out to $3000 \mathrm{~K}$. In this way the emissivity was estimated over the whole range of $\lambda$ between .40 and $4.00 \mu \mathrm{m}$ every .05 $\mathrm{\mu m}$ and of 
temperatures between 1000 and $3200 \mathrm{~K}$ every $200 \mathrm{~K}$. As it turned out the temperatures encountered in the experimental part of this study fell in the range from about. 1300 to $1800 \mathrm{~K}$ which is in the temperature range where actual experimental data was available in the references (for this wavelength interval).

The experimental data available in the literature at any temperature and wavelengths past $4.0 \mu \mathrm{m}$ was minimal. Data past $5.0 \mu \mathrm{m}$ was virtually non-existent.

Therefore, some analytical method seemed to be the next approach worth considering. Fortunately, one exists and the same method as in [11] was used. This method consists of using the expressions given in [17]. Equations 4-79, 4-84 and 4-85 from [17] were used to estimate the data in the interval of wavelength 4.0-20.00 $\mu \mathrm{m}$. The equations are listed below:

$\varepsilon_{\lambda, \mathrm{n}}=0.365 \sqrt{\frac{r_{e}}{\lambda}}-0.0464 \sqrt{\frac{r_{e}}{\lambda}}, \quad(4-79)$

$E_{\lambda, h}=0.476 \sqrt{\frac{r_{e}}{\lambda}}-0.148 \sqrt{\frac{r_{e}}{\lambda}}, \quad(4-84), 0<r_{e} / \lambda<0.5$

$\varepsilon_{\lambda, \mathrm{n}}=0.442 \sqrt{\frac{r_{\mathrm{e}}}{\lambda}}-0.0995 \sqrt{\frac{r_{\mathrm{e}}}{\lambda}} ; \quad(4-85), 0.5<\mathrm{r} \mathrm{e}^{/ \lambda<2.5}$

These three equations represent empirical relations for metals where $\varepsilon_{\lambda, n}$ is the normal spectral emissivity, ${ }_{\lambda}, h$ is the hemispherical spectral emissivitý, $\mathrm{r}_{\mathrm{e}}$ is the

electrical resistivity and $\lambda$ is the wavelength. To use these equations in a strictly correct manner one should obtain experimental values of $r_{e}$ and then one can calculate $\varepsilon_{\lambda, n}$ and $\varepsilon_{\lambda, h}$. Unfortunately, this was not the method used. The method that was used--and why--will be discussed a short while later. First, a few comments. 
All of the experimental data for spectral emissivity of tungsten used herein and indeed most found in the literature are normal spectral emissivity values, that is values at $90^{\circ}$ to the surface. The parameter needed in the calculations is hemispherical spectral emissivity. presumably experimental difficulties prevent reasonable measurements of hemispherical spectral emissivity. So a relation or set of relations that determine the functional dependence of hemispherical spectral emissivity to normal spectral emissivity is needed. For metals at least this dependence can be evaluated from Eqns. (31)-(33). The same experimental problems are present in measurements on insulators (quartz) so there needs to be a conversion for insulators as well. This conversion may be deduced from Figure 4-10 in [17] and will be detailed in the discussion of subroutine QUARTZ.

As stated above the use of Equations. (31)-(33) did not work as well as hoped. Values of $r_{e}$ were gathered from sources [18] and [19] at varying temperatures and substituted into Eqns. (31)-(33)., The, calculated values of $\varepsilon_{\lambda, n}$ from Eqns. (31)-(33) were compared with the experimental values from [12] at 4.0 $\mu \mathrm{m}$. Unfortunately, they only agreed well at a temperature of $2000 \mathrm{~K}$ and were about $158 \mathrm{high}$ at $1000 \mathrm{~K}$ and 128 low at $3200 \mathrm{~K}$. As a result, the procedure followed was to first use the experimental values of $\varepsilon_{\lambda, n}$ at $4.00 \mu \mathrm{m}$ from [12] to calculate values of $r_{e}$ from Eqn. (3l). These values were then substituted into Eqn. (32) or (33) to determine $\varepsilon_{\lambda, \mathrm{h}}$. The same values of $r_{e}$ calculated from $\varepsilon_{\dot{\lambda},}$, data at $4.00 \mathrm{\mu m}$ were used for all remaining calculations of wavelength from 4.00 to $20.00 \mu \mathrm{m}$. This was used since $r_{e}$ is a function of temperature.but not of wavelength. In this way hemispherical spectral emissivity values could be calculated from 4.00 to $20.00 \mu \mathrm{m}$ at $.05 \mu \mathrm{m}$ intervals for temperatures from 1000-3200 K. Since these values could be calculated, 
large amounts of data input were not needed, unlike that in. the ranges from .25 to $4.00 \mu \mathrm{m}$.

The emissivity values in the last section, from $20 \mu \mathrm{m}$ to $\infty$, were not calculated. Even at the lowest temperature the fraction of energy above $20.00 \mu \mathrm{m}$ is no greater than 1.58. So following the procedure of [11], the value of emissivity at $\lambda=20.00 \mu \mathrm{m}$ was used for all values of $\lambda$ greater than $20.00 \mu \mathrm{m}$.

The important features of the normal spectral emissivity curves can be seen in Figure 10. At $4.00 \mu \mathrm{m}$ the sections were joined with perfect continuity of magnitude and good continuity of slope and the assumption of constant emissivity past $\lambda=20.00 \mu \mathrm{m}$ can be seen to be a good one since the curves are almost horizontal.

To summarize, subroutine EMISS is activated by the input temperature. The normal spectral emissivity between .25 and $4.00 \mu \mathrm{m}$ is calculated from the voluminous emissivity values initially input into the subroutine. The normal spectral emissivity values from 4.00 to $20.00 \mu \mathrm{m}$ are calculated next as is the single value used trom $20.00 \mu \mathrm{m}$ to $\infty$. Then all of the normal values are converted to hemispherical spectral emissivity values by using Eqns. (32) and (33). The output of the subroutine includes the arrays EMISST and ALAMBD which contain the hemispherical spectral emissivity values and the wavelength values from $\lambda=.25$ to $\lambda=20.00 \mu \mathrm{m}$ at $.05 \mu \mathrm{m}$ intervals, respectively. Lastly, the output contains a single value of hemisperical spectral emissivity evaluated at $20.00 \mu \mathrm{m}$ which is used for all wavelengths greater than $20.00 \mu \mathrm{m}$.

\section{f. Subroutine QUARTZ}

This subroutine calculates the hemispherical spectral emissivity of the fused quartz used in the envelope 
calculations. The input is the average temperature of the envelope and the outputs are the hemispherical spectral emissivity at that temperature evaluated every $0.05 \mathrm{\mu m}$, from 0-36.1 $\mu \mathrm{m}$, a single value of emissivity from $\lambda=36.1 \mu \mathrm{m}$ out to $\infty$ and an array of wavelength values similar to those in subroutine EMISS.

The data needed to develop this subroutine was scarce indeed. Only two useful sources of information were eventually found (References 5 and 20). These sources detailed the "spectral normal radiating power" (normal spectral emissivity) of "KI Quartz Glass" which is a quartz glass containing water of about $3 \times 10^{-4}$ weight 8 . This is presumably close to the General Electric 214 fused quartz glass used in the envelope of the lamps. Since the only data on the spectral emissivity of quartz was from these papers, there was little choice but to use them. The data were complete enough to compare the given transmissivities of the GE quartz to the transmissivity inferred from the emissivity data from [5] and some estimates of reflectivity. The comparisons were favorable in that the trends were the same and the magnitudes close. Without going into too much detail the interesting features of the emissivity values and how the main parameters affect the emissivity of quartz will be outlined.

First, data from [5] was over virtually the whole wavelength spectrum from 2.1 to $200 \mu \mathrm{m}$ and at the temperatures 295, 673, 873 and $1073 \mathrm{~K}$ and glass thicknesses of $0.5,1.0,5.0,10.0$ and $30.0 \mathrm{~mm}$. ' The data were not at even wavelength intervals but varying ones depending on the wavelength. The reasons for this will become apparent later.

Data were input into the subroutine from $\lambda=2.100^{\circ} \mu \mathrm{m}$ to $\lambda=36.100 \mu \mathrm{m}$ in whatever intervals were available in [5]. Since the emissivity was hot tabulated from 0-2.100 $\mu \mathrm{m}$ 
the trends between 2.100-2.600 $\mu$ m were assumed true from 0-2.100 $\mathrm{mm}$. The trends were constant values of emissivity so all values of emissivity for wavelengths between 0 and $2.100 \mathrm{\mu m}$ were assumed to be the values at $2.100 \mathrm{\mu m}$. Since they were so low anyway (less than .006) the error incurred with this assumption seems negligible. The data from 2.100 to $36.100 \mu \mathrm{m}$ was in a tabulated form so could be input into QUARTZ. The emissivity values needed in the temperatures between 295-1073 $\mathrm{K}$ and wavelengths of 2.100-36.100 $\mathrm{mm}$ could be linearly interpolated between the values already in the subroutine. Another set of values for $1273 \mathrm{~K}$ were extrapolated using existing trends in the data of [5]. Lastly, a single value of emissivity from $36.100 \mu \mathrm{m}$ to $\infty$ was taken as the average of the value at $36.100 \mu \mathrm{m}$ and the next data point of [5] at $120.00 \mathrm{\mu m}$. As with EMISS, so little energy is present out at values of $\lambda$ greater than $36.100 \mu \mathrm{m}$ that little error was added. Figure 11 shows the normal spectral emissivity curves from [5] for a $1 \mathrm{~mm}$ thickness of KI quartz (the lamp envelope thickness is also $1 \mathrm{~mm}$ ) at various temperatures and wavelengths.

It should be emphasized that the normal spectral emissivity values from [5] were calculated from measured values of the index of refraction and absorption coefficients. The calculational procedure is a complicated one and is discussed in detail in [4], but will not be elaborated on in this paper. A lengthy search was performed by the authors of [5]. to determine the best values of the index of fefraction and absorption coeffioients as they varied with temperature and wavelength. From [5] the wavelength interval may be broken down into three parts, depending on the functional dependence of the emissivity on the grade of glass, temperature or thickness. In the wavelength interval from 0-3.5 $\mathrm{\mu m}$ the normal spectral emissivity depends on the temperature, thickness and the grade of glass. In the interval from 3.5-4.8 $\mathrm{um}$ the normal 
spectral emissivity depends on temperature and thickness, and in the interval from $4.8 \mu \mathrm{m}$ to $\infty$ the spectral emissivity depends on temperature only.

Another way to break down the wavelength range is to say that the "region of transparency" is from 0-4.800 $\mu \mathrm{m}$ and the "region of opacity" is from $4.800 \mu \mathrm{m}$ to $\infty$. These identifiers correspond to the fact that the quartz is essentially. transparent out to about $4.800 \mu \mathrm{m}$ and essentially opaque from $4.800 \mu \mathrm{m}$ to $\infty$. The region of opacity may be broken into two parts. The part due to the principle vibration bands of silicon and oxygen are between 8-10. $\mu \mathrm{m}$ and 19-25 $\mathrm{\mu m}$. The emissivity drops considerably in these regions. In these two regions the emissivity varies with temperature. In the regions outside the principle bands the emissivity is almost completely governed by the refractive index and is virtually independent of temperature.

So with the temperature input the subroutine Iinearly interpolates between temperatures existing in the subroutine and calculates the emissivity at that temperature and wavelengths every $.050 \mu \mathrm{m}$ from $0-36.100 \mu \mathrm{m}$ and the constant value out from $36.100 \mu \mathrm{m}$ to $\infty$. Then, as with EMISS, it estimates the hemispherical values from the normal values using information given in [17]. In this case, however, there are no analytical relations available to do the conversion so values were taken off Figure 4-10 in [17] at normal emissivity intervals of .05 from 0-1.0. The use of this figure is somewhat questionable since the abscissa is normal total emissivity rather than normal spectral emissivity, and since it does not go below a normal total emissivity of about .33 for insulators. Since there was no other data available in [17], the values in Fig. 4-10 were used. The values for emissivity below a normal total value of .33 were obtained by linearly extrapolating between the known end point at an emissivity of 0.33 and the point at 
emissivity of 0.00 where the "conductor" curve hits 0.00 . These ratios, although for hemispherical total divided by normal total emissivity, were assumed to be the same as hemispherical spectral divided'by normal spectral

emissivity. The abscissa was also changed from normal total to normal spectral emissivity. So the changed plot was the same except that the ordinate was assumed to be hemispherical spectral emissivity divided by normal spectral emissivity, and the abscissa was assumed to be normal spectral emissivity. Lastly, the part of the "insulator" curve from an ordinate of about .33 down to 0.00 was assumed linear from the end point of the existing curve to the starting point of the conductor curve. Figure 12 shows Figure 4-10 from [17] and the extrapolation.

\section{1. Theoretical Results}

The program calculates the heat $f l u x$ in $W / \mathrm{cm}^{2}$ reaching the differential area $\mathrm{dA}_{1}$ from the three components idealized in the model, the tungsten filament, the front half of the quartz cylinder and the back half of the quartz cylinder. The three parts were summed to obtain the total fiux. The contributions from the filament and the whole envelope were divided by the total to get the percentage each component contributed to the total. Note that these results are for a single lamp with no reflector behind it. The results were calculated to match what experimental data could be gathered and is presented in Table 1.

\section{Experimental Setup and Results}

The experimental. setup can be viewed in Figures 13-15. These are photographs of the setup during a typical test. Figure 13 shows a closeup of the lamp and the heat flux gage in its mount. The lamp filament can be seen glowing. The flux gage, a circular foil heat flux gage manufactured by 
Hy-Cal Engineering, Model C-1301-AX-15-072, S/N 72215, for the range of $0-15 \mathrm{Btu} / \mathrm{ft}^{2} \mathrm{sec}$ can be seen mounted to a movable assembly for fine adjustment of the position of the gage with respect to the lamp. Figure 14 shows a view looking over the top of the optical pyrometer towards the lamp, movable table and the variable power supply. Figure 15 shows another view of the setup looking at the ammeter, variable power supply and a digital voltmeter.

The largest portable power supply available had a maximum voltage output of $120 \mathrm{~V}$. The two lamps tested were $2000 \mathrm{~W}$ and $6000 \mathrm{~W}$ maximum at $240 \mathrm{~V}$ and $480 \mathrm{~V}$ rated voltage, respectively. Usually these types of lamps are mounted in an array consisting of many lamps and a reflector on one side to focus a larger portion of the total energy in one direction. An array was not used in this setup--just a single lamp mounted in "mid-air." Note also that only the 6000 . watt lamp was filled with a halogen gas. With only a $120 \mathrm{~V}$ power supply, high power levels could not be reached. The voltage to the lamp was recorded by a digital voltmeter and varied at approximately $10 \mathrm{~V}$ increments. The quartz envelope temperature was measured by a Barnes Engineering Co. Optitherm Series 12-8700 infrared thermometer. The thermometer, also called an optical pyrometer, has a digital output device with an emissivity adjustment knob. This adjustment is presumably a hemispherical total setting. Values of normal total emissivity for grade KI quartz glass for a thickness of $1.75 \mathrm{~mm}$ and various temperatures were obtained from [21] and [22]. The values were extrapolated down to a thickness of $1.0 \mathrm{~mm}$ and from normal to hemispherical total emissivity. These values were used for the emissivity setting on the optical pyrometer.

The general procedure consisted of establishing a steady condition at the lamp then reading pertinent values. The voltage was first set at about $10 \mathrm{~V}$ intervals from $50 \mathrm{~V}$ to 
the maximum the power supply would put out--about $113 \mathrm{~V}$. The system was allowed to stabilize. Then the (approximately) constant value of quartz envelope temperature was read and a corresponding value of emissivity was taken off the graph of [21]. If this value was the one already dialed in on the pyrometer, then no further adjustment of the emissivity knob was needed. If it wasn't, an iterative scheme was employed until the correct emissivity setting was observed on the pyrometer. Then the values of quartz envelope temperature, emissivity setting, input voltage, input current, heat flux gage millivolt reading were measured. With these values and previously measured geometrical parameters all the data needed to run the program was obtained.

The millivolt reading from the heat flux gage was converted to incident heat flux by using the calibration sheet provided with the gage. The gage calibration is NBS traceable. This heat flux value was assumed to be the same as the one impinging on a differential area $\mathrm{dA}_{1}$ located at the gage sensing area. The interchange occurring due to the presence of the finite size of the gage and mounting hardware was assumed to cause little error. Checks with the gage protruding from the mounting hardware produced no noticeable change in the data. Therefore, the mounting hardware may be eliminated as a signiflcant error source.

The calibration of the Hy-Cal gage for incident flux assumes an absorptivity value of 0.89 . This is a reasonable value for the range of wavelengths of most incident fluxes. The absorptivity of the Hy-cal coating varies with wavelength. It is about .92 at $0.4 \mu \mathrm{m}, .90$ at $3.0 \mu \mathrm{m}, .82$ at $10.0 \mathrm{\mu m}$ and about .54 at $30.0 \mu \mathrm{m}$. So depending on the wavelength of the incident flux the absorptivity of the coating could vary from .89. The incident flux had a combination of wavelengths since there were two sources--the 
filament and the envelope--each at different temperatures. The main program, LAMP, was modified to account for these variations in absorptivity. At each wavelength interval the emissivity times blackbody fraction product was further multiplied by the absorptivity of the Hy-Cal coating. This was done for each interval for the front half-cylinder. For the back half-cylinder and the tungsten filament the above product (of three terms) was further multiplied by the transmissivity of the quartz. After the whole wavelength interval was covered the sums formed by using the absorptivity values were divided by the sums formed without the absorptivity values to get an overall average value of absorptivity. for each component (filament, front half-cylinder and back half-cylinder). Finally, each value of average absorptivity was multiplied by the percent of the total flux contributed by that component and the three weighted values were summed to get a final value of absorptivity. Therefore, this value was weighted to the wavelengths of the incoming radiation and to the amount contributed by each component. At the extremes; the calculated values of absorptivity went no lower than .873 and no higher than .890. The largest error incurred would be, then, about 1.98 which is within the \pm 38 error bounds that Hy-Cal specifies for this type of gage. Therefore, the readings were not modified for this effect.

The readings from one setpoint were obtained in the above manner. The input voltage was then changed about $10 \mathrm{~V}$ and the process was repeated. Data were collected in this lidiner on a $6000 \mathrm{~W}$ lamp and on a $2000 \mathrm{~W}$ Iamp. For repeatability two sets of data for the 2000 watt lamp were taken at the same values of voltage and distance of the gage from the lamp. To get an idea of the change of flux with distance of the gage from the lamp, the value of distance was doubled. A set of runs at one value of distance of the 
gage from the $6 \mathrm{~kW}$ lamp with varying voltage was also performed.

The results of the experimental tests are also presented in Table 1. The heat flux gage accuracy is stated as \pm 38 in the Hy-Cal product literature.

\section{Error Analysis}

Before discussing the results and drawing some conclusions from the analysis and experiments, an error analysis on the model should be performed. The theoretical calculations, even if exact, are only as good as the input parameters. If the input parameters have large errors associated with them, then the calculations will have large errors no matter how good the model. Although care was taken to make accurate measurements, some parameters had to be taken on faith, such as the manufacturers supplied curve of filament temperature vs. input voltage.

A detailed error analysis is really not possible since a detailed account of the individual errors of each measurement is not known. Nonetheless, the method used will be vigorous and is taken from [23].

The relation for the error generated in a calculation such as the one done herein begins with the basic equation used to determine the heat flux--Equation (24). This basic equation was used for each component of the lamp and has five variables, the value for ' $\sigma$ ' being constant. Thcrcfore, the flux, dq, can be expressed as a function of the five basic variables. Note that dq is a function of five variables only in the case of the front half-cylinder of the quartz envelope. The back half-cylinder and tungsten filament are functions of six variables, the last one being the transmittance of the quartz. Since the back half-cylinder contributes so little to the total flux, the 
whole quartz envelope will be considered a function of fivevariables only. The transmittance of the quartz will be included in the tungsten calculations but not in the general equations generated below.

So:

$$
d q=f\left(F_{d l-3}, F_{d l-4}, T_{2}, F_{\lambda_{n-l}}-\lambda_{n}, \varepsilon_{d \lambda_{n}}\right)
$$

Using the relation generated in [23],

$$
\begin{aligned}
\Delta(d q) & =\left|\Delta F_{d l-3} \frac{\partial f}{\partial F_{d l-3}}\right|+\left|\Delta F_{d l-4} \frac{\partial f}{\partial F_{d l-4}}\right|+\left|\Delta T_{2} \frac{\partial f}{\partial T_{2}}\right|+\left|\Delta F_{0-\lambda_{1}} \frac{\partial f}{\partial F_{0-\lambda_{1}}}\right| \\
& +\left|\Delta F_{\lambda_{1}-\lambda_{2}} \frac{\partial f}{\partial F_{\lambda_{1}-\lambda_{2}}}\right|+\ldots+\left|\Delta \varepsilon_{d \lambda_{1}} \frac{\partial f}{\partial \varepsilon_{d \lambda_{1}}}\right|+\left|\Delta \varepsilon_{d \lambda_{2}} \frac{\partial f}{\partial \varepsilon_{d \lambda_{2}}}\right|-+\ldots
\end{aligned}
$$

where $\Delta(d q)=$ maximum possible error

etc,

$$
\begin{aligned}
& \Delta \mathrm{F}_{\mathrm{dl}-3}=\text { error in } \mathrm{F}_{\mathrm{dl}-3} \\
& \Delta \mathrm{F}_{\mathrm{dl}-4}=\text { error in } \mathrm{F}_{\mathrm{dl}-4}
\end{aligned}
$$

$$
\text { and } \begin{aligned}
f & =\text { function given by relation }(24) \\
\frac{\partial f}{\partial x} & =\text { partial derivative of function with } \\
& \text { respect to } x .
\end{aligned}
$$

The function ' $f$ ' is given by Equation (24),

$$
\begin{aligned}
f=d q= & {\left[F_{d 1-3}+F_{d l-4}\right] \sigma T_{2}^{4} x } \\
& {\left[\varepsilon_{d \lambda_{1,2}} F_{0-\lambda_{1}}+\varepsilon_{d \lambda_{2,2}} F_{\lambda_{1}-\lambda_{2}}+\ldots+\varepsilon_{d \lambda_{n, 2}} F_{\lambda_{n-1}-\lambda_{n}}\right] }
\end{aligned}
$$


so,

$$
\begin{aligned}
\frac{\partial f}{\partial F \frac{f l-3}{d}}= & {[1+0] \sigma \mathbf{T}_{2}^{4} } \\
& {\left[\varepsilon_{d \lambda_{1,2}} F_{n-\lambda_{1}}+\varepsilon_{d \lambda_{2,2}} F_{\lambda_{1}-\lambda_{2}}+\ldots+\varepsilon_{d \lambda_{n, 2}}\left[F_{\lambda_{n-1}-\lambda_{n}}\right]\right.}
\end{aligned}
$$

$$
\begin{aligned}
& \frac{\partial f}{\partial l-4}=[0+1] \sigma T_{2}^{4} \\
& {\left[\varepsilon_{\mathrm{d} \lambda_{1,2}} F_{0-\lambda_{1}}+\varepsilon_{\mathrm{d} \lambda_{2,2}} F_{\lambda_{1}}=\lambda_{2}+\ldots+\varepsilon_{\mathrm{d} \lambda_{\mathrm{n}, 2}} F_{\lambda_{n-1}-\lambda_{n}}\right]}
\end{aligned}
$$

$$
\begin{aligned}
& \frac{\partial f}{\partial T_{2}}=\left[F_{d l-3}+F_{d l-4}\right] 4 \sigma T_{2}^{3} \\
& {\left[\varepsilon^{\varepsilon} \lambda_{1,2} F_{0-\lambda_{1}}+\varepsilon d \lambda_{2,2} F_{\lambda_{1}-\lambda_{2}}+\ldots+\varepsilon_{d \lambda_{n, 2}} F_{\lambda_{n-1}-\lambda_{n}}\right]} \\
& \frac{\partial f}{\partial F_{0-\lambda_{1}}}=\left[F_{d 1-3}+F_{d 1-4}\right] \sigma T_{2}^{4}\left[\varepsilon_{d \lambda_{1,2}}+0\right] \\
& \frac{\partial f}{\partial F_{\lambda_{1}-\lambda_{2}}}-\left[F_{d 1-3}+F_{d 1-4}\right] \sigma T_{2}^{4}\left[\varepsilon_{d \lambda_{2,2}}\right]
\end{aligned}
$$

etc.

$$
\begin{aligned}
& \frac{\partial E}{\delta_{d \lambda_{1,2}}}=\left[F_{\mathrm{a} 1-3}+F_{\mathrm{Al}-4}\right] \sigma T_{2}^{1}\left[F_{0-\lambda_{1}}\right] \\
& \frac{\partial f}{\partial E_{d \lambda_{2,2}}}=\left[F_{d i-3}+F_{d i-4}\right] \operatorname{or}_{2}^{4}\left[F_{\lambda_{1}-\lambda_{2}}\right]
\end{aligned}
$$

etc.

Adding up the values $\left(\Delta F_{\lambda_{n-1}-\lambda_{n}}\right)\left(\frac{\partial F}{\partial F_{\lambda_{n-1}}-\lambda_{n}}\right)$,

38 


$$
\begin{aligned}
& \sum_{n} \Delta F_{\lambda_{n-1}-\lambda_{n}} \frac{\partial f}{\partial F_{\lambda_{n-1}}-\lambda_{n}}=\left[F_{d 1-3}+F_{d l-4}\right] \sigma T_{2}^{4} \\
& {\left[\Delta F_{0-\lambda_{1}} \varepsilon_{\mathrm{d} \lambda_{1,2}}+\Delta \mathrm{F}_{\lambda_{1}-\lambda_{2}} \varepsilon_{\mathrm{d} \lambda_{2,2}}+\ldots+\Delta \mathrm{F}_{\lambda_{n-1}-\lambda_{\mathrm{n}}} \varepsilon_{\mathrm{d} \lambda_{\mathrm{n}, 2}}\right]} \\
& =\left[F_{\mathrm{d} 1-3}+F_{\mathrm{dl}-4}\right] \sigma \mathrm{T}_{2}^{4}\left[\sum_{\mathrm{n}=1}^{\infty} \Delta F_{\lambda_{\mathrm{n}-1}-\lambda_{\mathrm{n}}} \varepsilon_{\mathrm{d} \lambda_{\mathrm{n}, 2}}\right] \\
& \sum \Delta \varepsilon_{d \lambda_{n, 2}} \frac{\partial f}{\partial \varepsilon_{d \lambda}, 2}=\left[F_{d l-3}+F_{d l-4}\right] \sigma r_{2}^{4} \\
& {\left[\Delta \varepsilon_{\mathrm{d} \lambda_{1,2}} \mathrm{~F}_{0-\lambda_{1}}+\Delta \varepsilon_{\mathrm{d} \lambda_{2,2}} F_{\lambda_{1}-\lambda_{2}}+\ldots+\Delta \varepsilon_{\mathrm{d} \lambda_{\mathrm{n}, 2}}{ }^{F} \lambda_{n-1}-\lambda_{\mathrm{n}}\right]} \\
& =\left[F_{d 1-3}+F_{d 1-4}\right] \sigma T_{2}^{4}\left[\sum_{n=1}^{\infty} d \varepsilon_{d \lambda_{n, 2}} F_{\lambda_{n-1}-\lambda_{n}}\right]
\end{aligned}
$$

So:

$$
\begin{aligned}
& \Delta(\mathrm{dq})=\left|\left(\Delta \mathrm{F}_{\mathrm{d} l-3}\right)\left(\sigma \mathrm{T}_{2}^{4}\right)\left(\varepsilon_{\mathrm{d} \lambda_{1,2}} \mathrm{~F}_{0-\lambda_{1}}+\varepsilon_{\mathrm{d} \lambda_{2,2}} \mathrm{~F}_{\lambda_{1}-\lambda_{2}}+\ldots+\varepsilon_{\mathrm{d} \lambda_{\mathrm{n}, 2}} F_{\lambda_{\mathrm{n}-1}-\lambda_{\mathrm{n}}}\right)\right| \\
& +\left|\left(\Delta \mathrm{F}_{\mathrm{dl}-4}\right)\left(\sigma \mathrm{T}_{2}^{4}\right)\left(\varepsilon_{\mathrm{d} \lambda_{1,2}} \mathrm{~F}_{0-\lambda_{1}}+\varepsilon_{\mathrm{d} \lambda_{2,2}} \mathrm{~F}_{\lambda_{1}-\lambda_{2}}+\ldots+\varepsilon_{\mathrm{d} \lambda_{n}, 2} \mathrm{~F}_{\lambda_{\mathrm{n}-1}-\lambda_{n}}\right)\right| \\
& +\left|\Delta T_{2}\left(F_{d l-3}+F_{d l-4}\right) \sigma\left(4 \mathrm{~T}_{2}^{3}\right)\left(\varepsilon_{\mathrm{d} \lambda_{1,2}} \mathrm{~F}_{0-\lambda_{1}}+\ldots+\varepsilon_{\mathrm{d} \lambda_{n, 2}} F_{\lambda_{n-1}-\lambda_{n}}\right)\right| \\
& +\left|\left(F_{d 1-3}+F_{d 1-4}\right) \sigma \mathrm{T}_{2}^{4}\left(\sum_{n=1}^{\infty}\left(\Delta \mathrm{F}_{\lambda_{n-1}}-\lambda_{n}\right)\left(\varepsilon_{\mathrm{d} \lambda_{n, 2}}\right)\right)\right| \\
& +\left|\left(F_{d l-3}+\cdot F_{d l-4}\right) \sigma T_{2}^{4}\left(\sum_{n=1}^{\infty}\left(\Delta \varepsilon_{d \lambda_{n, 2}}\right)\left(F_{\lambda_{n-1}-\lambda_{n}}\right)\right)\right|
\end{aligned}
$$

39 
Equation (45) is a general one for any case that could be encountered. In the experimental cases performed there are some simplifications that can be effected.

First, summations may be formed in the first three terms of (45), and the first two terms may be joined into one. Without the loss of generality:

$$
\begin{aligned}
& \Delta(\mathrm{dq})=\left|\left(\Delta \mathrm{F}_{\mathrm{d} 1-3}+\Delta \mathrm{F}_{\mathrm{dl}-4}\right) \sigma \mathrm{T}_{2}^{4}\left[\varepsilon_{\mathrm{d} \lambda_{1,2}} \mathrm{~F}_{0-\lambda_{1}}+\varepsilon_{\mathrm{d} \lambda_{2,2}} \mathrm{~F}_{\lambda_{1}-\lambda_{2}}+\cdots+\varepsilon_{\mathrm{d} \lambda_{\mathrm{n}, 2}} \mathrm{~F}_{\lambda_{\mathrm{n}-1}-\lambda_{\mathrm{n}}}\right]\right| \\
& +\left|4\left(F_{d 1-3}+F_{d 1-4}\right) \sigma \Delta T_{2} T_{2}^{3}\left[\varepsilon_{d \lambda_{1,2}} F_{0-\lambda_{1}}+\varepsilon_{d \lambda_{2,2}} F_{\lambda_{1}-\lambda_{2}}+\ldots+\varepsilon_{d \lambda_{n, 2}} F_{\lambda_{n-1,-}-\lambda_{n}}\right]\right| \\
& +\mid\left(F_{d l-3}+F_{d l-4}\right) \sigma T_{2}^{4}\left[\left(\sum_{n=1}^{\infty}\left(\Delta F_{\lambda_{n-1}-\lambda_{n}}\right)\left(\varepsilon_{d \lambda_{n, 2}}\right)\right)+\left(\sum_{n=1}^{\infty}\left(\Delta \varepsilon_{d \lambda_{n, 2}}\right)\left(F_{\lambda_{n-1}-\lambda_{n}}\right)\right] \mid\right.
\end{aligned}
$$

or

$$
\begin{aligned}
\Delta(\mathrm{dq}) & =\left|\left(\Delta \mathrm{F}_{\mathrm{dl}-3}+\Delta \mathrm{F}_{\mathrm{dl}-4}\right) \sigma \mathrm{T}_{2}^{4}\left[\sum_{n=1}^{\infty} \varepsilon_{\mathrm{d} \lambda_{\mathrm{n}, 2}} F_{\lambda_{\mathrm{n}-1}-\lambda_{\mathrm{n}}}\right]\right| \\
& +\left|4\left(F_{\mathrm{dl}-3}+F_{\mathrm{dl}-4}\right) \sigma \Delta \mathrm{T}_{2} \mathrm{~T}_{2}^{3}\left[\sum_{11-1}^{\infty} \varepsilon_{\mathrm{d} \lambda_{11,2}} F_{\lambda_{11-1}-\lambda_{\mathrm{n}}}\right]\right| \\
& +\left|\left(F_{\mathrm{dl}-3}+F_{\mathrm{dl}-4}\right) \sigma \mathrm{T}_{2}^{4}\left[\sum_{n=1}^{\infty}\left(\Delta F_{\lambda_{n-1}-\lambda_{\mathrm{n}}} \varepsilon_{\mathrm{d} \lambda_{\mathrm{n}, 2}}+\Delta \varepsilon_{\mathrm{d} \lambda_{n, 2}} F_{\lambda_{n-1}-\lambda_{n}}\right)\right]\right|
\end{aligned}
$$

Now comes the task of actually defining the magnitudes of the errors $\left(\Delta \mathrm{F}_{\mathrm{dl}-3}, \Delta \mathrm{T}_{2}\right.$, etc) and the maqnitudes of the parameters $\left(T_{2}, F_{a l=3}, \varepsilon_{a \lambda_{n}}\right.$ etç, $)$ to put into Equation (47A).

I will first choose the set of calculated data which showed the greatest discrepancy with respect to the experimental data for that case. By glancing at Table.1 these are the data for the 2000 watt lamp, second set of data. For that case, 


$$
\begin{aligned}
& h_{1}=0.376^{\prime \prime} \\
& \ell_{3}=5.44 " \\
& \ell_{4}=4.69 "
\end{aligned}
$$

During one of the runs a temperature traverse of the quartz envelope was performed, and it was found that the envelope temperature was not uniform. This was partially because of the filament locators in Figure 2. These would conduct heat from the filament to the envelope. A reasonable estimate of the error that was caused because of this non-uniformity of temperature is. \pm 28 of the average absolute temperature of the envelope. This value was obtained from those temperature traverses. The traverses were not taken at every temperature, but it will be assumed that the error bound holds for all temperatures. In addition, another \pm 28 error was arbitrarily added to account for inaccuracy of emissivity setting and calibration on the optical pyrometer. Note that the resistance of the emissivity potentiometer was read at various values of emissivity on the dial and an equation was generated to relate the emissivity vs. the resistance of the "pot." so the emissivity dial was really set by a resistance measurement rather than "eyeballing" the dial. With these approximations and assumptions, then, it was assumed that the quartz envelope temperature measurements were good to $\pm 4 \%$ of the absolute temperature. A calibration performed by the SNLA temperature standards laboratory for blackbody temperatures in the range 1131-1915 $\mathrm{K}$ showed that the pyrometer consistently read low. The errors ranged from a minimum of -1.08 to a maximum of -3.38 . Since the range of temperatures measured varied in the range 663-977 $\mathrm{K}$, one cannot directly. say there is any significant error associated with calibration. However, since my calculated values of flux were low compared with the measured values and the calibration showed that the pyrometer read consistently low, this may be a significant source of 
error. Therefore, the "arbitrary" \pm 28 error explained previously is a reasonable estimate of the calibration error trend just detailed.

The temperature data on the tungsten was taken from a product brochure [9] and there is no mention of the accuracy of those values: For lack of any information, the same error as that for the quartz will be assumed, namely \pm 48 .

The inaccuracies $\Delta F_{d l-3}$ and $\Delta F_{d l-4}$ are very small. The equations used to calculate $F_{\text {dl-3 }}$ or $F_{\text {dl-4 }}$ are exact analytically and the computer generated error is negligible. The only significant error source would seem to be in the actual measurement of the geometrical values $h$, $\ell_{3}$ and $\ell_{4}$. These were done with a micrometer and should be very accurate. A few values were run through the shape factor subroutine to determine the magnitude of the errors that would result from known errors in measurement. It was found that anything smaller than a catastrophic error in the measurement of the two lengths $l_{3}$ or $l_{4}$ causes essentially no error. But it was also found that an error of only .003" in the measurement of $h\left(=.376^{\prime \prime}\right)$ causes a 0.88 error in the shape factor. So it is felt that assuming both $\Delta F_{d l-3}$ and $\Delta F_{d l-4}$ equal 18 is reasonable. Also, for all practical purposes, $F_{d l-3}=F_{d 1-4}=.2593$ for the envelope calculation. A similar procedure for the filament shows the same thing, a .003" error in h produces.a 0.88 error in $F_{d l-3}$ or $F_{d l-4}$ and there is a negligible error affected by a mismeasurement in either length $l_{3}$ or $\ell_{4}$.

Since it has been shown that $\Delta F_{a 1-3}=\Delta F_{a 1-4}$ and $F_{\text {dl }-3} \cong F_{\text {dl-4 }}$, Eqn. (47) can be simplified further: 


$$
\begin{aligned}
& \Delta(\mathrm{dq})=\left|2 \Delta \mathrm{F}_{\mathrm{dl-3}}\left(\sigma \mathrm{T}_{2}^{4}\right)\left[\sum_{n=1}^{\infty} \varepsilon_{\mathrm{d} \lambda_{n, 2}} \mathrm{~F}_{\lambda_{\mathrm{n}-1}-\lambda_{\mathrm{n}}}\right]\right|+\left|8 \mathrm{~F}_{\mathrm{d} 1-3} \sigma \mathrm{T}_{2}^{3} \Delta \mathrm{T}_{2}\left[\sum_{n=1}^{\infty} \varepsilon_{\mathrm{d} \lambda \lambda_{n, 2}} F_{\lambda_{n-1}}-\lambda_{n}\right]\right| \\
& +\left|2 F_{\mathrm{di}-3}\left(\sigma \mathrm{T}_{2}^{4}\right)\left[\sum_{n=1}^{\infty}\left(\Delta \mathrm{F}_{\lambda_{\mathrm{n}-1}-\lambda_{\mathrm{n}}} \varepsilon_{\mathrm{d} \lambda_{\mathrm{n}, 2}}+\Delta \varepsilon_{\mathrm{d} \lambda_{\mathrm{n}, 2}} \mathrm{~F}_{\lambda_{\mathrm{n}-1}-\lambda_{\mathrm{n}}}\right)\right]\right|
\end{aligned}
$$

or

$$
\begin{aligned}
& \Delta(d q)=\left|\left(\sum_{n=1}^{\infty} \varepsilon_{d \lambda_{n, 2}} F_{\lambda_{n-1}-\lambda_{n}}\right)\left(2 \Delta F_{d l-3} \sigma T_{2}^{4}+8 F_{d 1-3} \sigma T_{2}^{3} \Delta T_{2}\right)\right|
\end{aligned}
$$

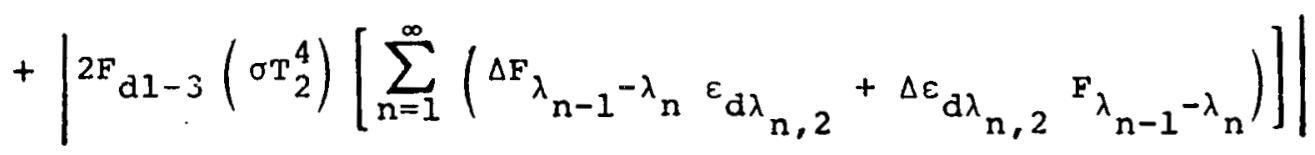

Since Eqn. (48) has temperature as a variable the maximum temperatures encountered will be used. For the quartz this is $944 \mathrm{~K}$ and for the tungsten filament this is $1795 \mathrm{~K}$. These correspond to the set of runs with the largest errors. The data point considered is that at a voltage of $113.2 \mathrm{~V}$.

Looking back to the section. on subroutine FRACTN (Section II B3b) it was said that the maximum error in the values calculated as compared with the tabulated ones in [6] was 0.048 which is really not significant. It is therefore reasonable to say that $\Delta F_{\lambda_{n-1}-\lambda_{n}}=0$ and so (48) can be modified further,

$$
\begin{aligned}
\Delta(d q) & \cong\left|\left(\sum_{n=1}^{\infty} \varepsilon_{\mathrm{d} \lambda_{n, 2}} F_{\lambda_{n-1}-\lambda_{n}}\right)\left(2 \Delta F_{d l-3}\left(\sigma T_{2}^{4}\right)+8 F_{d l-3}\left(\sigma T_{2}^{3}\right) \Delta T_{2}\right)\right| \\
& +\left|2 F_{d l-3} \cdot\left(\sigma T_{2}^{4}\right)\left[\sum_{n=1}^{\infty} \Delta \varepsilon_{d \lambda_{n, 2}} F_{\lambda_{n-1}-\lambda_{n}}\right]\right|
\end{aligned}
$$


The error in emissivity values for quartz is really not known at all since the values were calculated rather than measured. The values of emissivity for the tungsten were reported to be \pm 28 maximum throughout the range of wavelength. For lack of anything better the $\pm 2 q$ band will also be used for the quartz emissivity. So in general,

$$
\Delta \varepsilon_{\mathrm{d} \lambda_{\mathrm{n}, 2}}=.02 \varepsilon_{\mathrm{d} \lambda_{\mathrm{n}, 2}}
$$

Therefore, (49) may be modified as follows:

$$
\begin{aligned}
\Delta(A \tau) & =\left|\left(\sum_{n=1}^{\infty} \varepsilon_{\mathrm{d} \lambda_{n, 2}} F_{\lambda_{n-1}-\lambda_{n}}\right)\left(2 \Delta F_{\mathrm{d} 1-3} \sigma \mathrm{T}_{2}^{4}+8 F_{\mathrm{d} 1-3}\left(\sigma \mathrm{T}_{2}^{3}\right) \Delta \mathrm{T}_{2}\right)\right| \\
& +\left|2 F_{\mathrm{dl}-3}\left(\sigma \mathrm{T}_{2}^{4}\right)\left[\sum_{n=1}^{\infty} .02 \varepsilon_{\mathrm{d} \lambda_{n, 2}} F_{\lambda_{n-1}-\lambda_{n}}\right]\right|
\end{aligned}
$$

or finally,

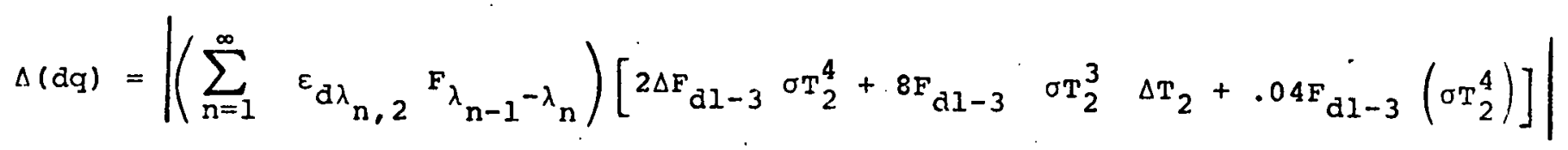

$=\left|\left(\sum_{n=1}^{\infty} \varepsilon_{d \lambda_{n, 2}} F_{\lambda_{n-1}-\lambda_{n}}\right) !\left(\sigma T_{2}^{4}\right)\left[2 \Delta F_{d l-3}+8 F_{d l-3} \frac{\Delta T_{2}}{T_{2}}+.04 F_{d l-3}\right]\right|$

The value of the summation can be calculated from the program LAMP and the other values are as follows,

$2 \mathrm{~kW}$ Lamp, $\mathrm{h}=.376$ inches, $\mathrm{V}=113.2$ volts

$$
\begin{aligned}
& \left(\mathrm{T}_{2}\right) \mathrm{T}_{\mathrm{q}}=944 \mathrm{~K} \\
& \left(\mathrm{~T}_{2}\right) \mathrm{T}_{\mathrm{T}}=1795 \mathrm{~K} \\
& \mathrm{~F}_{\mathrm{dl}-3} \text { quartz }=.25930 \\
& \mathrm{~F}_{\mathrm{dl}-3 \text { tungsten }}=.08709 \\
& \Delta \mathrm{F}_{\mathrm{dl}-3 \text { quartz }}=.00259
\end{aligned}
$$




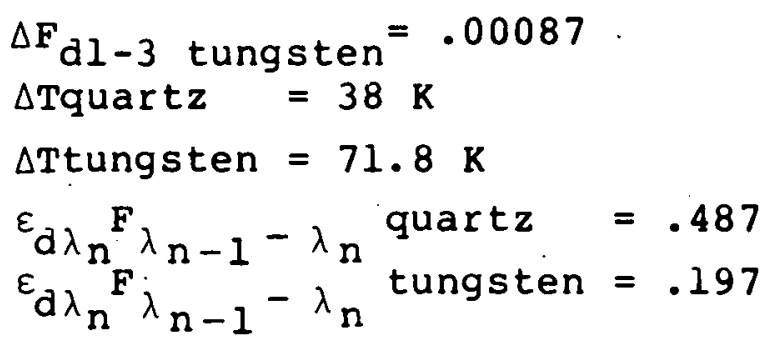

So, for the quartz envelope the error in dq can finally be calculated, $\Delta(d q)$ :

$$
\begin{aligned}
\Delta(\mathrm{dq}) & =\left(. 4 8 7 ( 5 . 6 6 9 3 \times 1 0 ^ { - 1 2 } ) ( 9 4 4 ) ^ { 4 } \left[(2)(.00259)+(8)(.2593)\left(\frac{38}{944}\right)\right.\right. \\
& +(.04)(.2593)] \\
& \cong(2.1925)[.00518+.08351-.01037] \cong \pm 0.217 \mathrm{~W} / \mathrm{cm}^{2}
\end{aligned}
$$

from the program LAMP:

$$
\mathrm{dq}_{\text {calculated }}=1.222 \mathrm{w} / \mathrm{cm}^{2}
$$

therefore:

$$
\frac{\Delta(\mathrm{d} q)}{\mathrm{dq}}= \pm 17.88
$$

For the tungsten filament:

$$
\begin{aligned}
\Delta(\mathrm{dq}) & =(.197)\left(5.6693 \times 10^{-12}\right)(1795)^{4}\left[(2)(.00087)+(8)(.0871) \frac{71.8}{1795}\right. \\
& +(.04)(.0871)] \\
& =11.5945[.00174+.02787+.00349]=.366 \mathrm{~W} / \mathrm{cm}^{2}
\end{aligned}
$$

dq calculated $=2.0219 \mathrm{~W} / \mathrm{cm}^{2}$ 
Now the effect of the quartz transmittance needs to be included. Since the transmittance multiplies each term in the summation the error term looks like this:

$(\tau=$ transmittance $)$

$\Delta \tau_{1} \frac{\partial f}{\partial \tau}=\Delta \tau_{1}\left(F_{d l-3}+F_{d l-4}\right)\left(\sigma T_{2}^{4}\right) \sum_{n=1} \varepsilon_{d \lambda_{n, 2}} F_{\lambda_{n-1}-\lambda_{n}}$

From [9] $\Delta \tau_{i}=$ error in transmittance is about \pm 38 . So:

$$
\Delta \tau_{i} \frac{\partial f}{\partial \tau_{1}}=(.03)(2)(.08709) 5.6693 \times 10^{-12} .(1795)^{4}(.197) \mid=.061
$$

so

$$
\Delta(\mathrm{dg})=.366+.061=.427
$$

and

$$
\frac{\Delta(\mathrm{dg})}{\mathrm{dq}}=\frac{.427}{2.0219}=21.18
$$

Therefore, assuming that the quartz envelope contribution is low by 17.88 and the tungsten filament contribution is low by 21.18 the total flux will be low by about 19.58. So even with a very approximate set of error terms, the maximum error calculated is close to the 25.28 error seen in Table 1. Note that the overall error is particularly sensitive to errors in temperature and emissivity. For example, if the temperature error is increased to \pm 58 (from \pm 48 ) and the emissivity errors to \pm 38 (from \pm 28 ) the errors become,

$$
\Delta(\mathrm{dq}) \text { quartz }=\frac{.273}{1.222}=22.38
$$

and

$$
\Delta(\mathrm{dq}) \text { tungsten }=\frac{.546}{2.0219}=27.08
$$


So the error in the total flux would be about 24.68 .

Although the values used in the calculations were approximate, the analysis gives an insight into where the major errors probably come from and why the analysis has errors up to $27 \%$ when compared to the experimental values. As can be seen from the calculations, the two most important error sources are the inaccuracy in temperature and the inaccuracy in emissivity. The temperature error has the largest effect. This would be expected since the fourth power temperature dependence causes a large coefficient in the term

$$
\left|\Delta \mathrm{T}_{2} \frac{\partial f}{\partial \mathrm{T}_{2}}\right|
$$

The error in emissivity causes a large error in the total because its individual error is large (3\%) compared with that of the shape factor term (1\%).

Assuming that the error bounds (on each of the measurements or inputs) are reasonable, then the model does calculate the measured flux to within the limits of error of the analysis. This, of course, strictly only applies to this set of data but it is a reasonable assumption that the errors in other cases will be similar.

Note that no mention was made in the "errors" in assuming that the filament was a solid cylinder rather than a spiral wound from cylindrical wire. There is really no easy way of estimating this effect. An extensive literature search was performed to try to find possible ways of improving the model of the filament, but no useful information was found. 


\section{Discussion of Results}

There are a few obvious trends that can be seen in Table 1. First, the calculated values are less than the measured values in all cases. The amount less ranges from 27.28 to 15.98 depending on the distance the gage is from the lamp and the power input to the lamp. The first set of data for the 2000 watt lamp $\left(\mathrm{h}==_{1,} .375^{\prime \prime}\right)$ showed a consistent error varying only from 18-23\% over the voltage range 50-113.2 V. The second set of data $(2000$ watt, $240 \mathrm{~V}$ rated maximum lamp, $\mathrm{h}=.376^{\prime \prime}$ ) showed the same trends with the errors ranging from 24-278. The third set of data 12000 watts, $h=.564 "$ ) however, shows a marked decline in the errors as the voltage decreases from 113.55 to $70.7 \mathrm{~V}$. The same trend can be seen in the last set of data for the 6000 watt (480 $\mathrm{V}$ rated maximum) lamp $(\mathrm{h}=.588 ")$. It is not clear why the error decreases substantially like this. It may be a combination of these factors: the gage sensing area is not a differential area but a small but finite one. $1.5 \mathrm{~cm}$ diameter) and that the contribution of the total flux from the filament increases as the voltage increases. Recalling the error analysis, it was said that the model of the filament and uncertainties in its calculated temperature may contribute a large part to the total error.

Another fact that can be observed is that the contribution from the quartz to the total flux is sizable, as much as 598 (6000 watt lamp) and as little as 388 (2000 watt lamp). If the model is correct, one can say that sizable portion of the flux comes from the quartz envelope at the low power levels studied. From first glance, one would not assume this since the tungsten filament is the component that is directly dissipating the electrical energy input to the lamp. However, the predictions of the model agree, at least qualitatively, with the indirect evidence from the Five-Tube Test. To review, in that test cooling the lamp 
envelopes (with the same electrical input) produced readings. on the heat flux gage much lower than when the fans were turned off. Since it has been shown that the quartz envelope can contribute a large portion of the total flux, cooling the envelopes can reduce the total flux considerably.

Lastly, Table 2 has results predicted from pfahl's program [l] for the experimental cases run herein. Pfahl's program can calculate the heat flux at just about any point in the field surrounding the lamp. However, my shape factor equations only allowed me to calculate the flux at any point parallel to the lamp axis as long as the normal to that point passes through the center of the lamp. Since the intent here was not to try to map out the entire field, this loss of generality is not a problem. The main concern was to try to understand the thermal operation of the lamp.

As can be seen from Table 2, the differences between Pfahl's predictions and the experimental results vary.from a maximum of 21.08 for the 6000 watt lamp to a minimum of 0.48 for the 2000 watt lamp. The "lamp efficiency" in Pfahl's program was set equal to 1.0. A lamp efficiency other than 1.0 will simply reduce all the flux values by the same amount. As can be seen in the table, in all cases the error starts out negative and proceeds to positive. So with a real efficiency value (less than 1.0) the negative errors would get larger and the positive errors smaller.

\section{CONCLUSIONS}

1. The model calculated the measured heat flux to within the error in the analysis

2. The models' predictions are consistantly low as compared with the measured values. 
3. The quartz envelope can contribute a significant amount of energy to the total flux.

4. The amount of the contribution from the quartz increases as the input voltage decreases. 


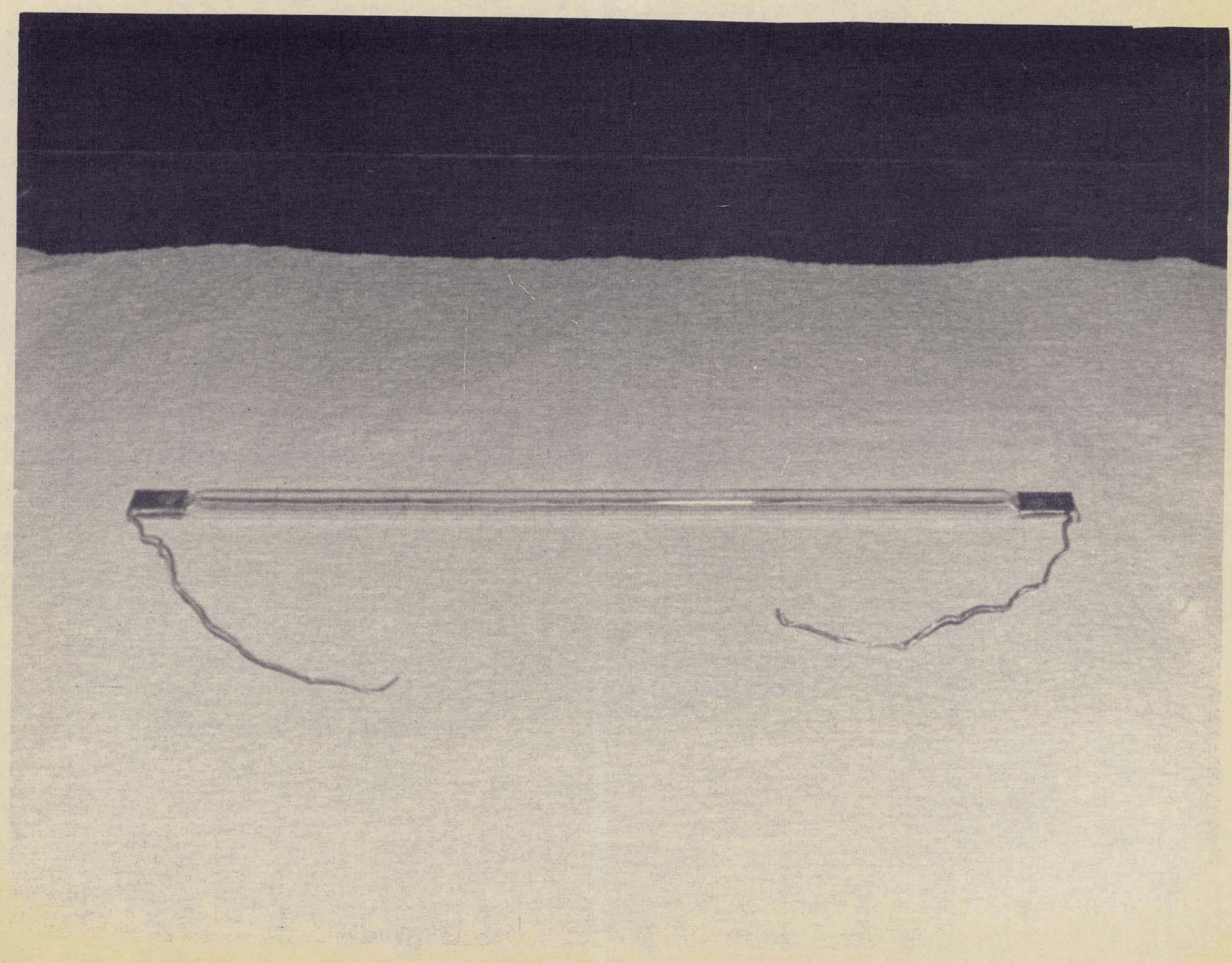




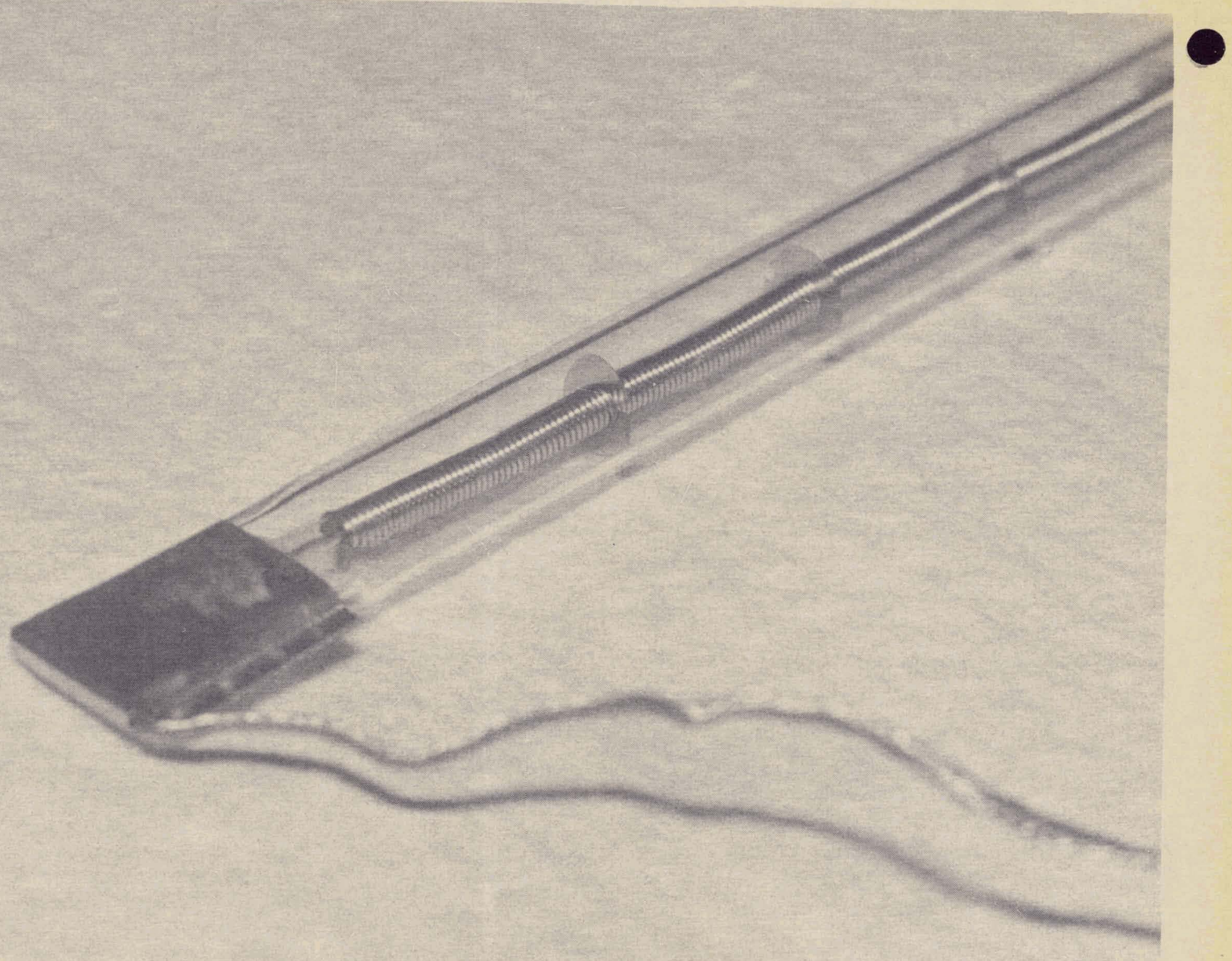

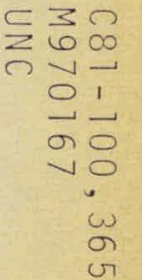

I'iqure 2

Close-up of "'ypical Linear Infrared Lamp 


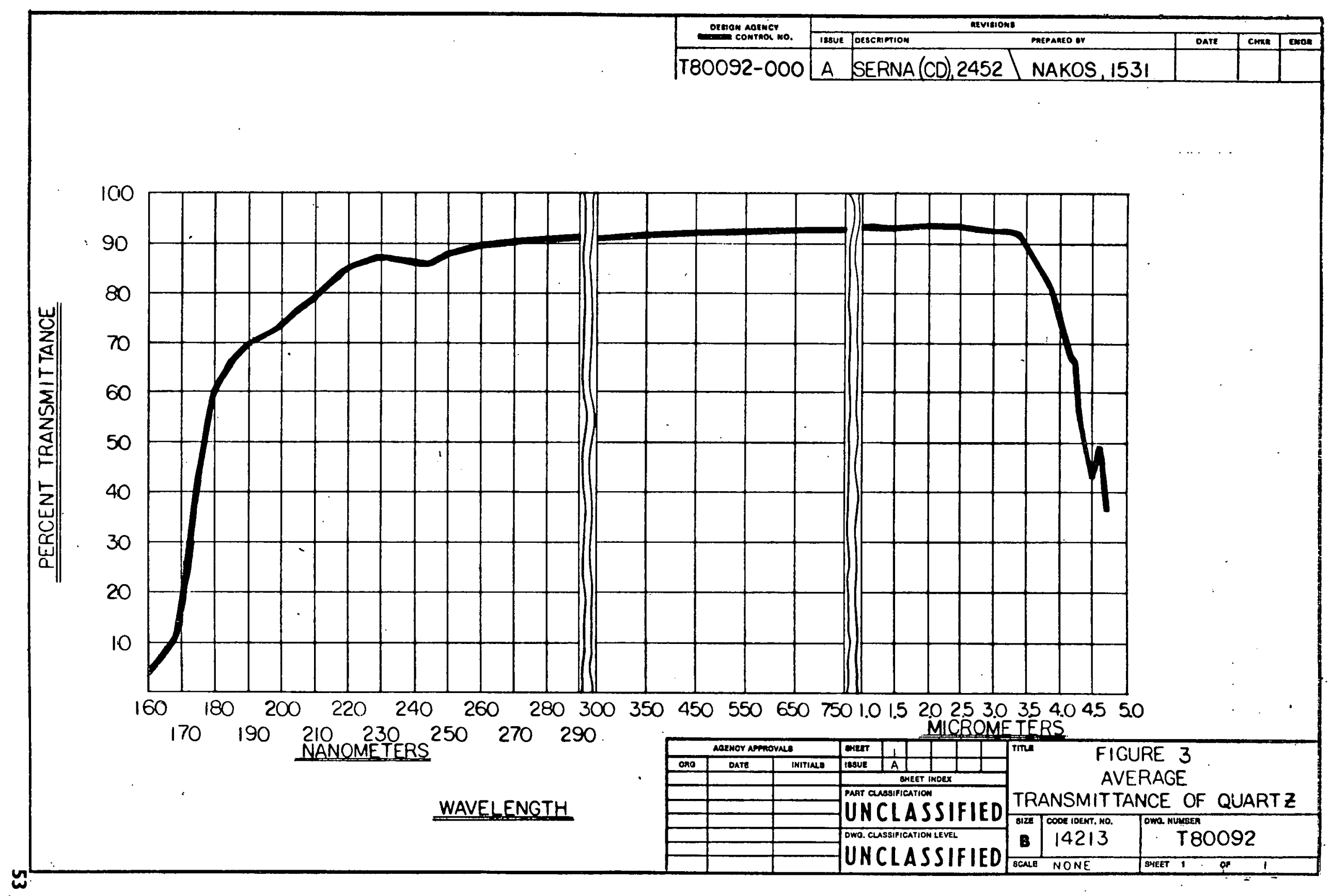




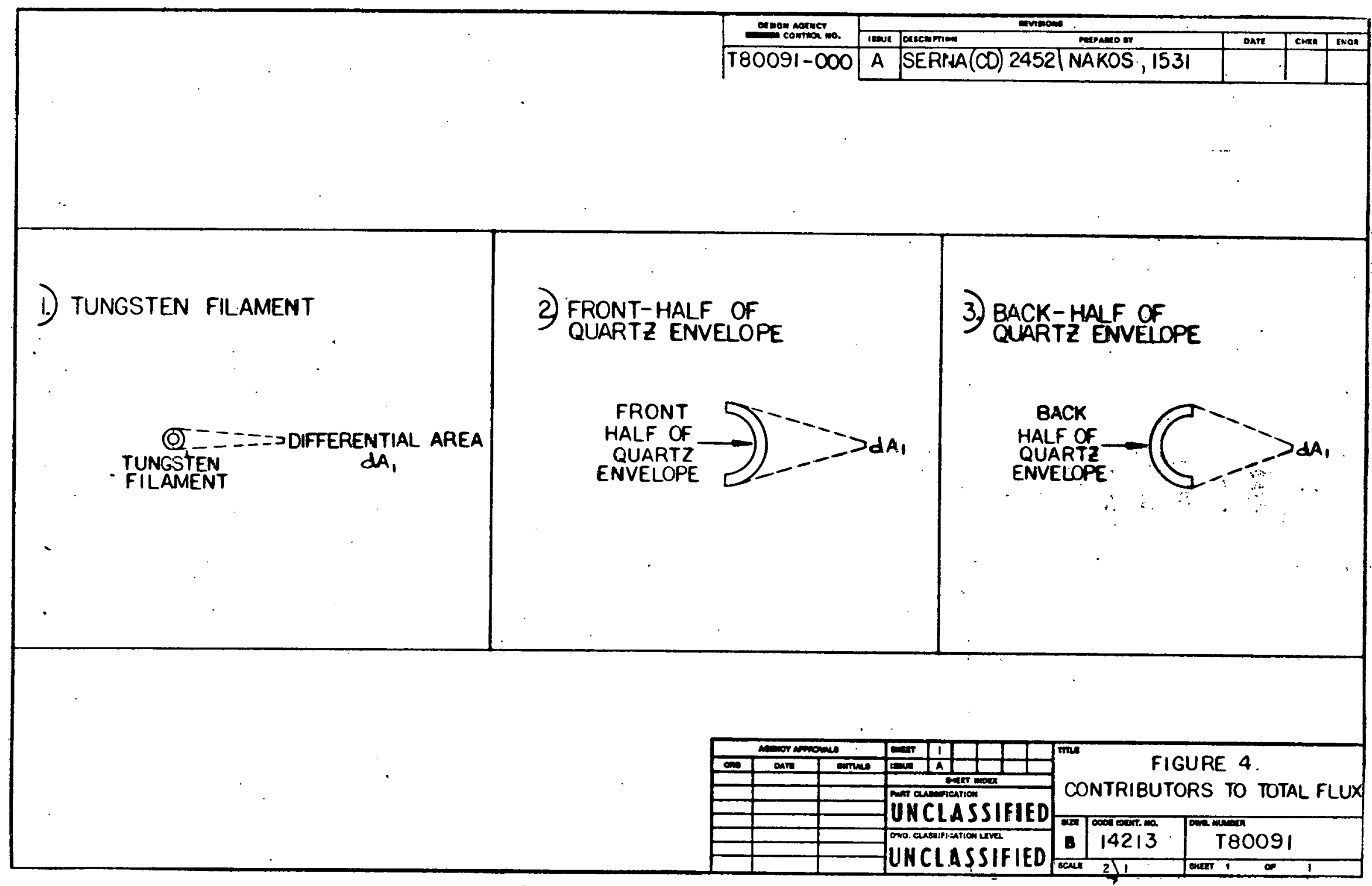




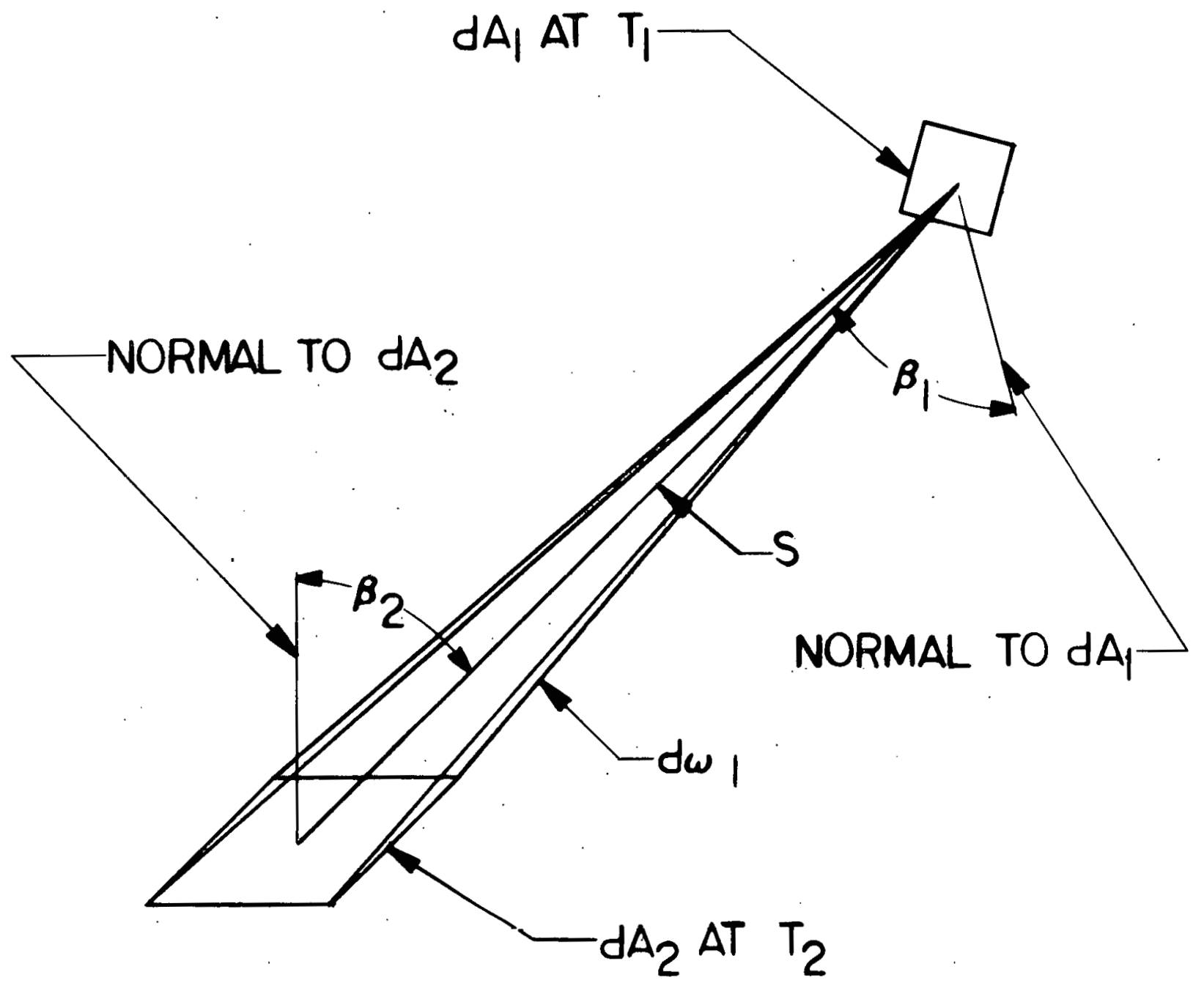

FIGURE 5 .

TWo BLACK DIFFERENTIAL AREA ELEMENTS. 


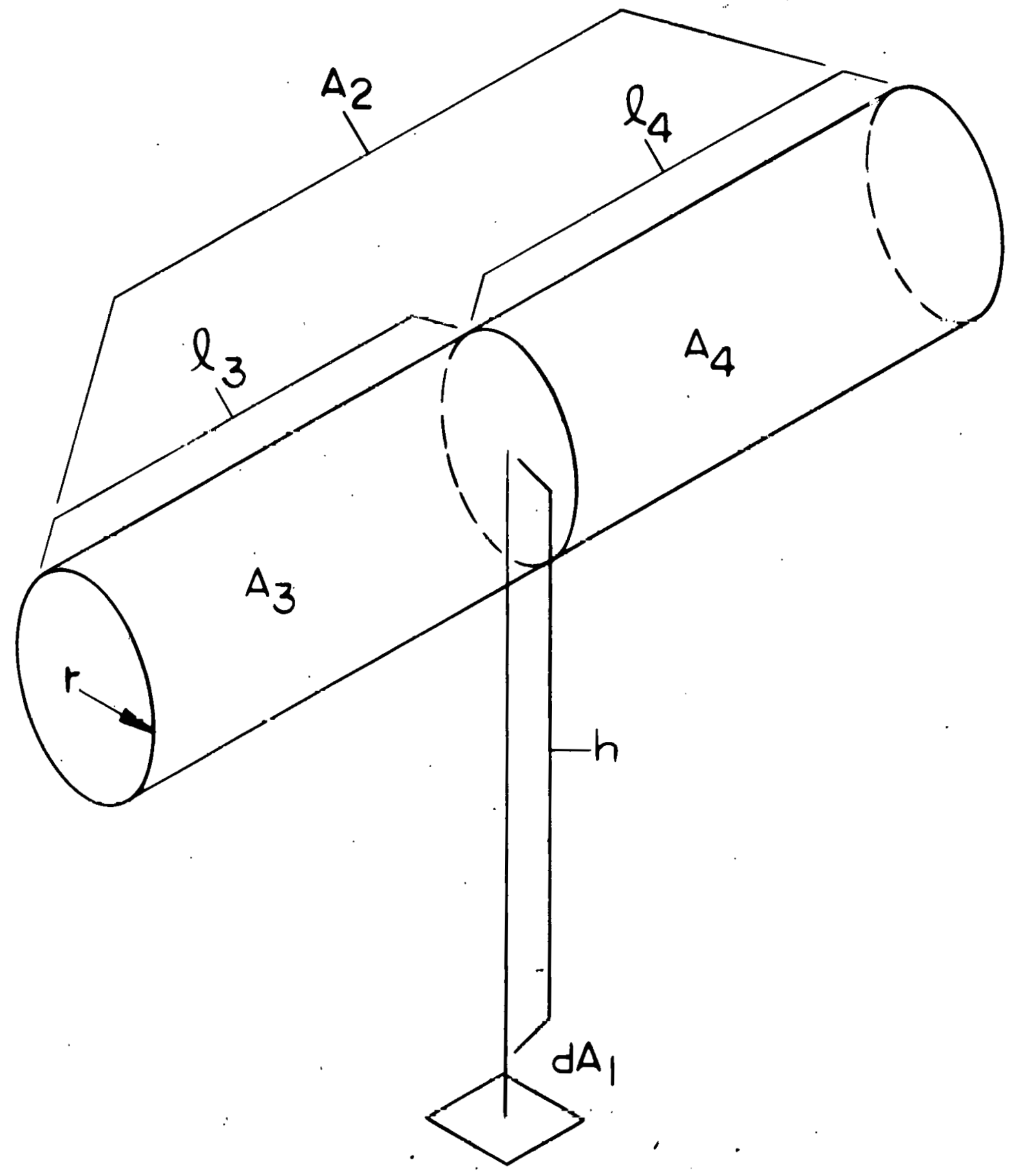

FIGURE 6

ENVELOPE OR FILAMENT $A_{2}$

BROKEN INTO TWO PARTS $A_{3}$ AND $A_{4}$.

56 
PLANE ELEMENT dA 1 TO RIGHT CIRCULAR CYLINDER OF FINITE LENGTH \& AND RADIUS $r$; NORMAL TO ELEMENT PASSES THROUGH ONE END OF CYLINDER AND IS PERPENDICULAR TO CYLINDER AXIS.

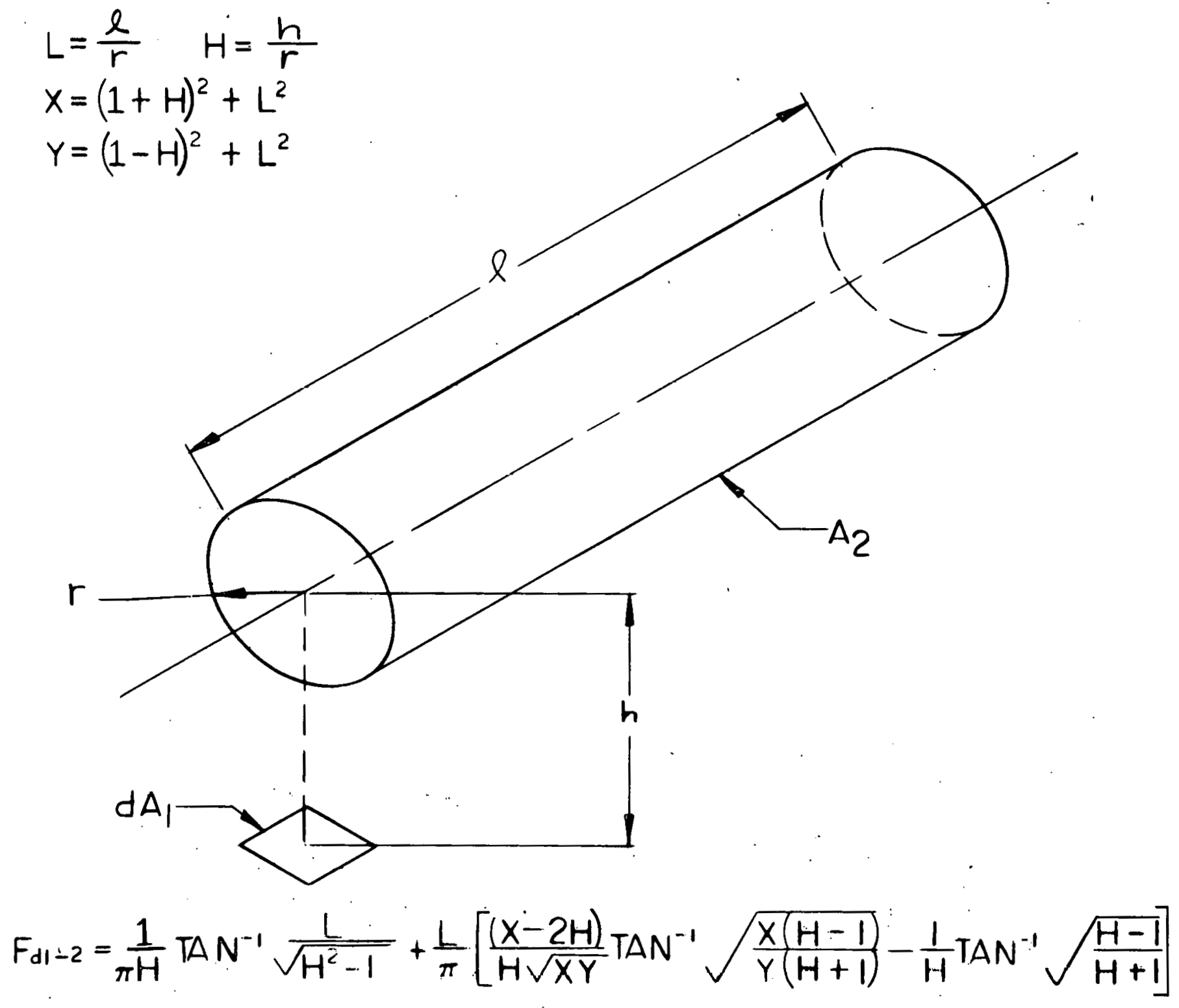

FIGURE ?

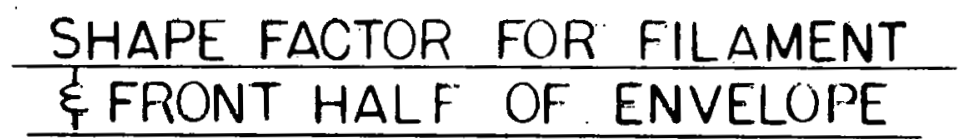




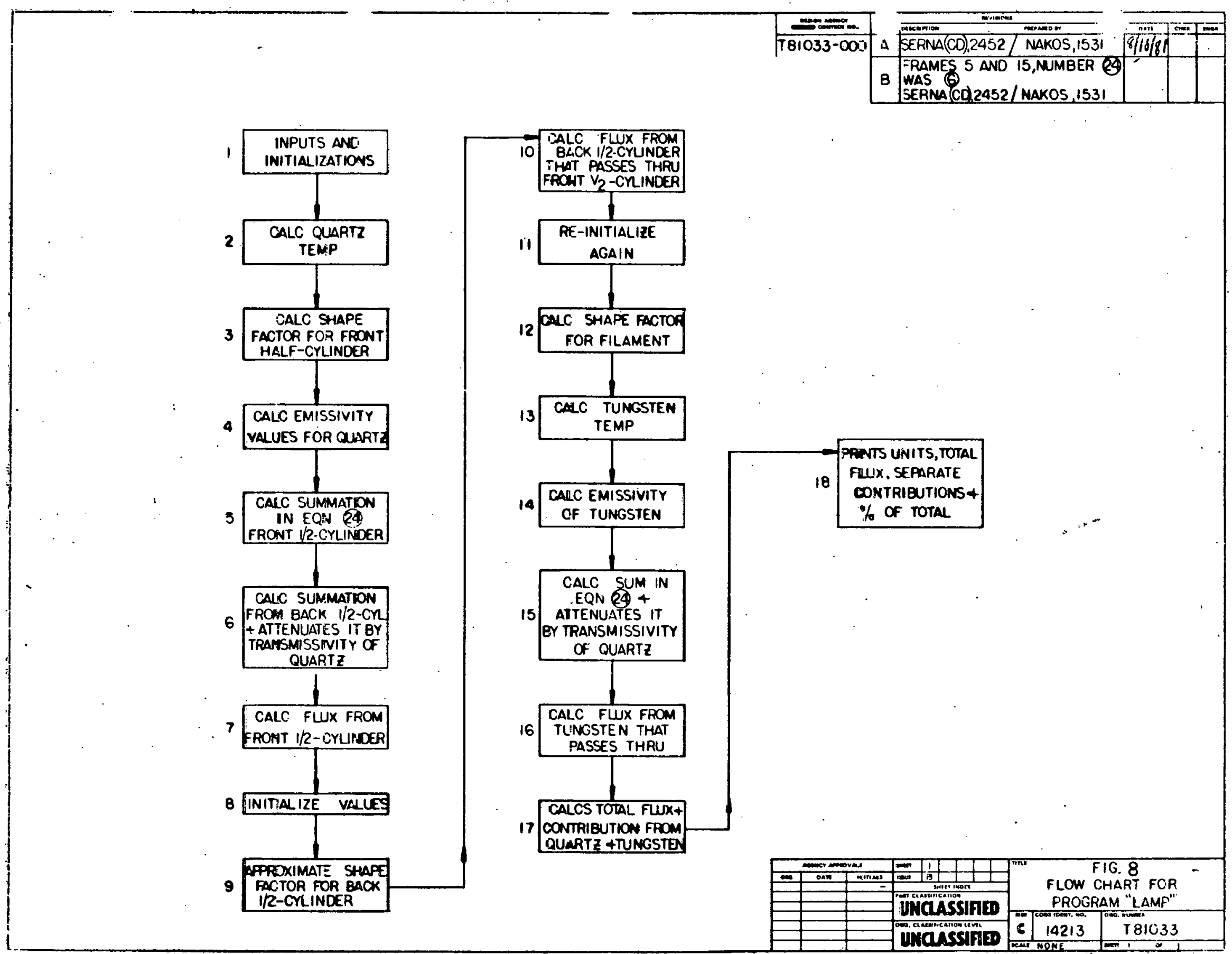




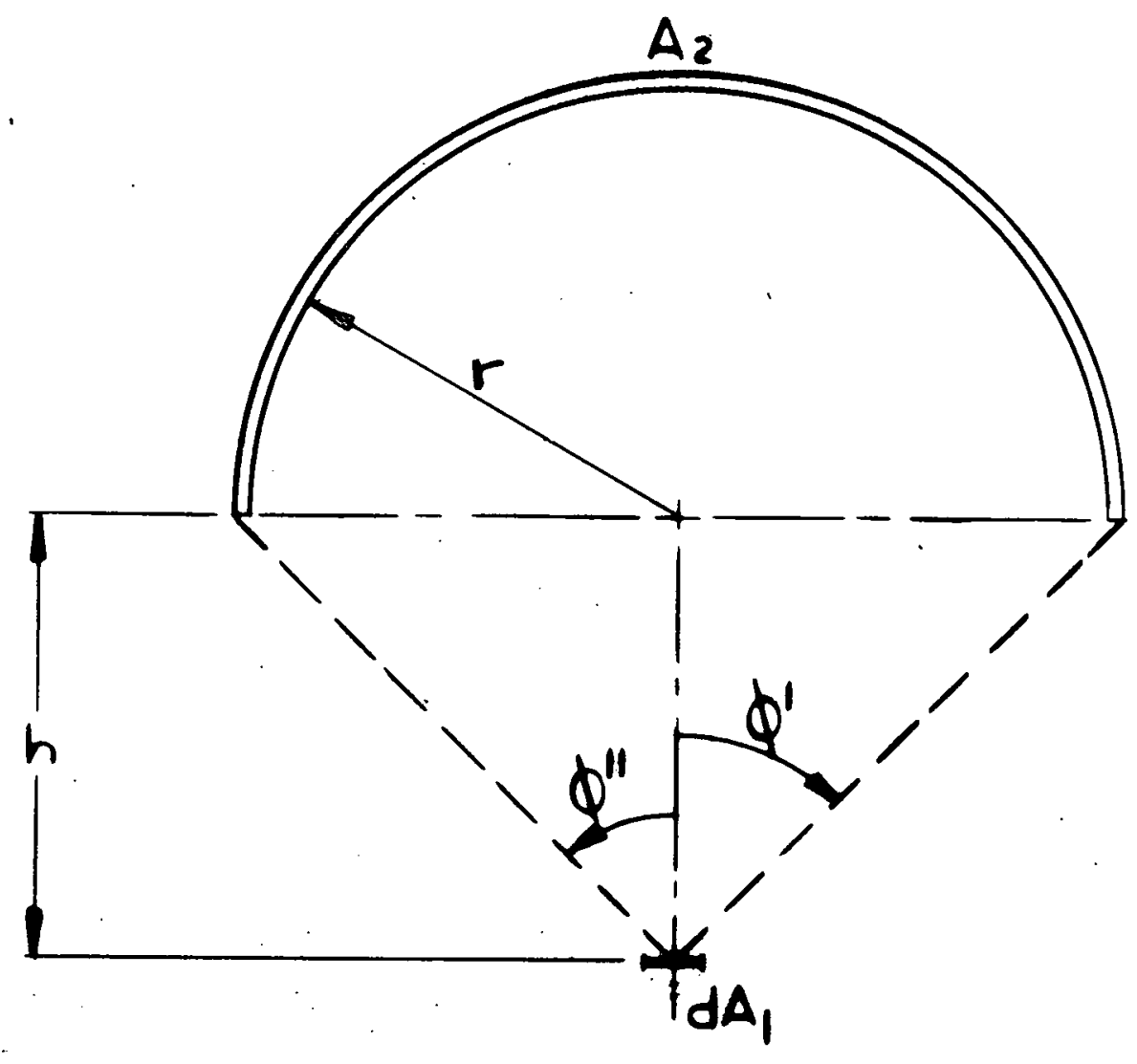

$$
\begin{gathered}
F d \mid-2=\frac{\sin \phi^{\prime}-\sin \phi^{\prime \prime}}{2} \\
\text { IF } \phi^{\prime}=-\phi^{\prime \prime}: \\
\text { FdI }-2=\sin \phi^{\prime}
\end{gathered}
$$$$
\begin{aligned}
& \text { FIGURE } 9 \\
& \text { SHAPE FACTOR FOR INFINITELY LONG } \\
& \text { CYLINDER TO DIFFERENTIAL AREA- } \\
& \text { BACK HALF-CYLINDER TO GAGE }
\end{aligned}
$$ 


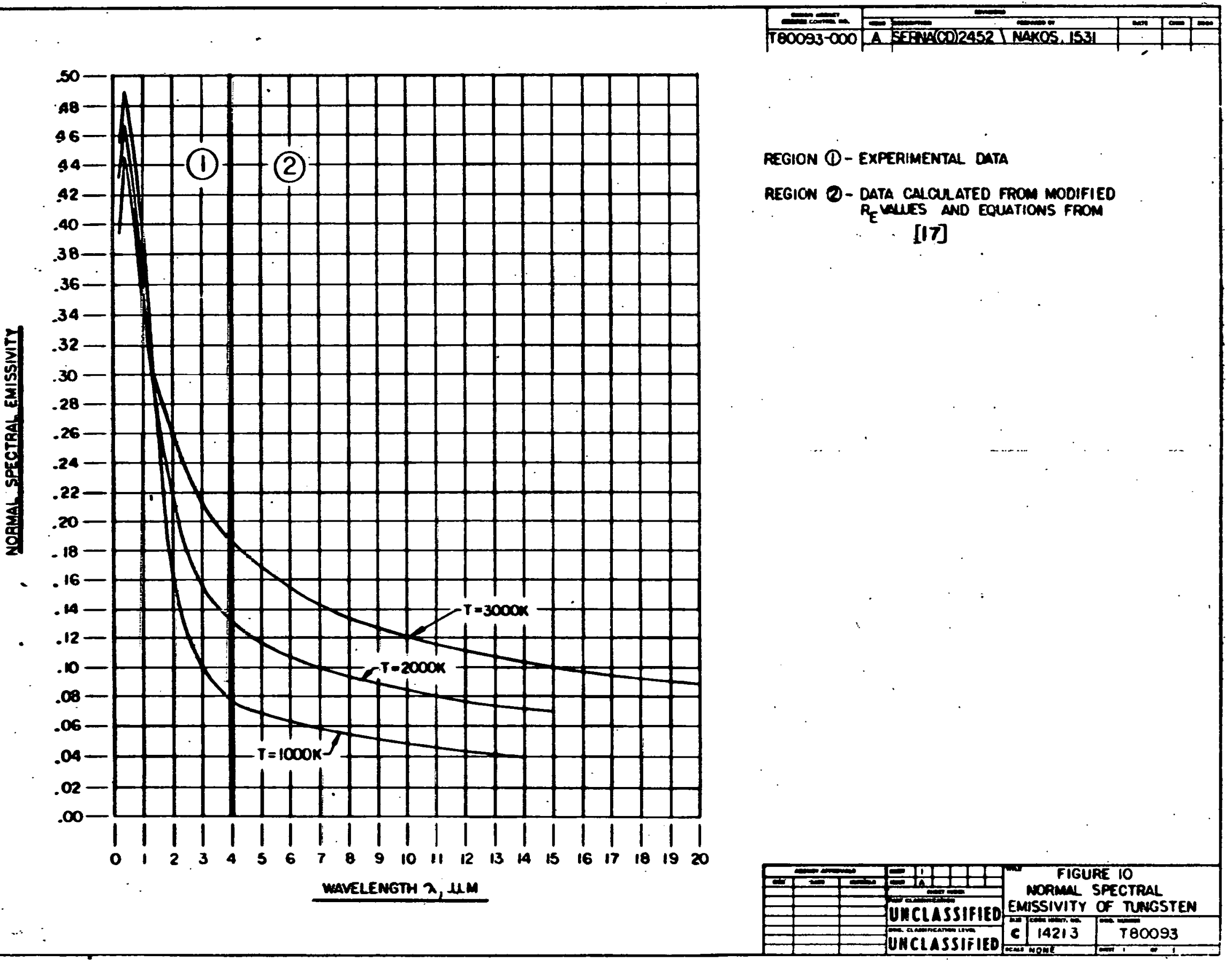




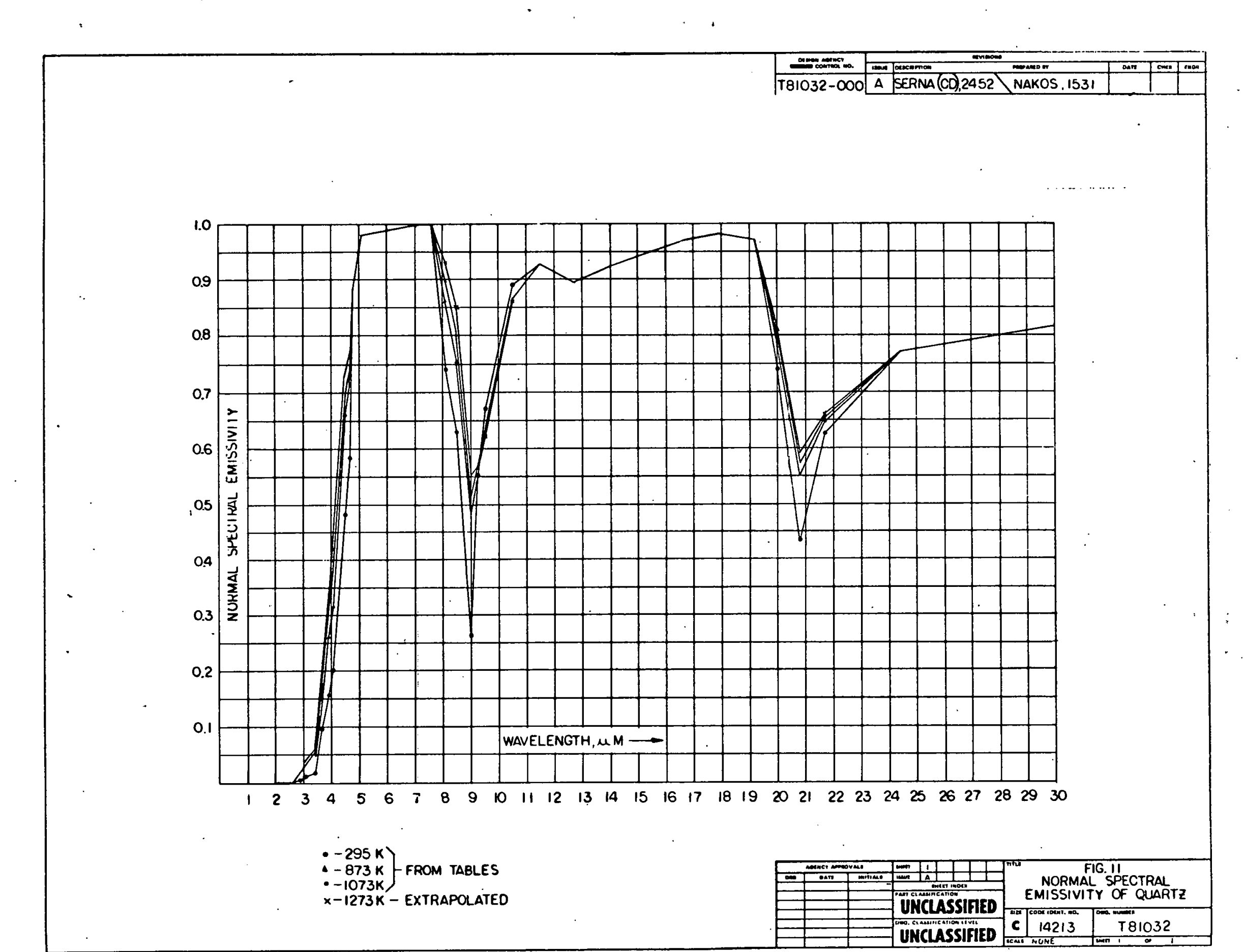




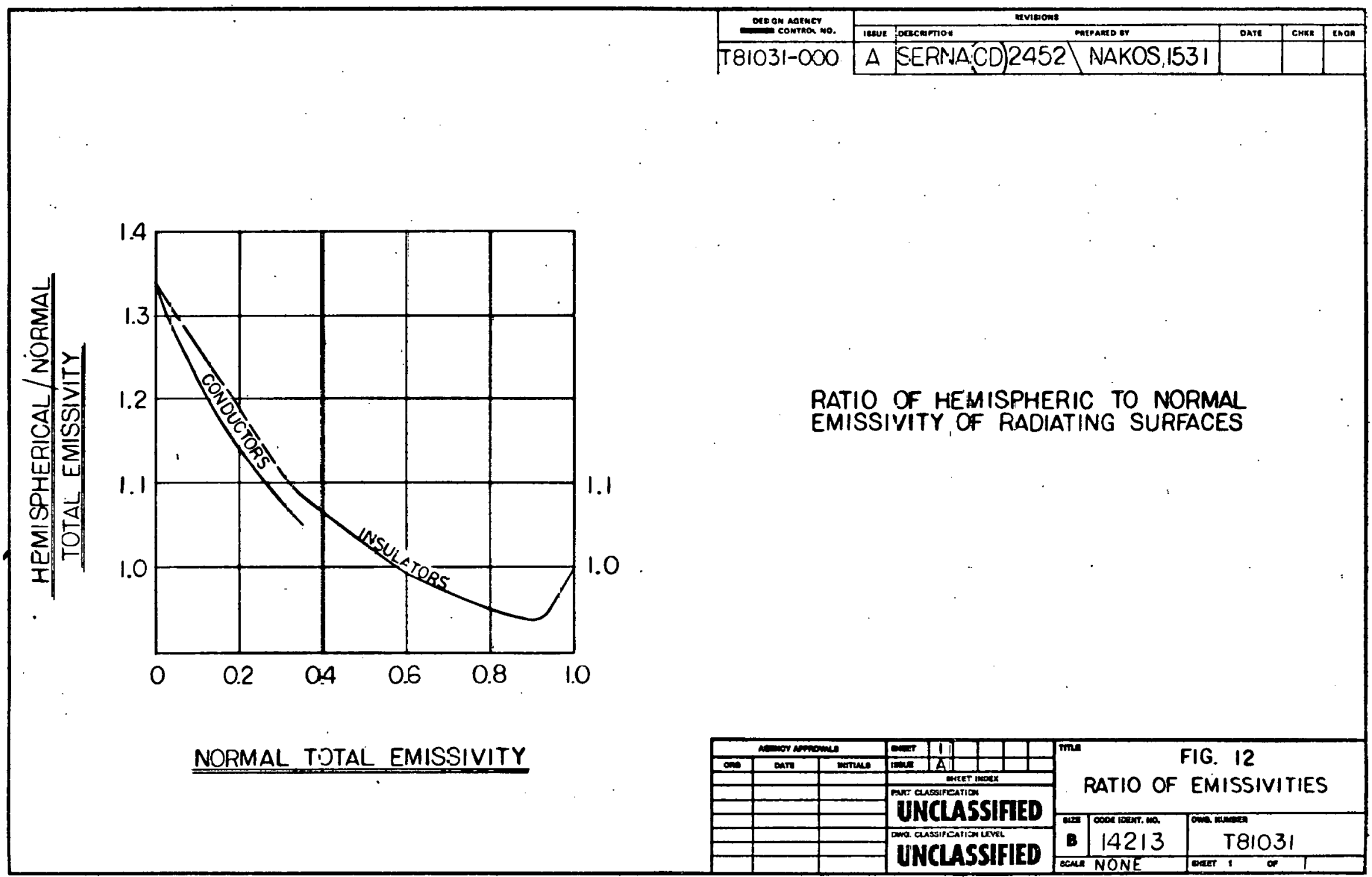


TABLE 1

\section{DATA SUMMARY}

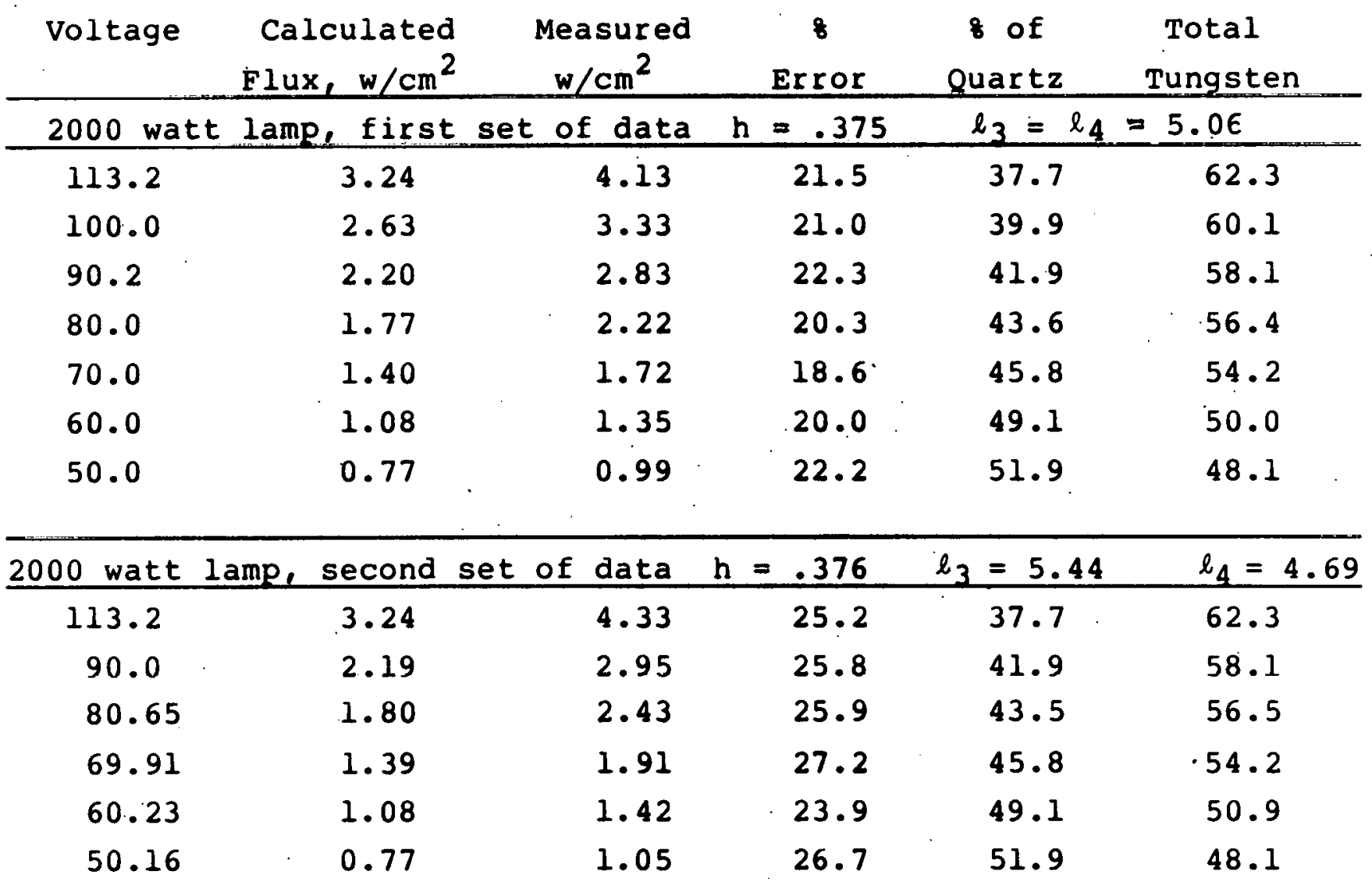

\begin{tabular}{rrrrrr}
\hline 2000 watt lamp & $h=.564$ & $\ell_{3}=5.44$ & \multicolumn{2}{c}{$\ell_{4}=4.69$} \\
\hline 133.55 & 2.16 & 2.83 & 23.7 & 37.8 & 62.2 \\
90.55 & 1.48 & 1.91 & 22.5 & 42.0 & 58.0 \\
70.70 & 0.95 & 1.13 & 15.9 & 45.7 & 54.3
\end{tabular}

\begin{tabular}{rrrrrr}
\hline 6000 watt lamp & $h=.588$ & $\ell_{3}=5.44$ & \multicolumn{2}{c}{$\ell_{4}=4.69$} \\
\hline 113.45 & 2.05 & 2.78 & 26.3 & 42.4 & 57.6 \\
90.05 & 1.36 & 1.82 & 25.3 & 45.8 & 54.2 \\
70.05 & 0.89 & 1.12 & 20.5 & 50.7 & 49.3 \\
50.30 & 0.52 & 0.62 & 16.1 & 58.8 & 41.2 \\
\hline
\end{tabular}

Note: Rated voltage on the 2000 watt lamp is 240 volts and on the 6000 watt lamp is 480 volts. 
C81-100,178 UNC

M970167

$3 / 11 / 81$

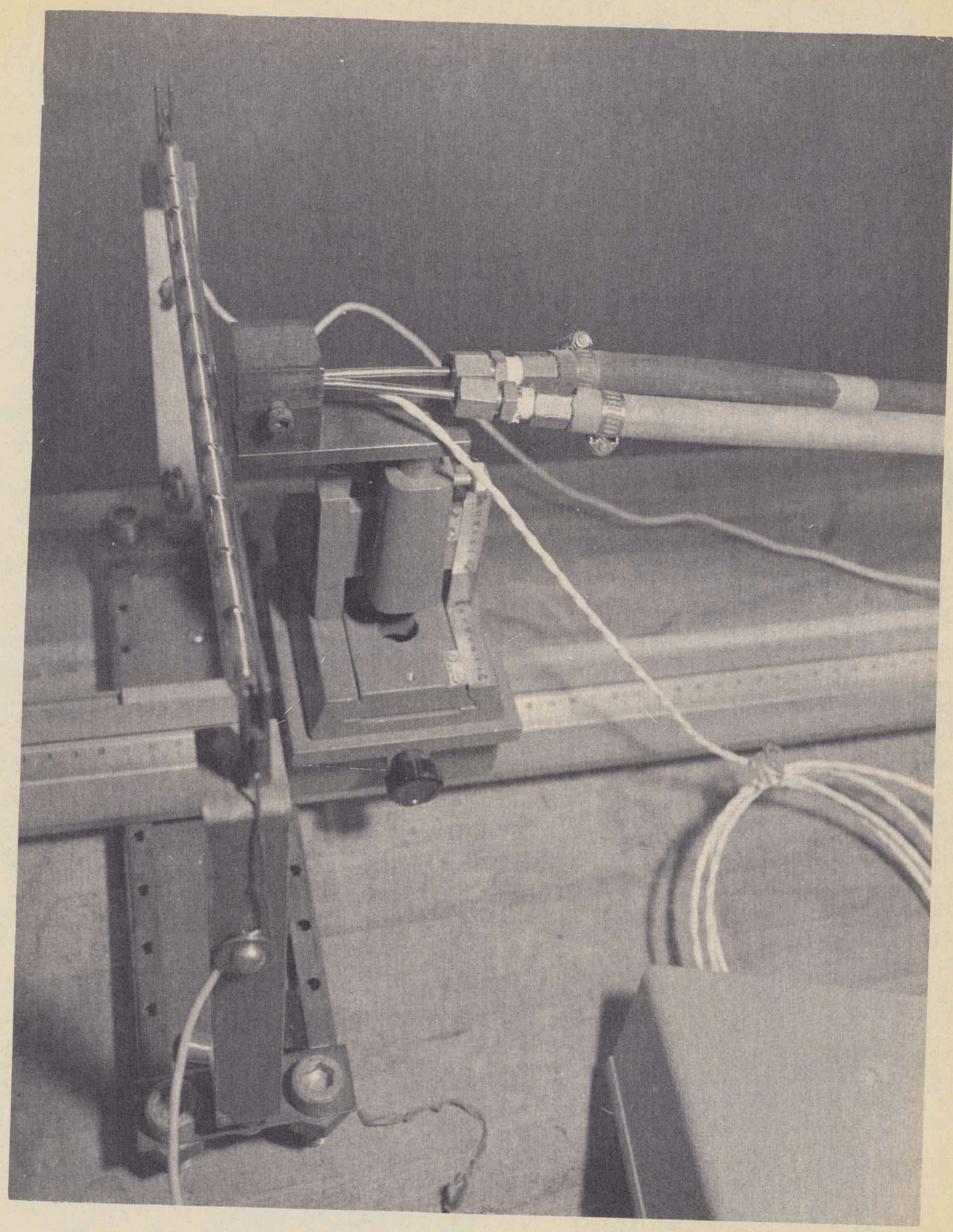

Pigure 13

Lighted Lamp and Heat Flux Cage in its Mount 
C81-100,179 UNC

11970167

$3 / 11 / 81$

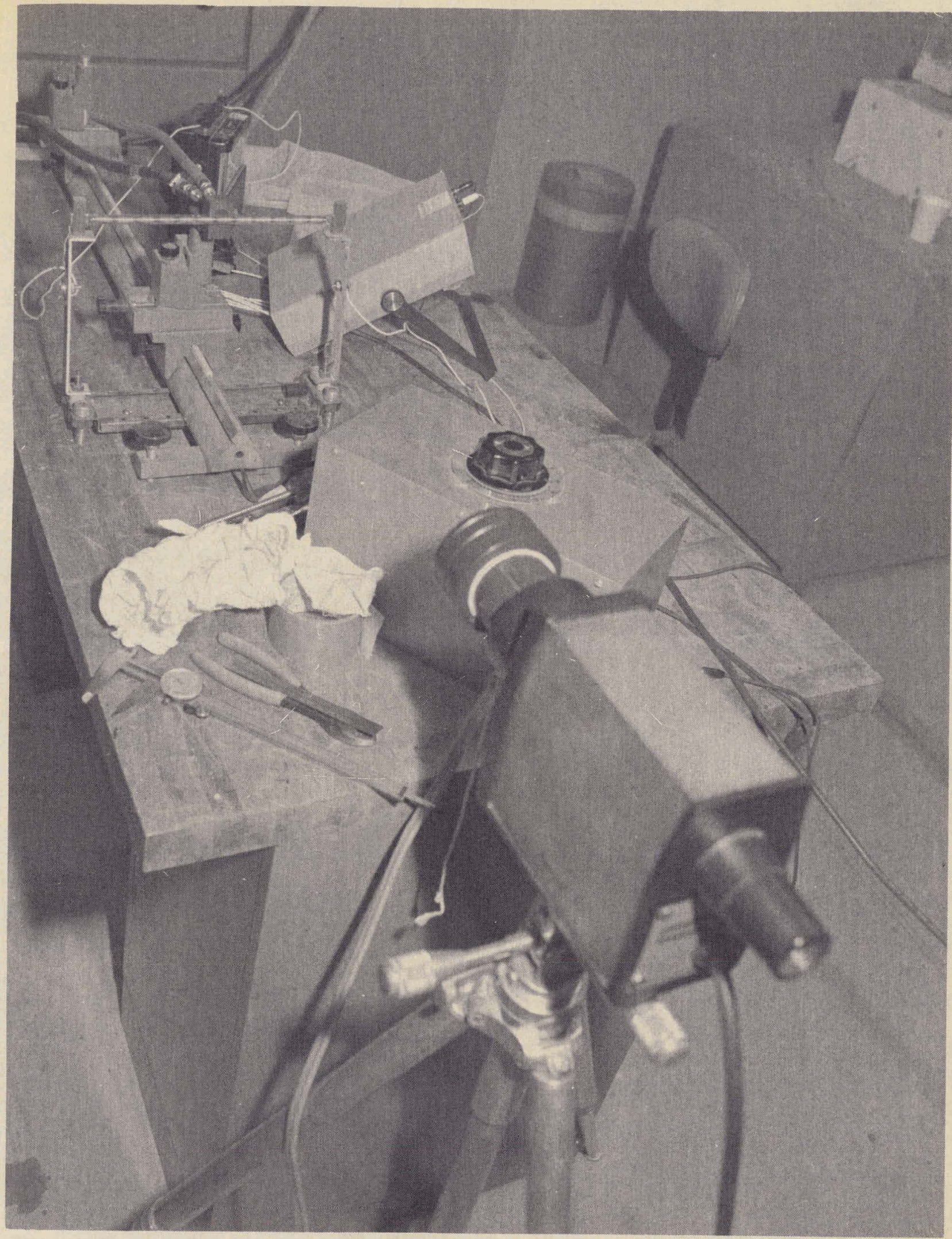

Eigure 14

Experimental Setup Looking Over optical Pyrometer 


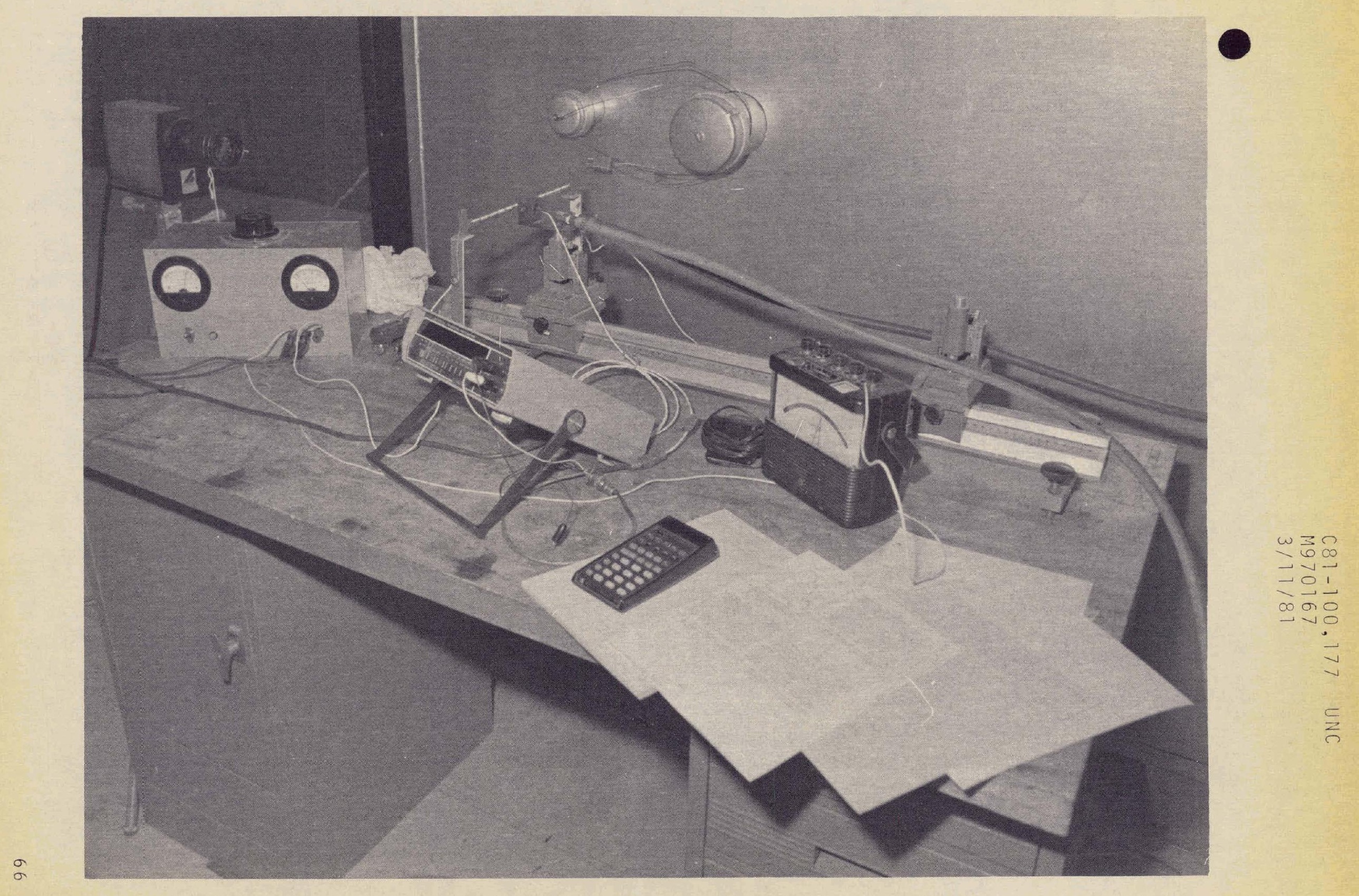


TABLE 2

\begin{tabular}{rcrc} 
Voltage & $\begin{array}{c}\text { Measured } \\
\text { Flux w/cm }\end{array}$ & Flux w/cm & \& Eror \\
\hline & 2000 watt lamp, first set of data & $h=.375^{\prime \prime}$ \\
\hline 113.2 & $\begin{array}{c}\text { ETA }=1 \\
100.0\end{array}$ & 4.06 & -1.7 \\
90.2 & 4.13 & 3.35 & +0.7 \\
80.0 & 3.33 & 2.84 & +0.4 \\
70.0 & 2.83 & 2.37 & +6.8 \\
60.1 & 2.22 & 1.92 & +11.6 \\
50.0 & 1.72 & 1.52 & +12.6
\end{tabular}

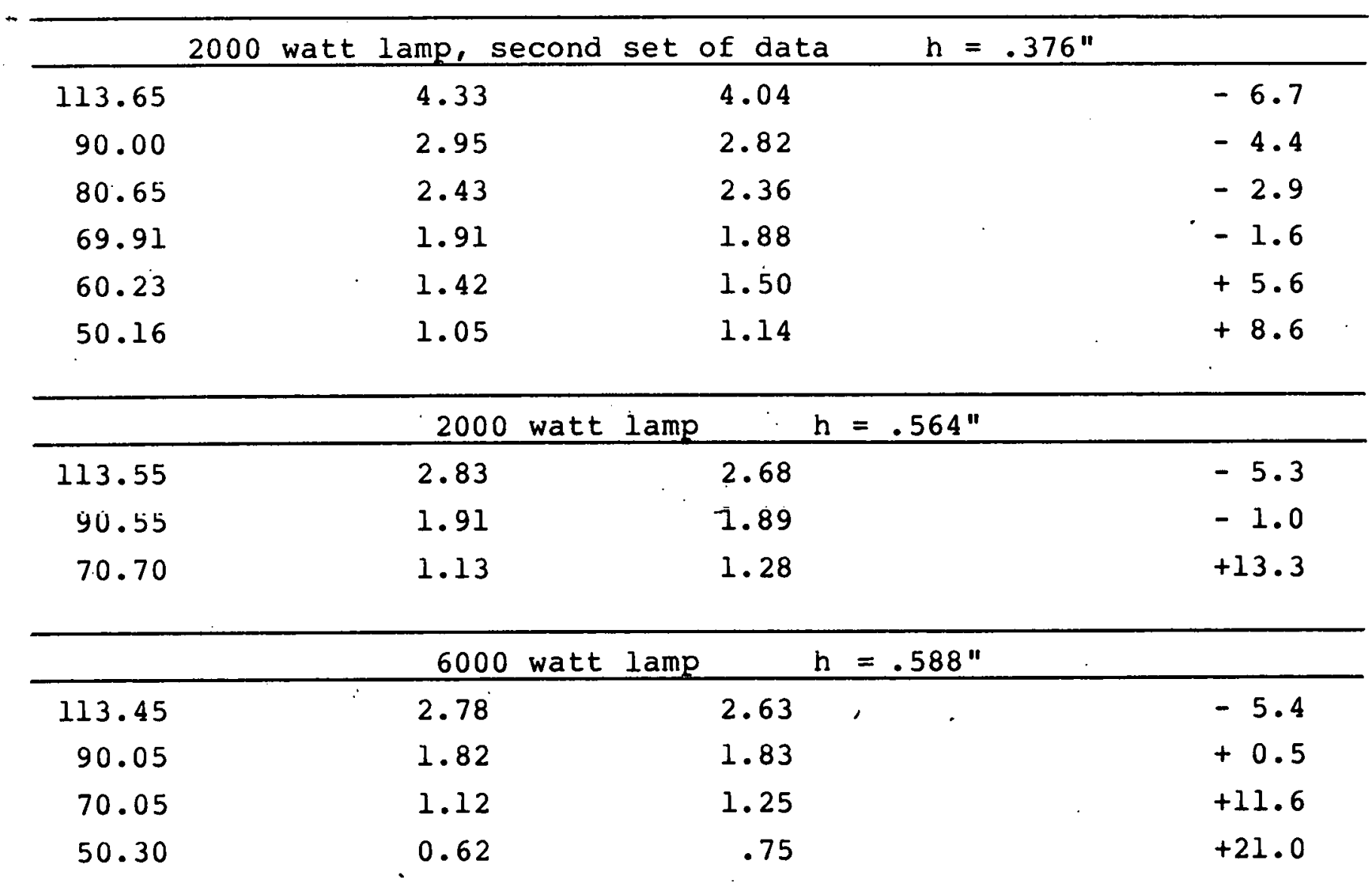




\section{References}

1. R. C. Pfahl, Jr., Energy Distribution From a Finite Line Source, Memorandum 20223-28, Western Electric Co. Inc., 1972.

2. I. Berlec, Electrical, Thermal, and Luminous Properties of Coiled Coil Filaments, Journal of IES, January 1980.

3. R. Gardon, A Review of Radiant Heat Transfer in Glass, Journal of the American Ceramic Society, Volume 44, No. 7 , 1961.

4. R. Gardon, The Emissivity of Transparent Materials, Journal of the american Ceramic Society, Volume 39, No. 8, 1956.

5. V. A. Petrov and S. V. Stepanov, Radiation Characteristics of Quartz Glasses - Spectral Radiating Power, Teplofizika Vysokikh Temperatur, Volume 13, No. 2, pp. 335-345, March-April, 1975

6. R. Siegel and J. R. Howell, Thermal Radiation Heat Transfer, McGraw-Hill Book Co., New York, NY, 1972.

7. M. Jakob, Heat Transfer, Volume II, John Wiley \& Sons, Inc., New York, NY, 1963.

8. Anon., Bureau of Naval Weapons Report No. 8558, October 1964.

9. Anon., General Electric Product Data Sheet 7710-f, Type 214 Clear Fused Quartz Circular Tubing, December 1975.

10. "Handbook of Chemistry and Physics," 49th ed., pp. E-228, Chemical Rubber Publishing Co., 1968-1969.

11. J. R. Branstetter, Radiant Heat Transfer Between Nongray Parallel Plates of Tungsten, NASA Technical Note $D=1088$, August 1961.

12. L. N. Latyev, V. Ya. Chekhovskoi, E. N. Shestakov, Monochromatic Emissivity of Tungsten in the Temperature Range 1200-2600K and in the Wavelength Range 0.4-4 $\mu \mathrm{m}, \mathrm{High}$ Temperatures-High Pressures, 1970, Volume 2, pp. 175-181.

13. V. D. Dmitriev and G. K. Kholopov, Spectral Emissivity of a Tungsten Strip in the Visible and Near Infrared, Zhurnal Prikladnoi Spekfroskopii, Volume 6, No. 4, pp. 425-430, 1967. 
14. I. I. Kovalev and G. F. Muchnik, Normal Spectral Emissive Power of Tungsten, Niobium, Molybdenum, and Tantalum in the Wavelength Range $\Delta \lambda=0.66-5.12 \mu \mathrm{m}$ and the Temperature Interval 1400-3000 K, Teplofizika Vysokikh Temperatur, Volume 8, No. 5, pp. 983-988, September-October 1970 .

15. J. C. Devos, A New Determination of the Emissivity of Tungsten Ribbon, Physics, Volume 20, 1954, pp. 690-714.

16. R. D. Larrabee, The Spectral Emissivity and Optical Properties of Tungsten, Tech. Rep. 328, M.I.T., May 21, 1957.

17. M. Jakob, Heat Transfer, John Wiley \& Sons, Inc., New York, NY, Volume 1,1964 .

18. A Cezairliyan and J. L. McClure, High-Speed (Subsecond) Measurement of Heat Capacity, Electrical Resistivity, and Thermal Radiation Properties of Tungsten in the Range 2000 to $3600 \mathrm{~K}$; Journal of Research of the NBS A. Physics and Chemistry, Volume 75A, No. 4, July-August 1971 .

19. C. J. Smithells, Metal Reference Book, Volume III, Plenum Press, New York, NY, 1967, pp. 687.

20. V. A. Petrov and S. V. Stepanov, Radiative Characteristics of Fused Quartz, Angular and polarization Characteristics, Teplofizika Vysokikh Temperatur, Volume 13, No. 3, pp. 531-537, May-June 1975.

21. V. A. Petrov and V. Y. Reznik, The Effect of Thickness and Temperature Upon the Total Emissivity of Quartz Glass, proceedings of the 6th Symposium on Thermophysical Properties, 1973.

22. V. A. Petrov and V. Yu. Reznik, Integral Normal Radiating Power of Brand "KI" Quartz Glass at High Temperatures, Teplofizika Vysokikh Temperatur, Volume 10, No. 4, pp. 778-782, July-August 1972 .

23. E. O. Doebelin, Measurement Systems, Application and Design, McGraw-Hill Book Co., New York, NY, 1975. 


\section{Acḱnowledgements}

The author would like to thank P. H. Adams, P. L. Class and N. R. Keltner for their helpful editing of this report. I would especially like to thank Walter Roose, Division 3144, who provided me with the material enabling me to complete this report, all the secretaries who helped in the production, and J. Serna for his excellent drafting support. 


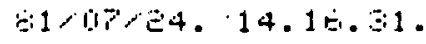

FE:DIFIAIM LFIF $\quad$ APPENDIX

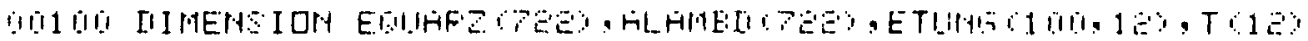

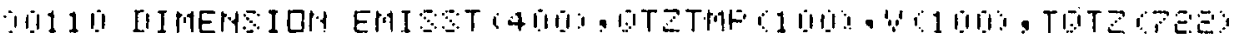

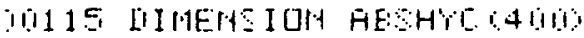

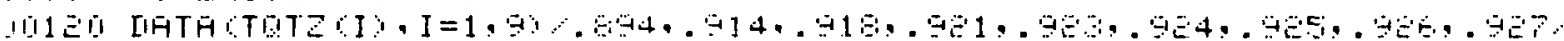

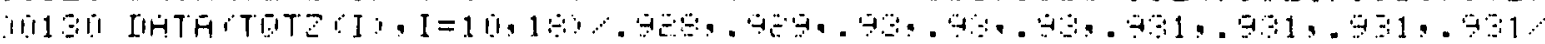

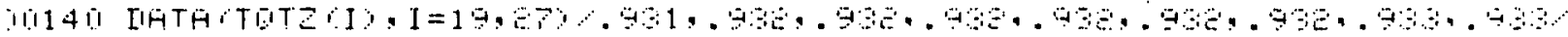

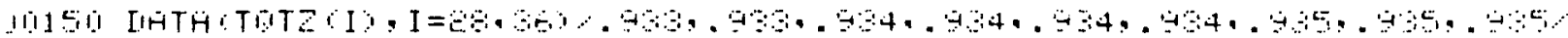

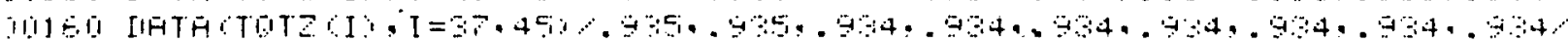

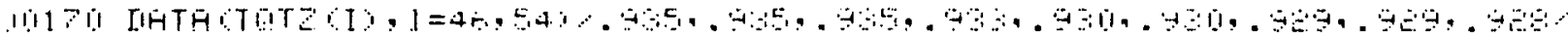

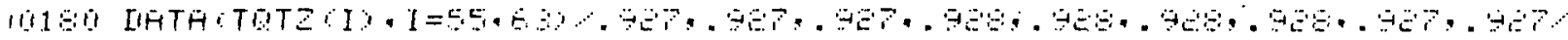

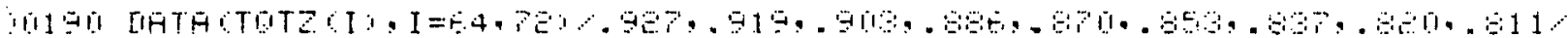

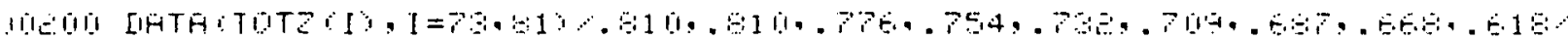

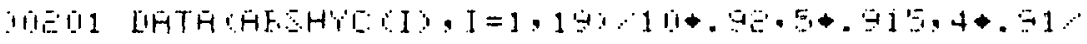

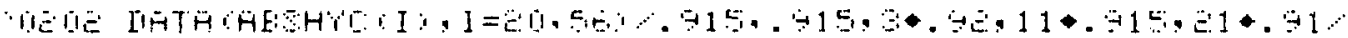

I1⿴囗十 [HTH

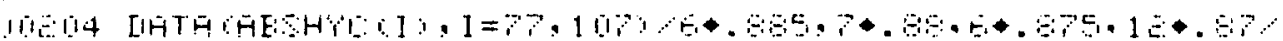

11205. II+TH

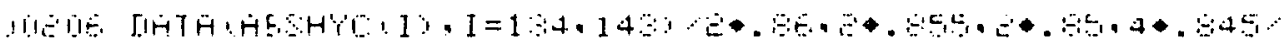

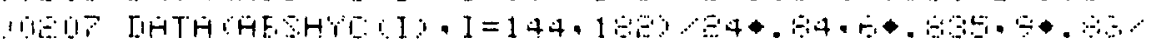

I

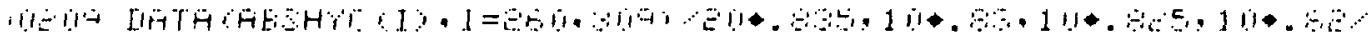

1

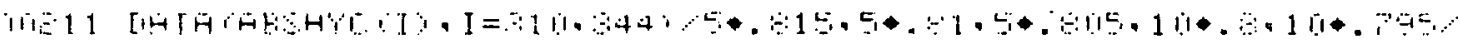

1,

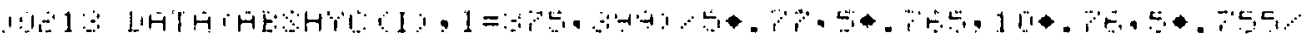

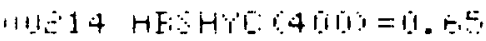

.

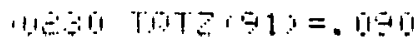

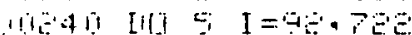

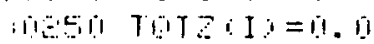

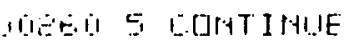

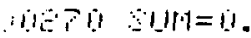

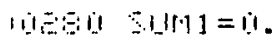

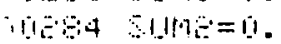

$1000.90 \%=0$

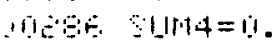

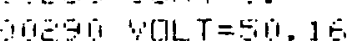

11001\% $\mathrm{H}=.3 \mathrm{OH}$

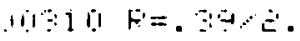

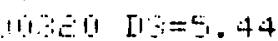

(1)

11130 FUCLT $=8+11$.

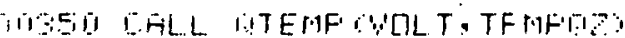

1010 TII1= TERPFIO

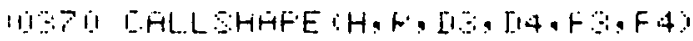

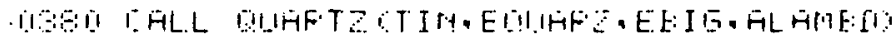

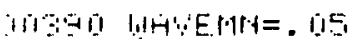

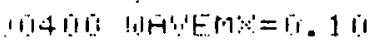

OIS1O TEPFI-TIN

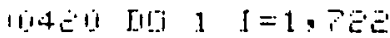

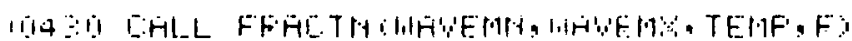

iाi $4+1=I+1$

$11+44.1=I$

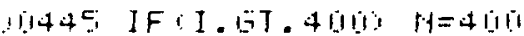

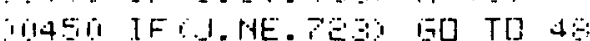

$10480.1=70$

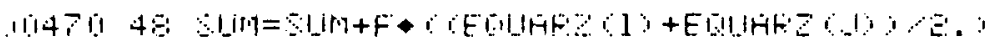

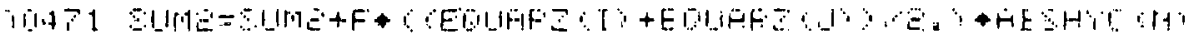

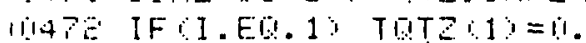

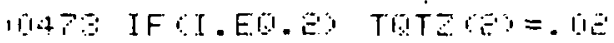

(1) 


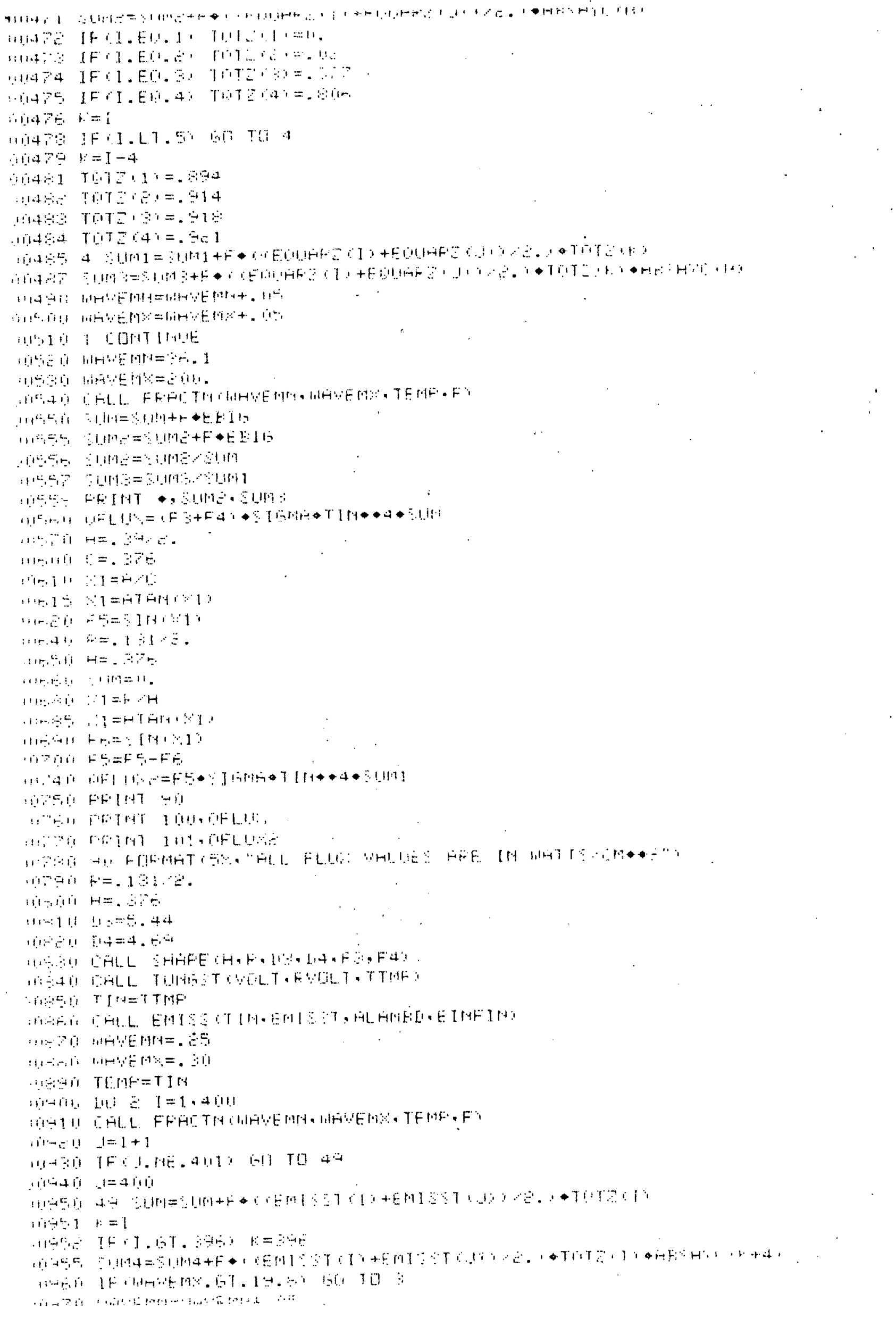




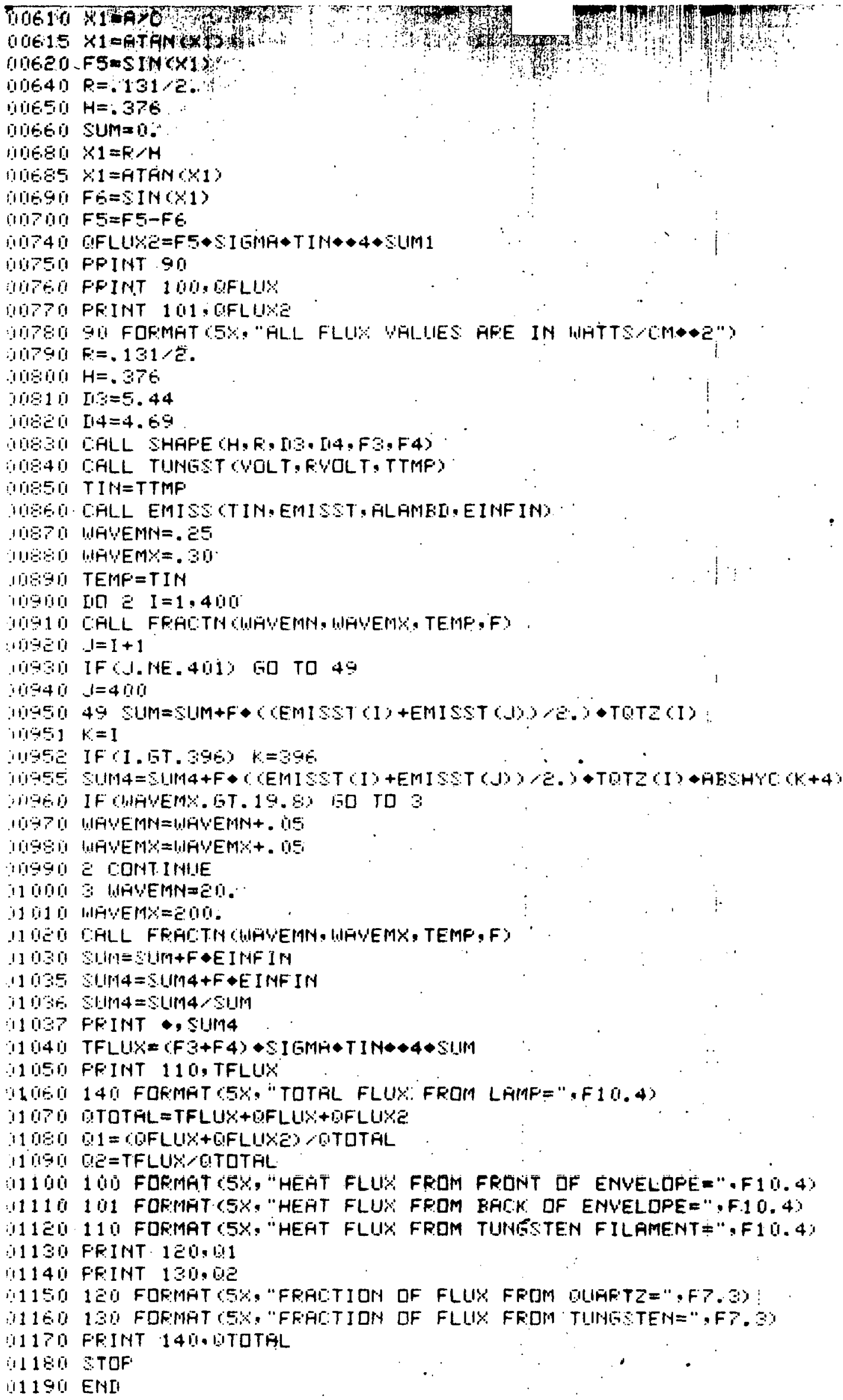


01680 SUBRDUTINE FRACTM (WAVEMN, LUAVEMK, TEMP, F.)

$01690: 01=0.59544 E-4$.

$01700 \quad C 2=14333:$

1 1: SIGMA=5-.6693E-20

$01730 \quad C=2 . * 3.14159 \bullet C 1 / 5 I G M A$

01730 . TLMN $=$ TEMP WUVEMN

01740 TLMX=TEMP $\triangle$ UAVEMX

01750 DELTA=TEMP (WAVEMX-WAVEMN) $/ 10$.

$01760-F=.17 E-P$

01770. TLM $=$ TLMM

$01>3010 F 1=C, T L M \cdots 5 /(E \times P(C 2 / T L M)-1$,

$01790 \mathrm{TLM}=T L M+D E L T A$

01800 IF (TLM.GT.TLMX) GD TO 20

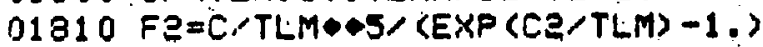

$\left.F>0 F=F+\left(C(F 1+F 2) / Z_{2}\right) \cdot D E L T A\right)$

in. 130 50 TO 10

OI 1940 20 RETURN

01350 इYD

O1\$60 SUJBRDITINE TUNGST (VDLT, RYOLT, TTMP)

01370 PERCNT $=$ VQL T TRVDLT

$01330: 2=.333166 * A L D G 10$ (PERCMT)

01391 CDLORT $=10 . \cdots Z$

01900 CDLDRT =COLIRT +2450 .

Q1310 IF (COLDRT.GT. 2662.) GD TO 10

01920 TTMP $=.9667 P-C Q L Q R T+26.45525$

i 30 RETURN

0174010 TTMP $=.31575 \bullet C J L D R T+162.2735$

01950 RETURN

01950 END 


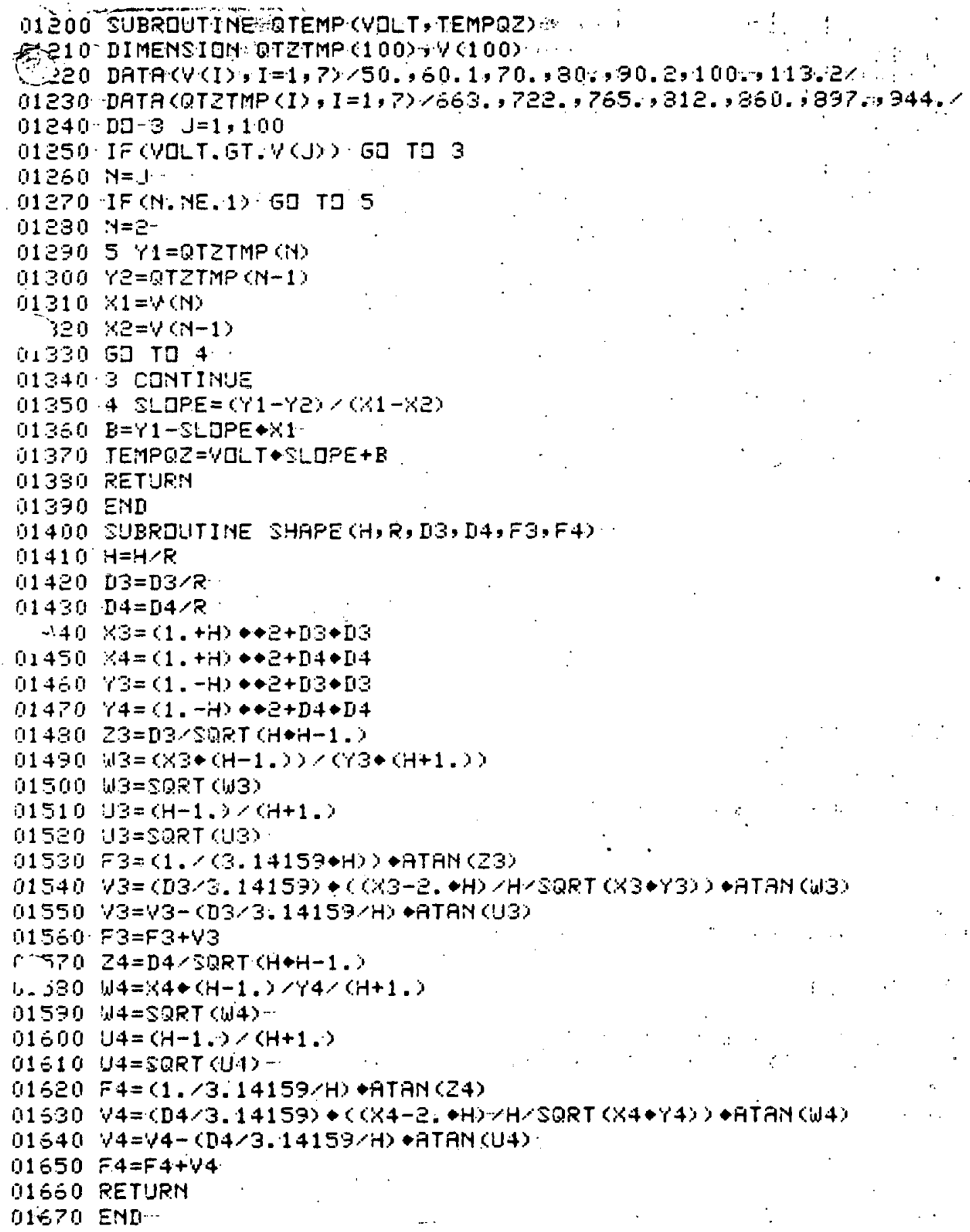


B1.07:EE. $11.14: 04$.

FEOGFFM LAMF

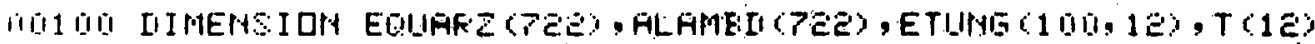

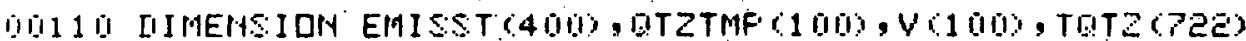

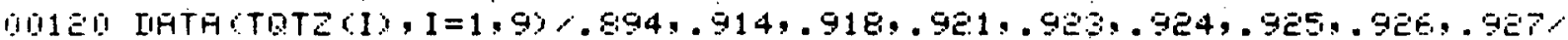

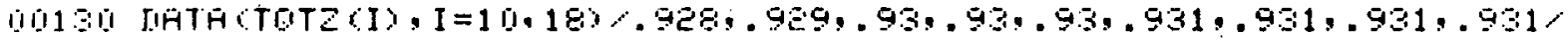

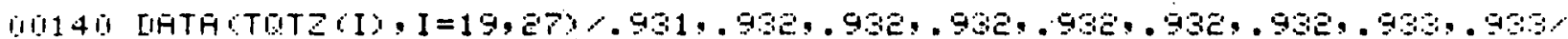

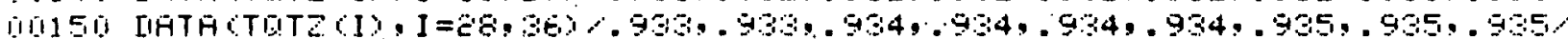

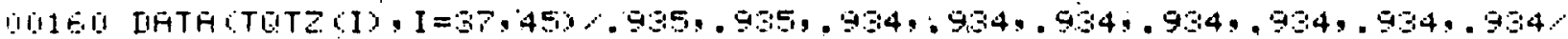

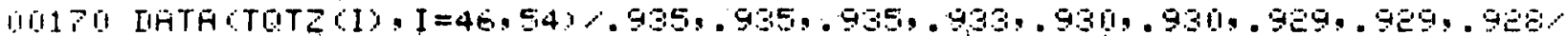

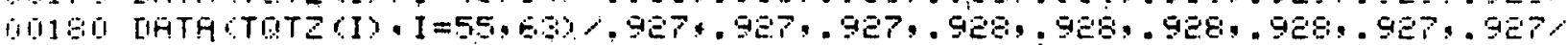

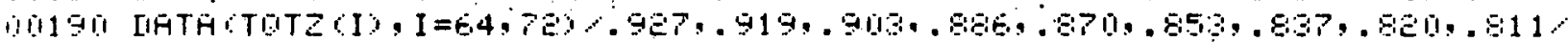

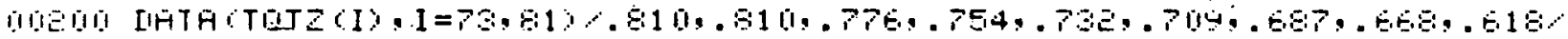

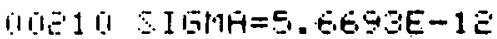

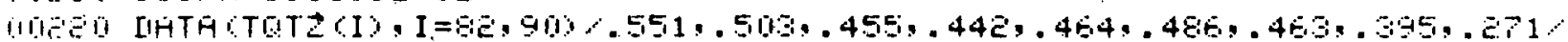

110

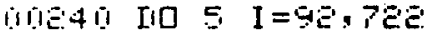

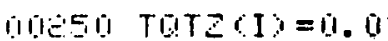

DViEg 5 EOHT INHE.

in

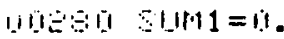

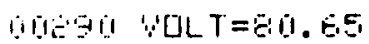

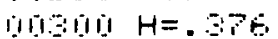

111010 $F=$

110:- $[1=5.44$

in $30114=4.69$

$10.94 \pi$ FUDL T=CAII.

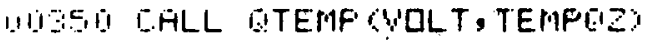

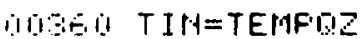

IOIO LFLLSHAFE (H,F, [I, [14,F3,F4)

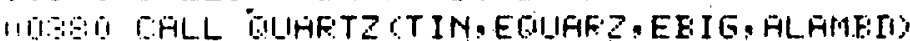

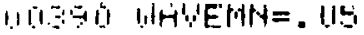

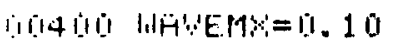

1.1141 11 TEMF $=$ TIN

(1) 4 EI [II] 1 I=1, $7 \mathrm{EE}$

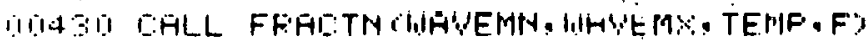

$11+4+1=I+1$

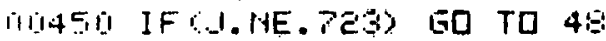

111400 $1=723$

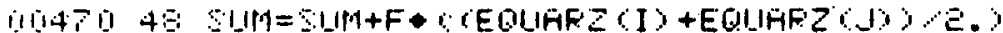

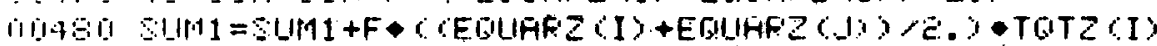

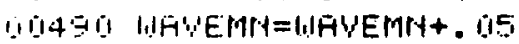

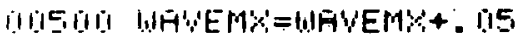

DOS10 1 E:DHT INLIE

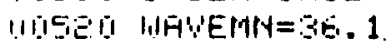

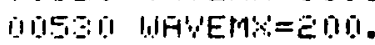

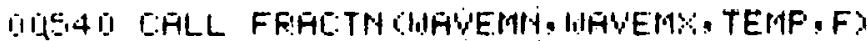

W1

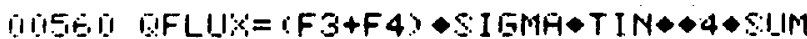

iा

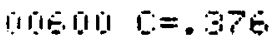

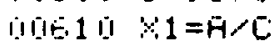

MUE $15, \quad \times 1=$ ATAN $(\% 1)$

1110 $F=5 I N\left(X_{1}\right)$ 


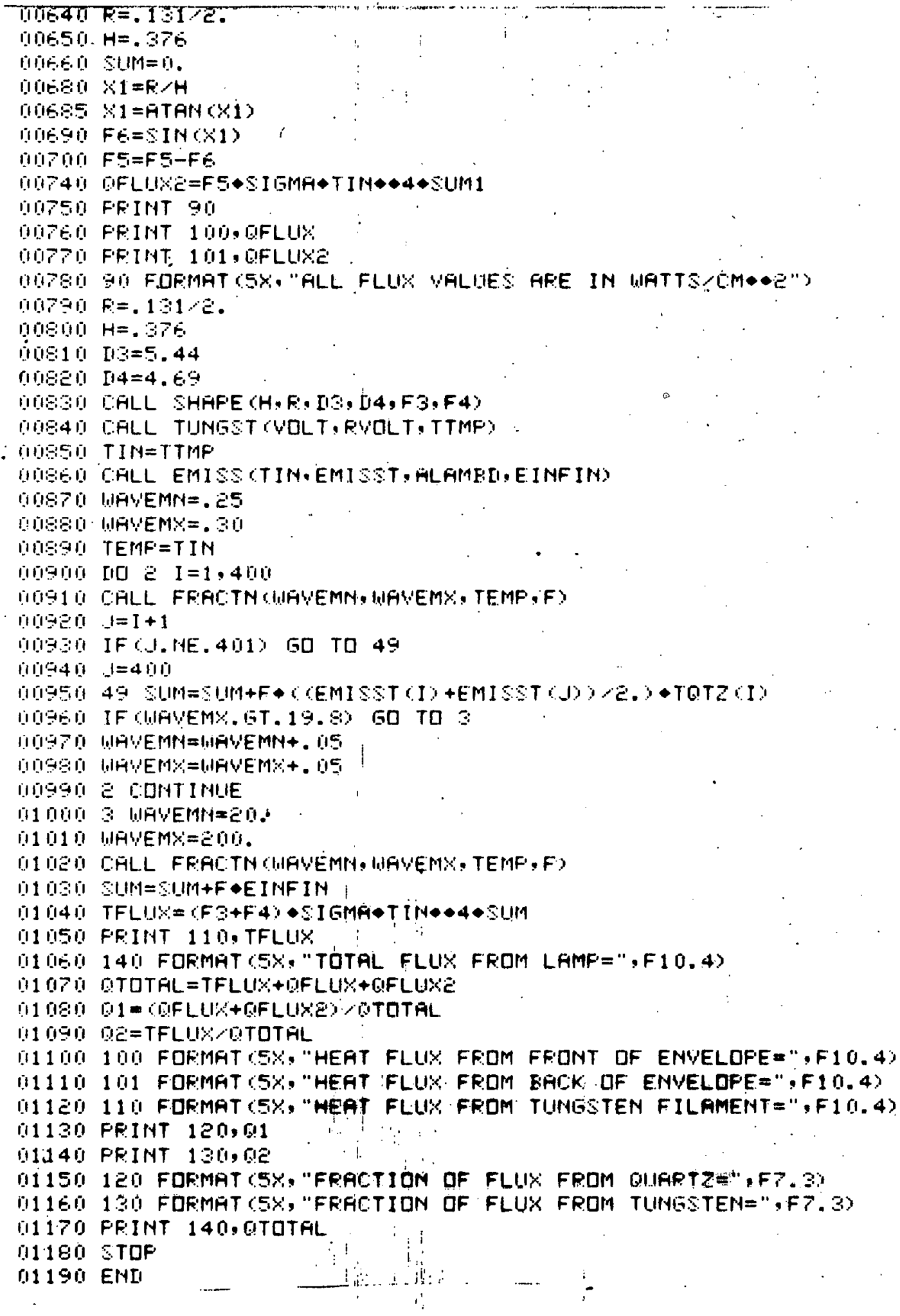




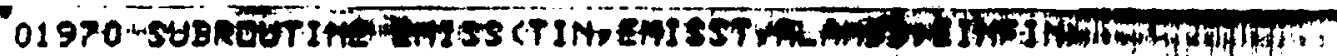

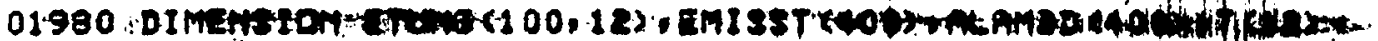

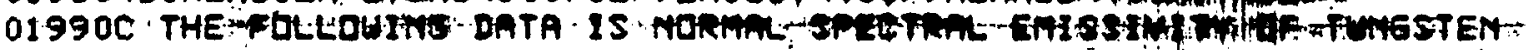

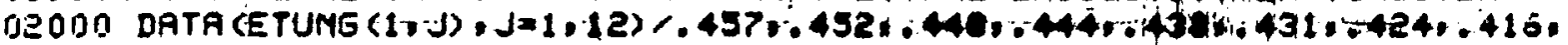
$02010+.409, .40210094 \% .336 \%$

020อ0 DATA (ETUNG $(2, J), J=1,12), .491, .497, .482, .478, .47 .3, .467, \ldots+63, .456$, $02030+.452, .446,-.441, \cdots 436$,

02040 DATA (ETUNG $(3, \mathrm{~J}), \mathrm{J}=1,12), .489, .485, .480, .475, .471, .466, .463, .453$, (. J50+.455,.450,.445,.440,

02060 DATA (ETUMG $(4, J), j=1,12), .490, .486, .431, .477, .472, .463, .464, \ldots+59$, $02070+.455, .450,: 445,: 440 /$

DE080 DATA (ETUNG (5, J), J=1, 13 ) $, 488, .434, .430, .4768 .472, ; 462, .463, .459$, $02030+.455, .451, .446, .441$,

02100 DATA (ETUNG $(6, J), J=1,12), .473, .474, .470, .466, .452, .458, .455, .451$, $02110+.443, .443, .433, .435$

D?120 DATA (ETUNG $(7, J), J=1,12), .472, .463, .464, .459, .454, .450, .445, .441$, $02130+.436, .431, .427, .423$,

02140 DRTA (ETUNG (3,J), J=1, 1 3 ) $/ 466, .461, .456, .451, .446, .441, .430, .431$, Q $3150+.426, .421, .416, .411 \%$

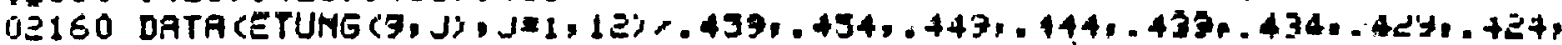
$021>0+.413, .414, .409, .404$,

30 DATA (ETIJNG $(10, J), J=1,12) / .451, .446, .441, .436, .431, .426, .421, .416$, $0=130+.411, .406, .401, .395$

0Е200 DATA (ETUNG $(11, J), J=1,12) / .443, .433, .433, .423, .422, .413, .412, .403$, $02210+.402, .337, .332, .337$,

02220 DATR (ETUNG $(12, j), J=1,12) / .433, .423, .423, .413, .413, .403, .404, .393$, $02230+.394, .339, .334, .379$,

0ミ240 LATA (ETUNG $(13, J), J=1,12) / .423, .413, .413, .407, .403, .393, .394, .390$, $02550+.335, .330, .376, .371$,

0ここ60 DATA (ETUNG $(14, J), J=1,12) / .413, .403, .403, .377, .374, .370, .335, .331$, 0ㄹํำ+.3?6,.372,.367,.363,

0ミ230 DATA (ETUNG $(15, j), J=1,12), .402, .397, .392, .333, .335, .330, .376, .373$, 0อ2 $290+.368, .364, .360, .356$,

02300 DATA (ETUNG $(16, J), J=1,13), .390, .336, .322, .373, .375, .371, .367, .364$, $r-310+.360, .356, .353, .343$,

1.-. 20 DATA (ETUNG $(17, J), J=1,12), .379, .375, .372, .369, .366, .362, .359, .356$, $02330+.352, .349, .345, .343$,

02340 DATA (ETUNG $(13, \mathrm{~J}), \mathrm{J}=1,12) / .366, .364, .362, .357, .356, .353, .350, .347$, $02350+.344, .341, .333, .335$

0.350 DATA (ETUNG $\langle 13, \mathrm{~J}\rangle, \mathrm{J}=1,12\rangle, .355, .353, .351, .349, .347, .345, .342, .340$, $0 \equiv 370+.337, .335, .333, .331$,

$0 \Xi 330$ DATA (ETUMG $(20, J), J=1,12) / .344, .342, .340, .337, .337, .330, .334, .333$, $02330+.331, .330, .329, .323$,

02400 DATA (ETUME $(21, J), J=1,12), .330, .329, .329, .338, .327,: 327, .326, .326$, $02410+.335, .325, .324, .324$,

02420 DATA (ETUNE $(22, J), J=1,12) / .317, .317, .317, .313, .310,+310, .319, .317$, 130+.313,.320, .320,.320,

b_+40 DATA (ETUNG $(23, J), J=1,12) / .304, .305, .306, \ldots 307, .308, .303, .310, .312$, $02450+.313, .3141, .315, .316 \%$

02460 DATA (ETUNG $(24, \mathrm{~J}), \mathrm{J}=1,1 \mathrm{l}$ ) $, .294, .296, .296, .293, .239, .301, .302, .304$, $024>0+.305, .306, .308, .309$.

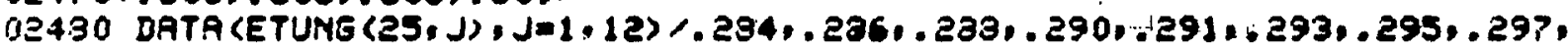
$02430+.299, .301, .303, .305$,

02500 DATA (ETUNG (26, J), J=1, 12),.275,.27P, . 279, .231,.283,.235, .237, . 230, $03510+.2931 .234, .297, .2994$

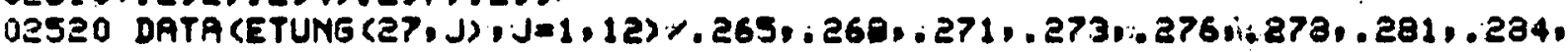
$02530+.286, .-289, .292, .294$,

02540 DATA (ETUNG $(23, J), J=1,12), .256, .259, .262, .265 \mathrm{r}, 268, .271, .274, .277$, - $150+.280 . .283, \cdots 286, .289 \%$

1 $=560$ DATA (ETUNG $(29, J), J=1,12) / .246, .250, .254, .257, \ldots 261, .264 \ldots .268, .272$, $03570+.275, .279, .283, .397 \%$

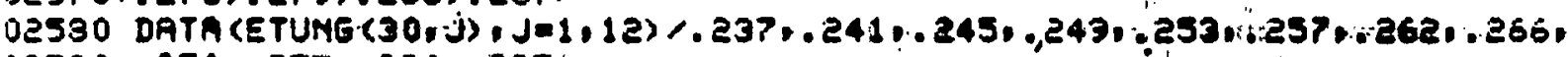
$02530+.270, .275 .2000 .0285 \%$

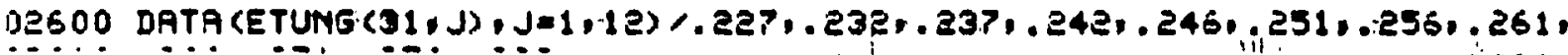




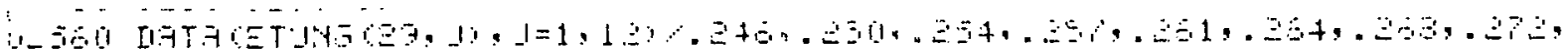

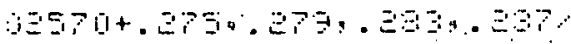

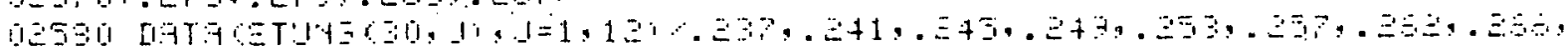

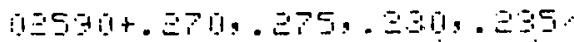

1 1

15:

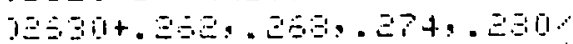

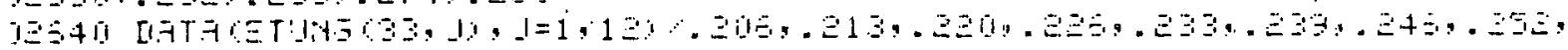

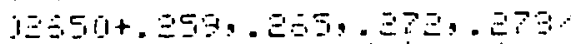

IE

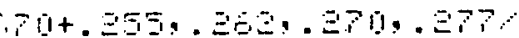

1.50 1. 1

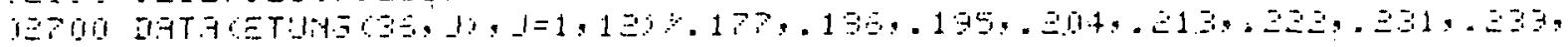

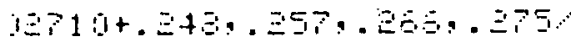

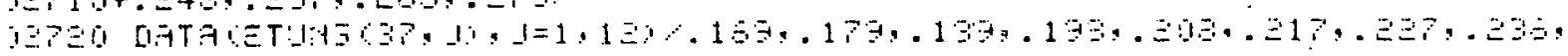

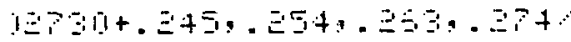

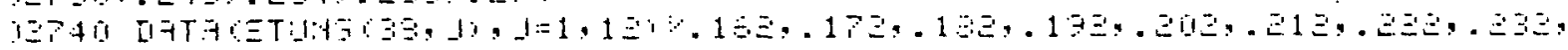
1275.

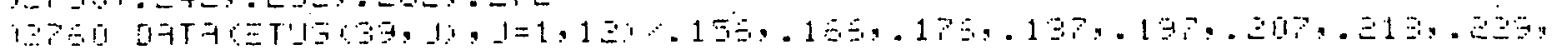

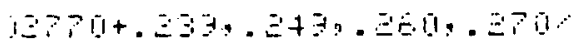

1301 i.

, त

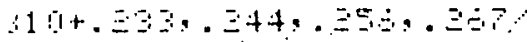

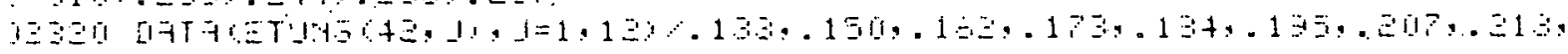

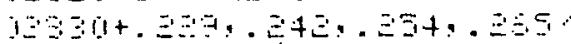

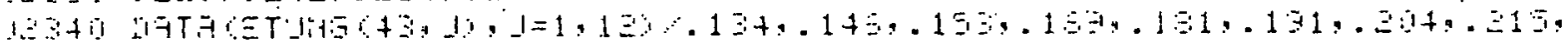

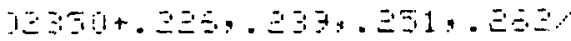

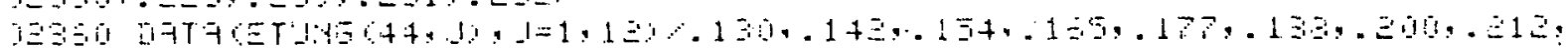

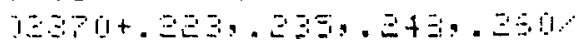

过

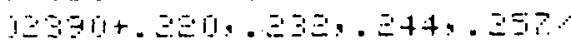

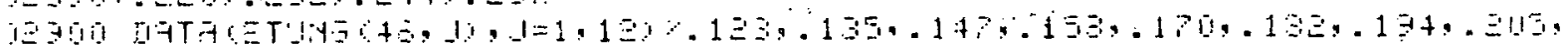

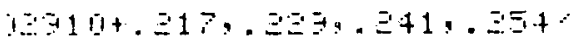

1三人 i.

40 1979,

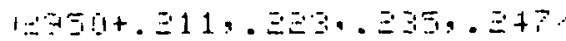

13:

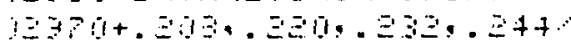

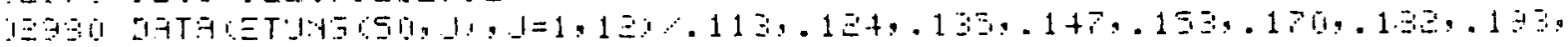
1.

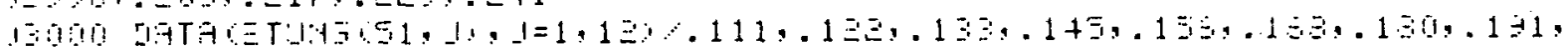

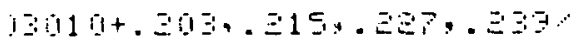

130 107.

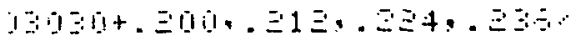

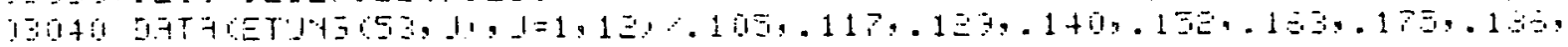
-

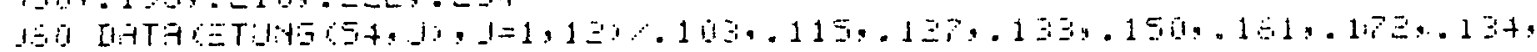

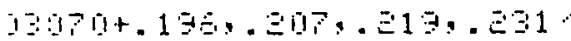

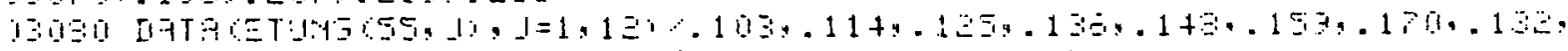
$9391+.194, .20 \div 9.27, .239$

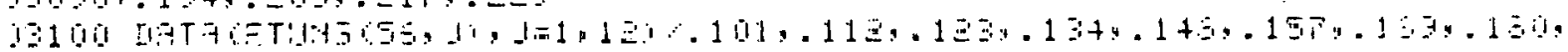

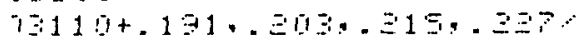

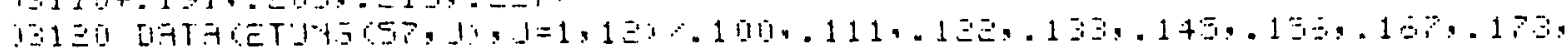

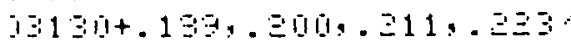

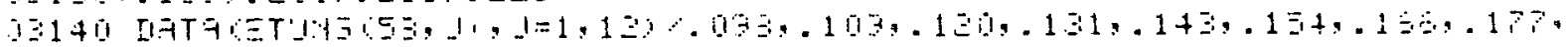

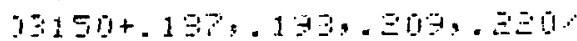

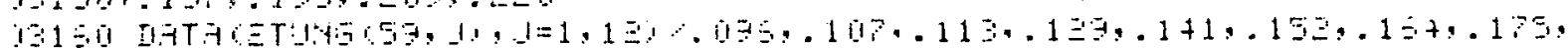
$\therefore$ -

$\therefore$.

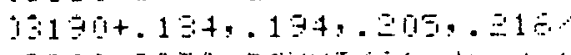




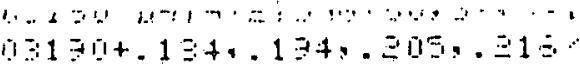

130 1.

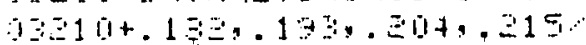

1300

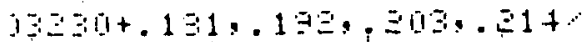

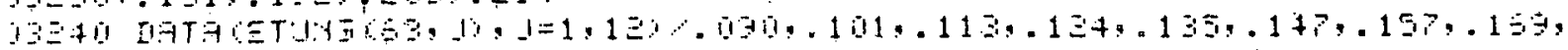
$135010.190, .131, .202, . \Xi 13$

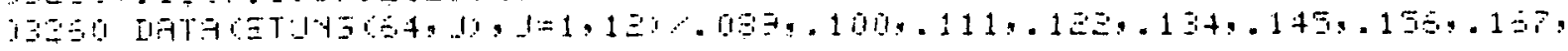

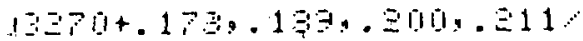

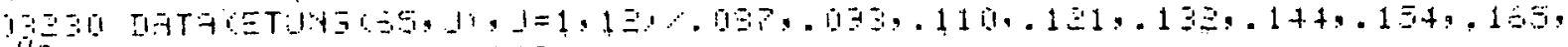
1E:

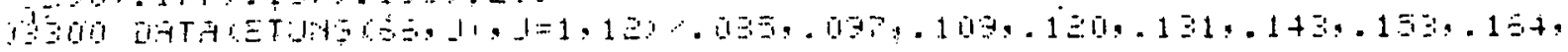

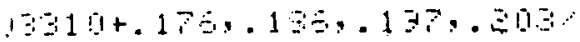

13

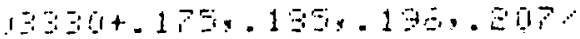

13+6

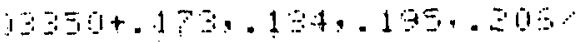

158

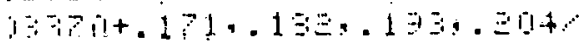

17

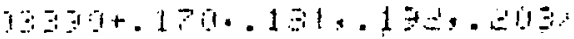

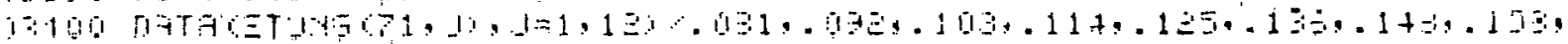
$13+10+.159,150, .191, .30$

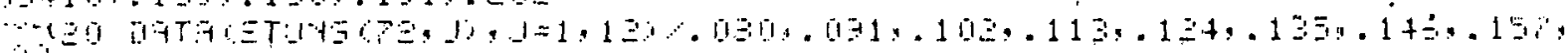

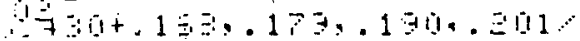

15 1 1 1

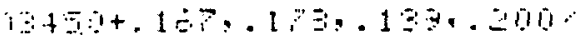

154 व

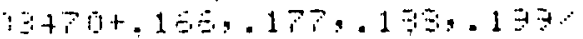

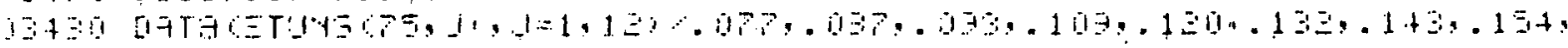

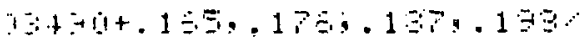

I $13510.15+.17=1539.197$

y

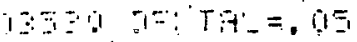

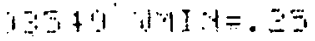

$\because 30$ din $=20$.

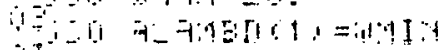

1

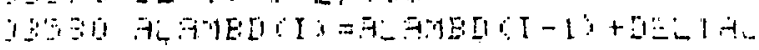

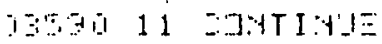

930 T $11=1010$.

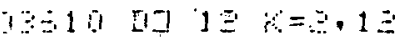

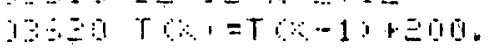

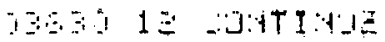

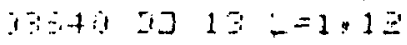

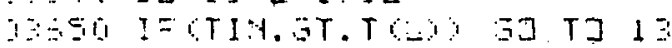

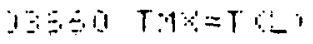

$\because 9 \% \quad 4=$

$\left[\begin{array}{llll}1 & 5 & 5 & 14\end{array}\right.$

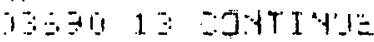

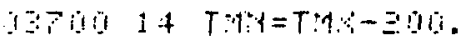

B

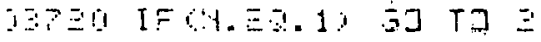

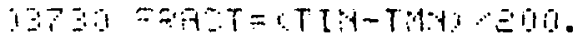

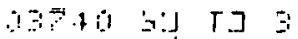

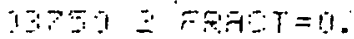

$137 \div 0=3$

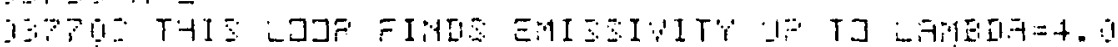

$1330 \vdots 10151=1,7 \vdots$

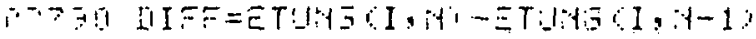

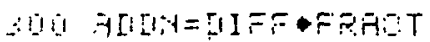

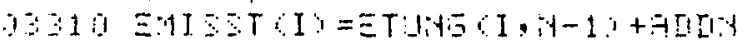

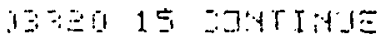




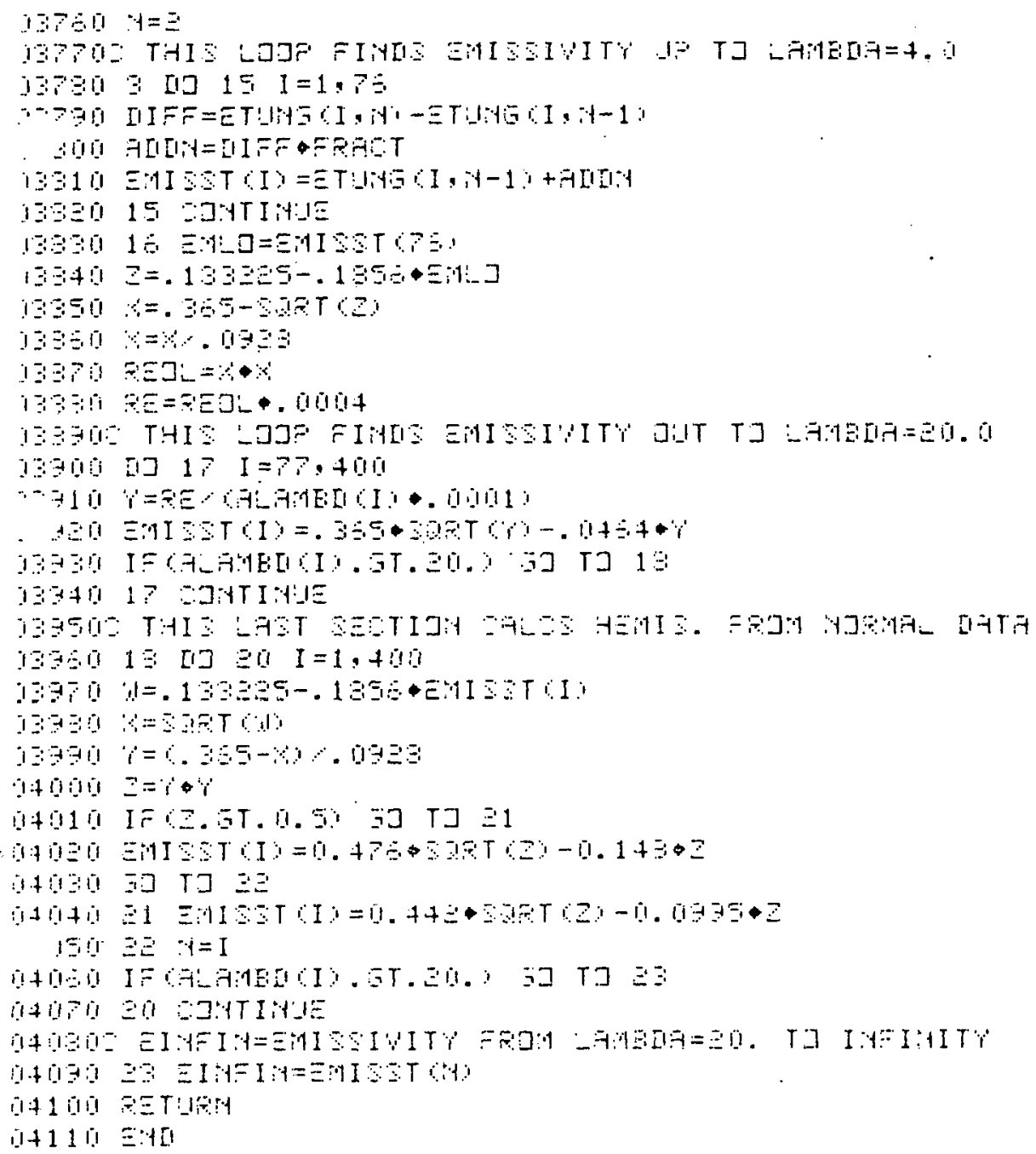




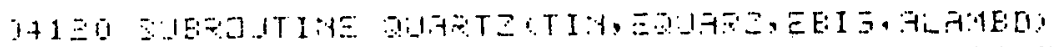

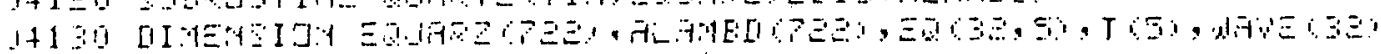

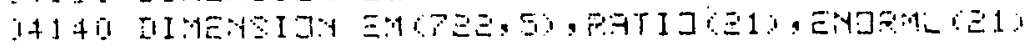

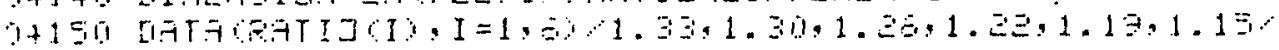

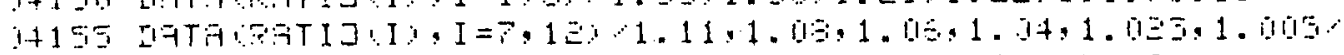

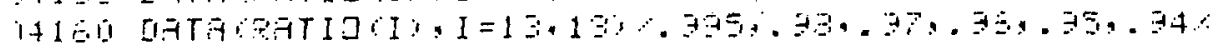

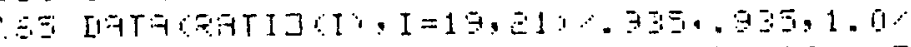

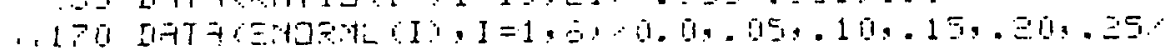

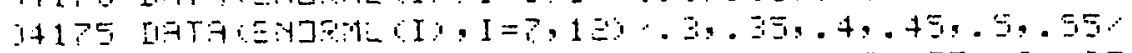

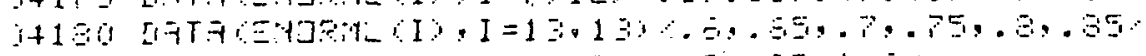

$1+195$ IनTन

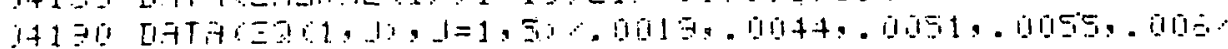

14

14三1 व

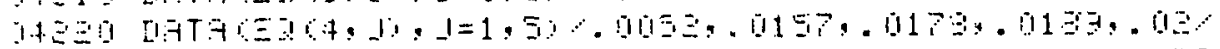

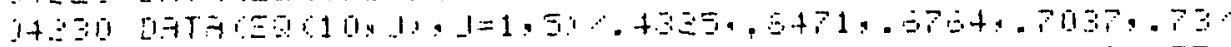

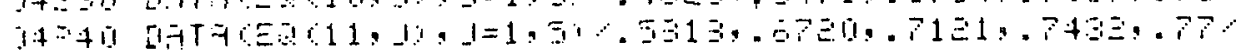

1.

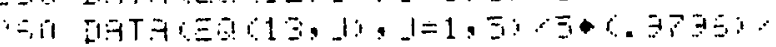

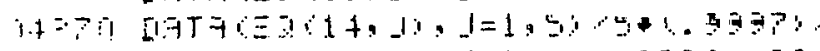

14

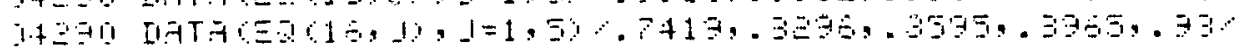

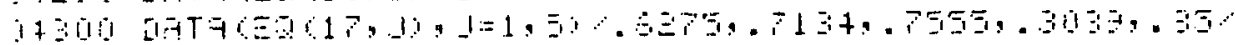

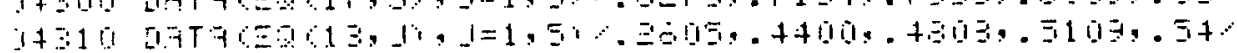

$1+50$ 1.

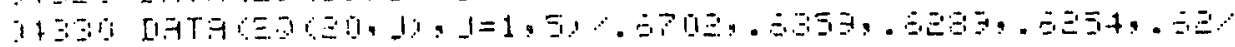

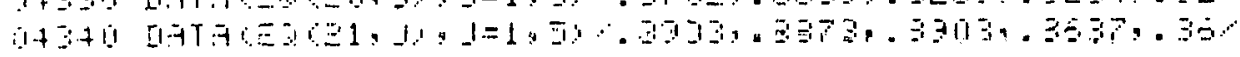

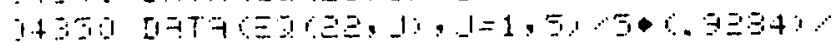

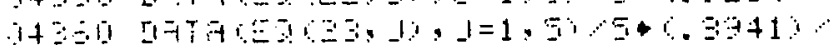

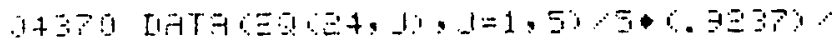

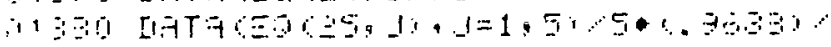

औव

A+4

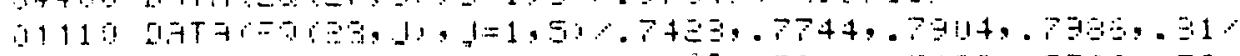

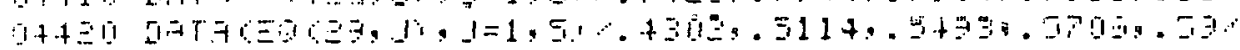

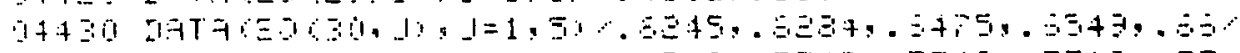

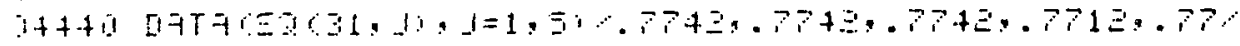

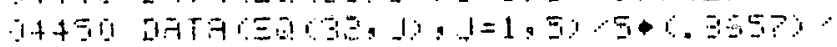

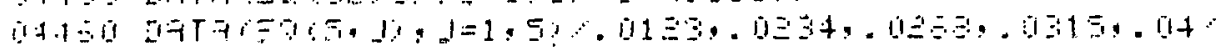

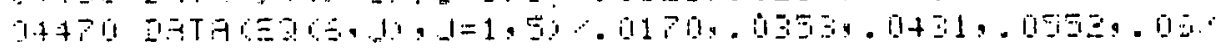

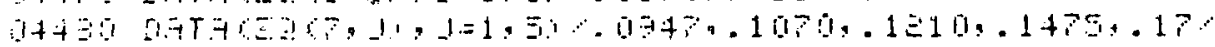

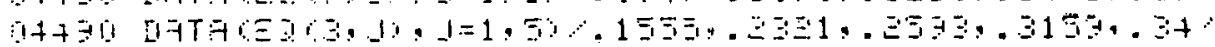

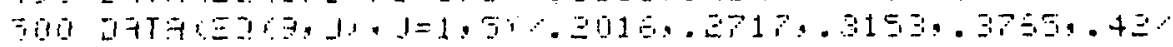

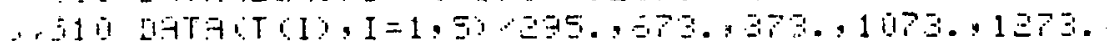

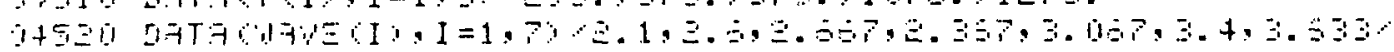

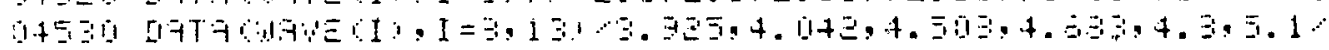

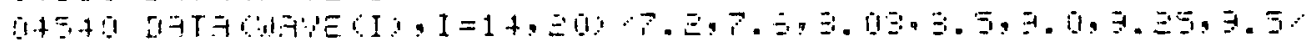

1.

1. 50 ,

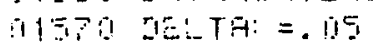

$1+5=11011: 1=0.95$

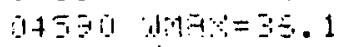

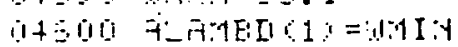

91.19 II] $101=\Xi 97 コ 一$

1.+

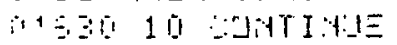

$3+10$ [1] $11 \quad 1=1.5$

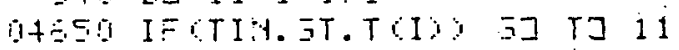

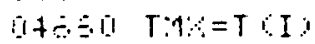

$1+500: 1=1$

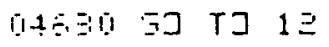

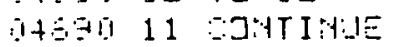

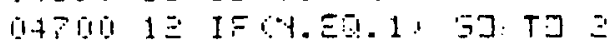

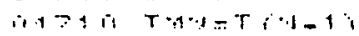




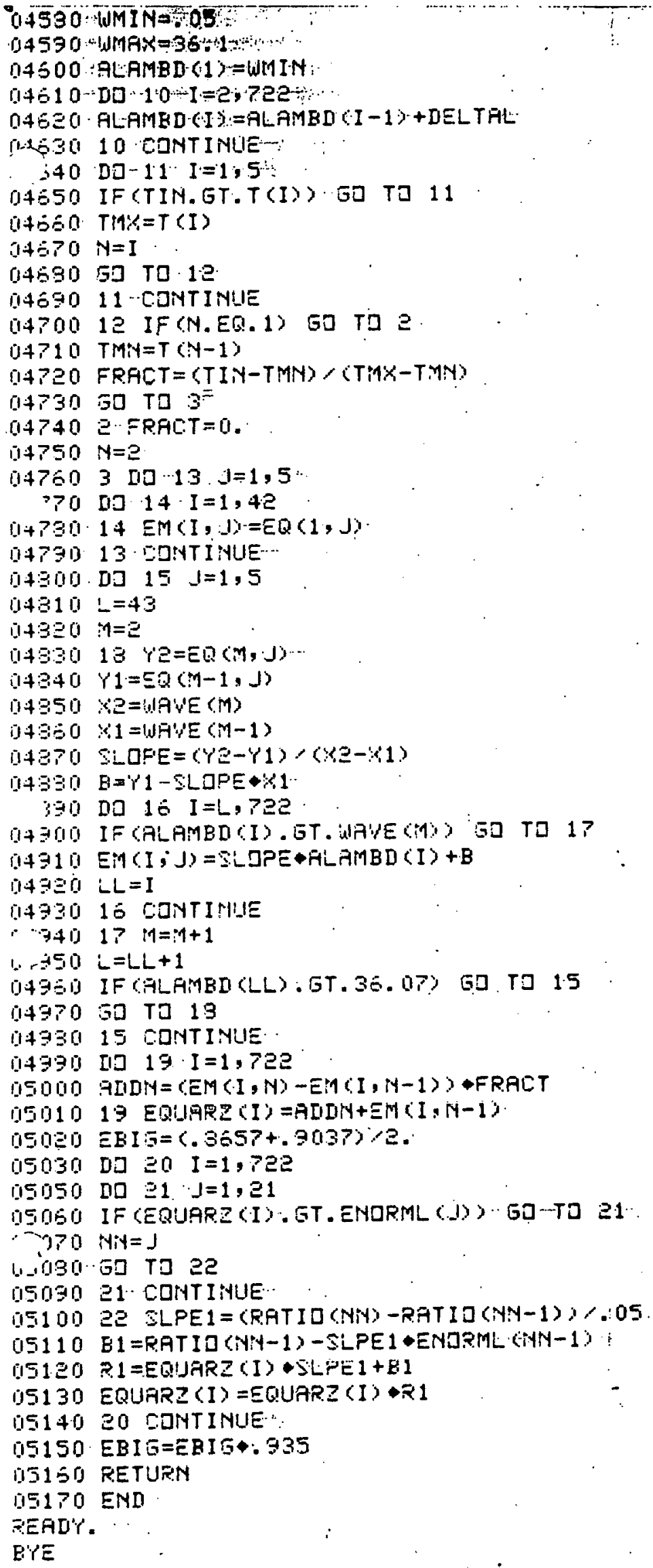


Distribution:

R. C. Pfhal

Engineering Research Center

Western Electric Co.. Inc.

P. O. Box 900

Princeton, New Jersey 08540

V. C. Paek

Engineering Research Center

Western Electric Co., Inc.

P. O. Box 900

Princeton, New Jersey 08540

Ivan Berlec

Commercial \& Industrial products

General Electric Co., Inc.

1705 Noble Road

P. O. Box 2494

Cleveland, Ohio 44112

1530 W. E. Caldes

1531 P. H. Adams

1531 J. T. Nakos

1531 P. L. Class

(5)

1537 N. R. Keltner

1537 T. Y. Chu

1537 B. F. Blackwell

1556 S. A. Ingham

2551 R. B. Foster

4755 B. W. Marshall

5511 J. W. Nunziato

5512 D. F. McVey

5513 D. W. Larson

8124 D. M. Bel1

8124 M. Abrams

8452 E. T. Cull

3141 L. J. Erickson (5)

3151 W. L. Garner (3)

3154-3 C. H. Dalin (25)

for DOE/TIC 


\section{DO NOT MICROFILM \\ THIS PAGE}

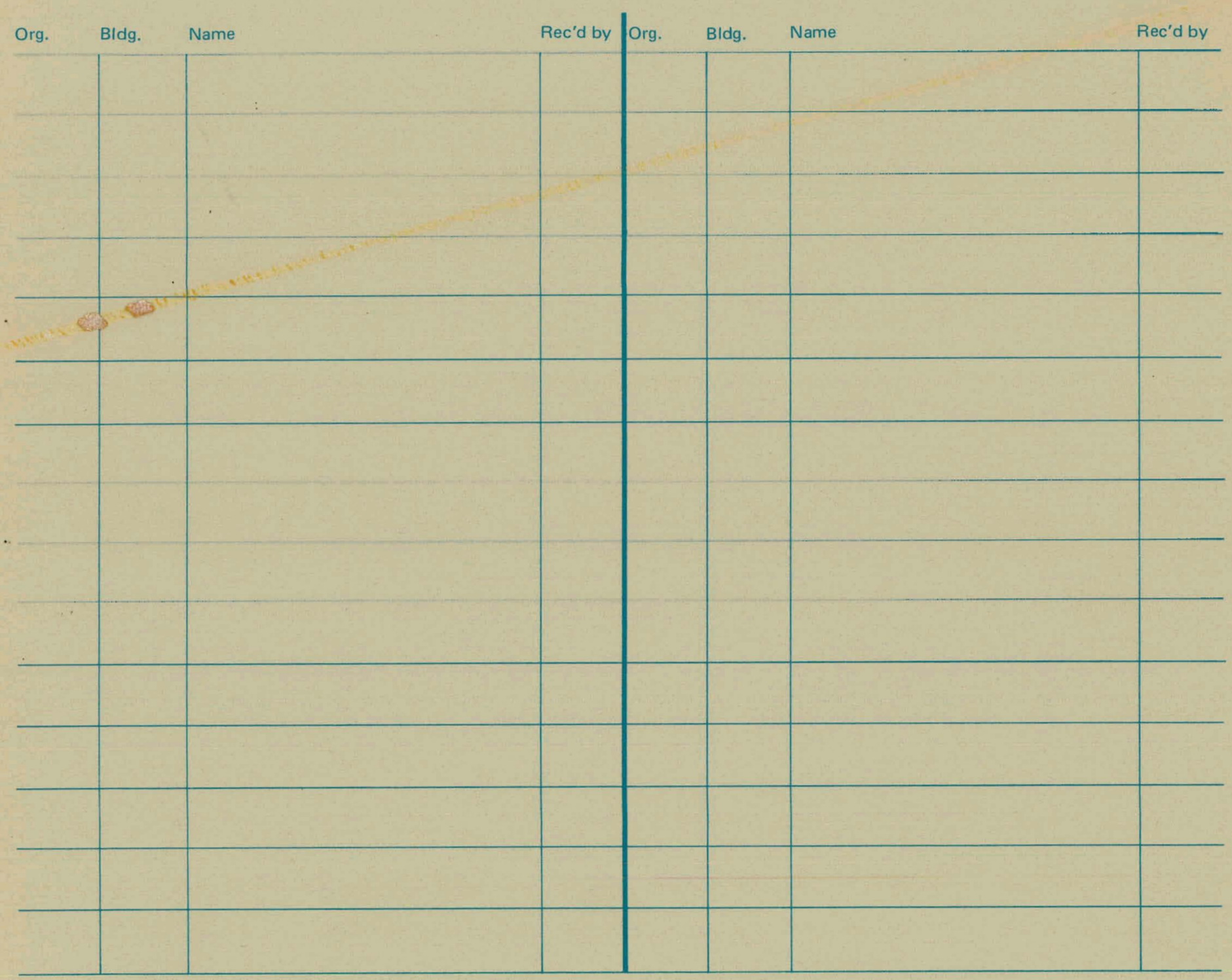

